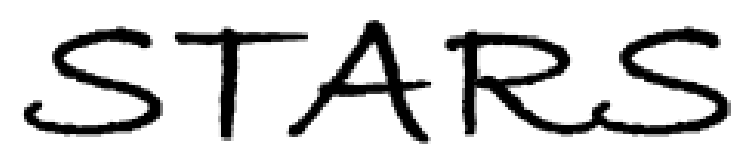

University of Central Florida

STARS

\title{
Factors Related To Birth Transition Success Of Late-preterm Infants
}

Karen L. Wright

University of Central Florida

\section{Part of the Nursing Commons}

Find similar works at: https://stars.library.ucf.edu/etd

University of Central Florida Libraries http://library.ucf.edu

This Doctoral Dissertation (Open Access) is brought to you for free and open access by STARS. It has been accepted for inclusion in Electronic Theses and Dissertations, 2004-2019 by an authorized administrator of STARS. For more information, please contact STARS@ucf.edu.

\section{STARS Citation}

Wright, Karen L., "Factors Related To Birth Transition Success Of Late-preterm Infants" (2011). Electronic Theses and Dissertations, 2004-2019. 1992.

https://stars.library.ucf.edu/etd/1992

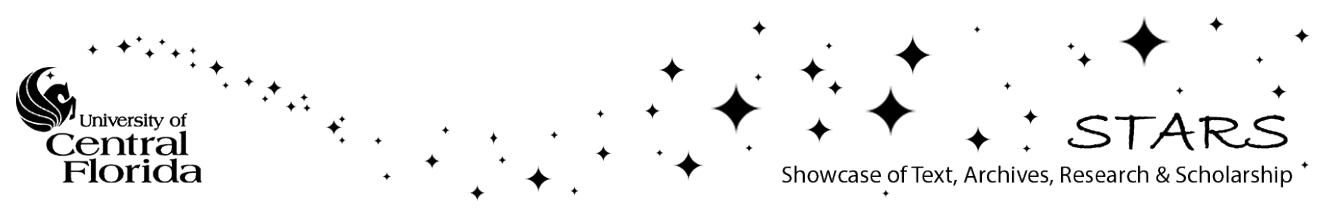




\title{
FACTORS RELATED TO BIRTH TRANSITION SUCCESS OF LATE-PRETERM INFANTS \\ by \\ KAREN L. WRIGHT \\ M.S.N. Medical University of South Carolina, 1997
}

\author{
A dissertation submitted in partial fulfillment of the requirements \\ for the degree of Doctor of Philosophy \\ in the Department of Nursing \\ in the College of Nursing \\ at the University of Central Florida \\ Orlando, Florida \\ Spring Term \\ 2011
}

Major Professor: Jacqueline Fowler Byers 
(C) 2011 Karen L. Wright 


\begin{abstract}
Problem: Identifying the factors effecting birth transition success of late preterm infants may improve early recognition of newborn compromise. Multiple explanatory variables may be associated with birth transition success or failure. The purpose of the study was to determine the prevalence of, and clinical-epidemiological and demographic predictive factors for birth transition success of late preterm infants.
\end{abstract}

Methods: A retrospective case-control chart review was used to compare the characteristics of successful and unsuccessful birth transition of 35 and 36 week gestational age late-preterm infants delivered in a large tertiary-care center during calendar year 2007. A mixture of categorical and numeric variables related to maternal, birth, and physiologic constructs were analyzed for their effects on birth transition as a binary outcome variable (success or failure).

Results: Of 22 variables tested, four predictor variables were associated with birth transition failure: labor $(\mathrm{OR}=.42, p=.014), 5$-minute Apgar score $(\mathrm{OR}=1.79, p=$ $.043)$, gender $(\mathrm{OR}=.47, p=.003)$, and respiratory rate $(\mathrm{OR}=2.08, \mathrm{p}=.001)$ as tested by logistic regression. The model was able to accurately assign transition failure and success at a rate of $66.7 \%$ and $74 \%$ respectively. The overall model was statistically significant (likelihood ratio chi square $=38.97(4), p<.001)$. The Hosmer $\&$ Lemseshow test indicated that the model's estimates fit the data at an acceptable level $\left(\chi^{2}=7.72, p=\right.$ $.358)$. 
Discussion/Implication: The absence of labor was identified as a risk factor for transition failure in this population. Male preterm infants were nearly twice as likely to fail transition as females in this population. The case group had a higher frequency of lower 5-minute Apgar scores, resulting in significantly lower mean scores. The failed transition group had more than twice the number of newborns with abnormally high respirations than the control group. These findings indicate that identification infants at risk for birth transition failure begins with the recognition of the absence of labor as a significant risk factor for birth transition failure of late preterm infants. 
For Billie and Charlie, and for Reggie. 


\section{ACKNOWLEDGMENTS}

I wish to first acknowledge my incredible doctoral committee. I could not be more grateful for the support afforded me by Dr. Jacqueline Byers, Dr. Maureen Covelli, Dr. Anne Norris, Dr. Valerie Sims, and Dr. Ana Leon. A special thank you to my brilliant chair, Jacquie Byers - you, as well as the rest of this committee, will forever hold my respect. I wish to express my gratitude to my friend and colleague Angela Lash for her endless artistic assistance throughout my academic career on multiple dissertation related projects. I also wish to thank my wonderful editor, Nancy Rosenbaum for editing my dissertation.

I also wish to thank Dr. Christoph U. Lehmann for inspiring the title and subject of this dissertation, and for joining Dr. Joseph Werthammer and Dr. Gilbert Ratcliff as a strong inspiration of neonatology thought and inquiry by example.

I cannot express deeply enough my appreciation to Wade Martin for taking this journey with me. Also I am thankful to my sisters Donna and Ann, for being there for me when I needed them.

Finally, I wish to acknowledge Patrick Bouvier Kennedy as a brave little boy who continues to save the lives of countless newborns. 


\section{TABLE OF CONTENTS}

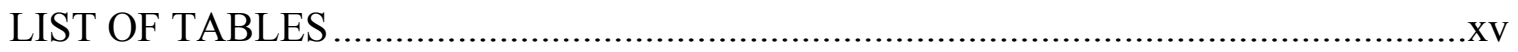

CHAPTER ONE: FACTORS RELATED TO BIRTH TRANSITION SUCCESS

OF LATE-PRETERM INFANTS..............................................................

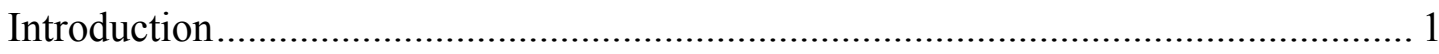

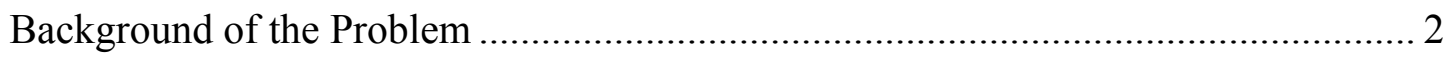

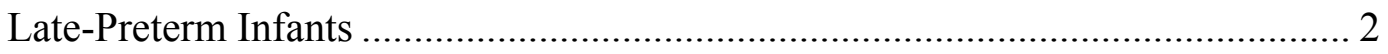

Preterm Births in Florida ………………………….................................. 3

Physiology of and Factors in Neonatal Birth Transition .............................................. 5

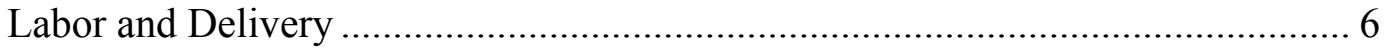

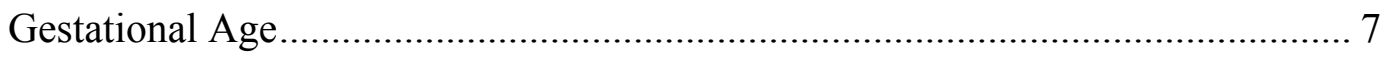

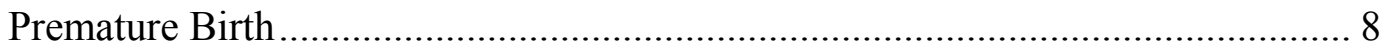

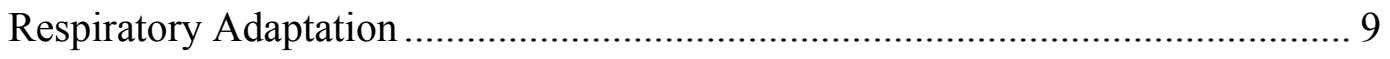

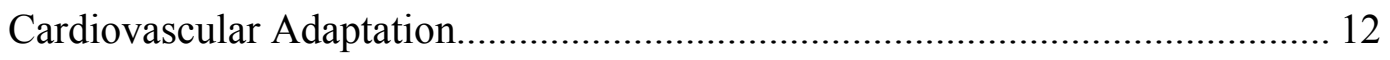

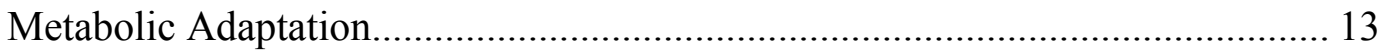

Neurologic Adaptation................................................................................ 15

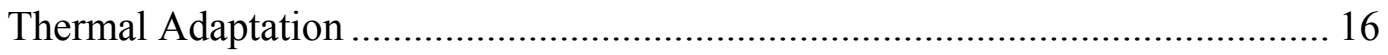

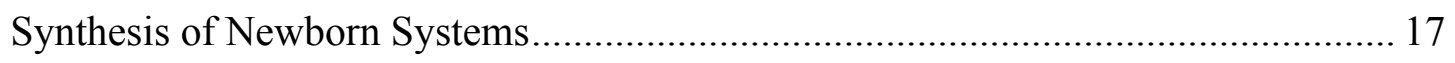

Statement of the Problem and Significance ……………........................................... 18

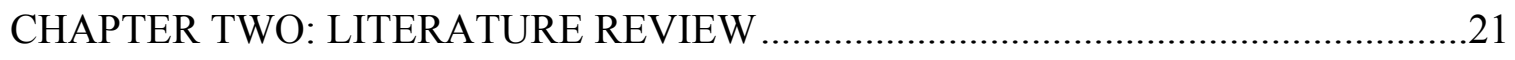

Birth Transition, Transition Variables, and Late-Preterm Infants .............................. 22 


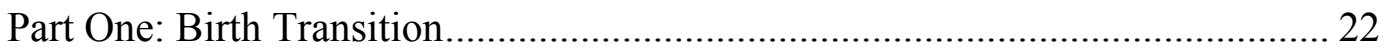

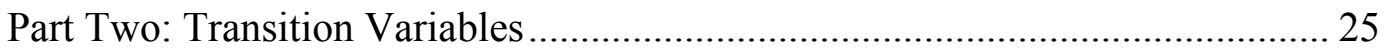

Part Three: Late-Preterm Infant Review ............................................................ 34

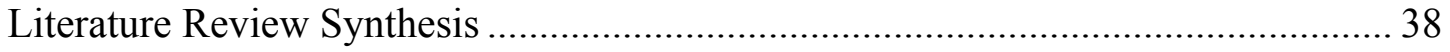

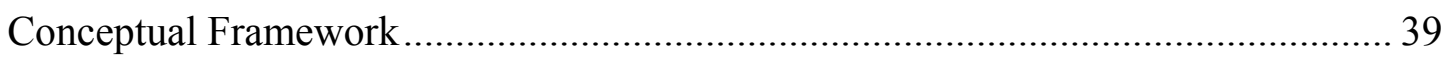

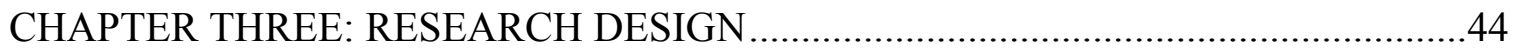

Case and Control Group Selection.............................................................................. 44

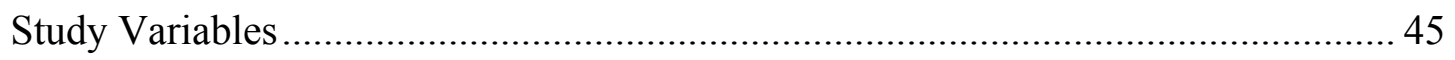

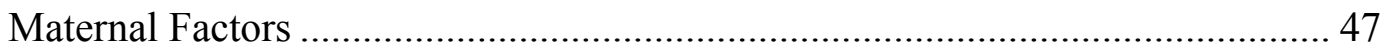

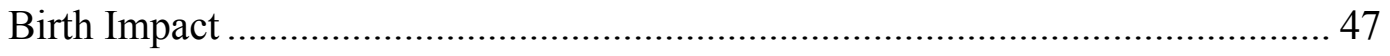

Neonatal Physiologic Maturity ……………………….................................... 48

Study Site, Population, Sampling Frame, and Sample ……………………............. 52

Inclusion and Exclusion Criteria.......................................................................... 54

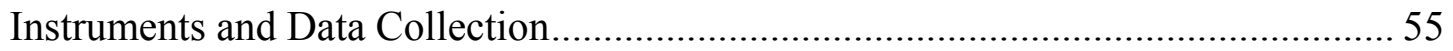

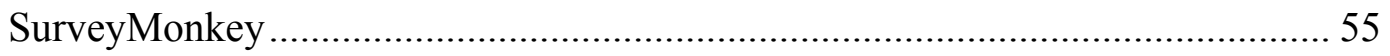

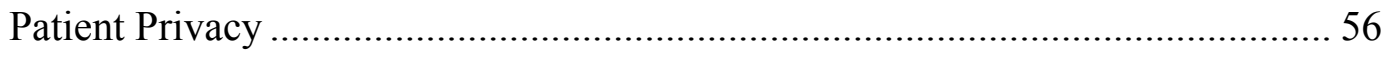

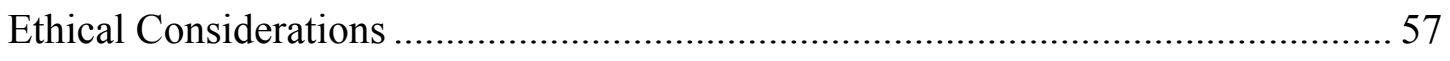

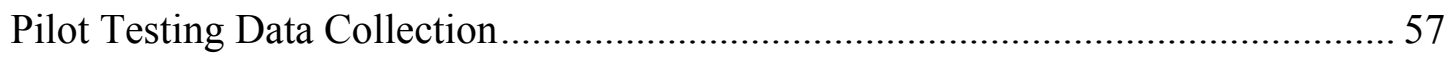

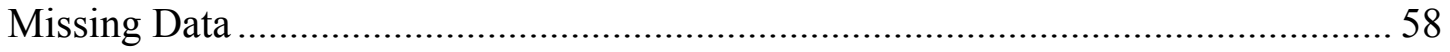

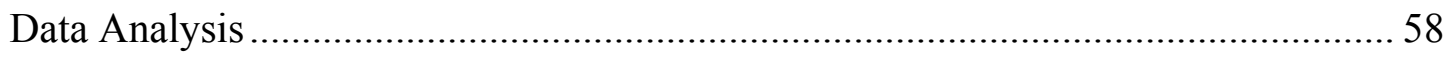

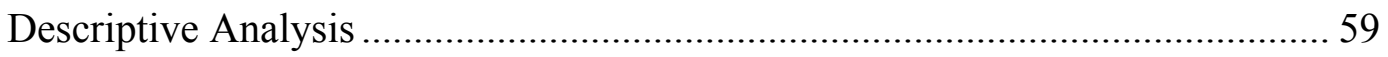

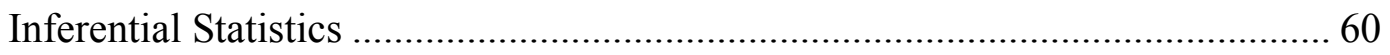

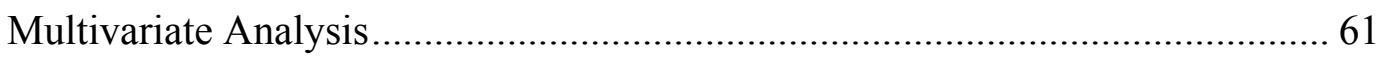

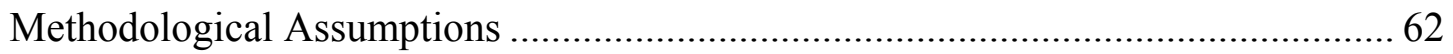




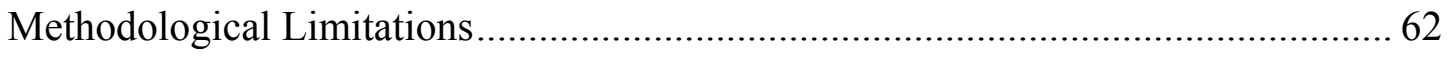

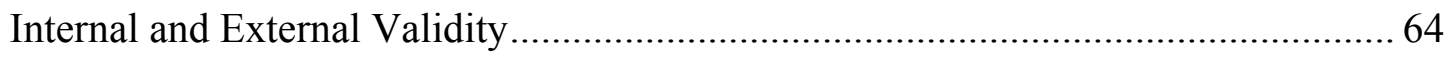

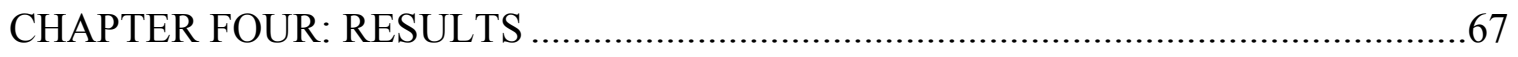

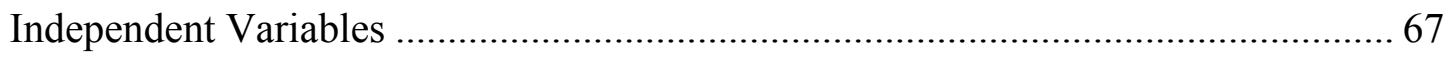

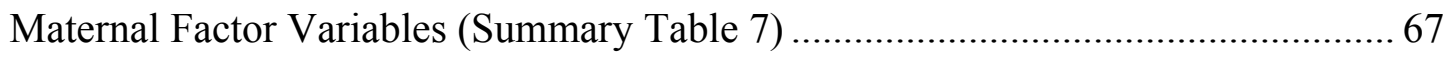

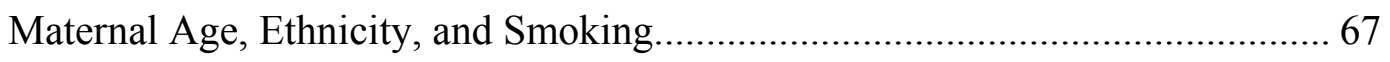

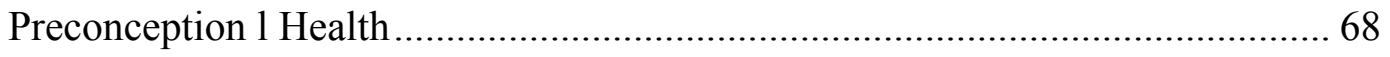

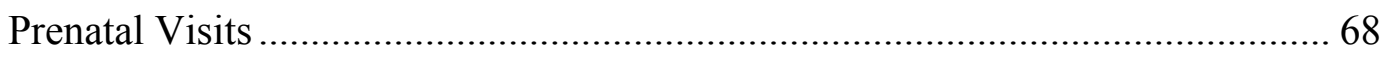

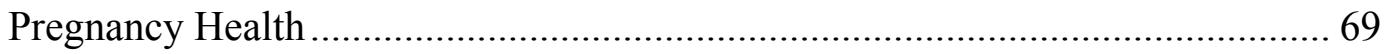

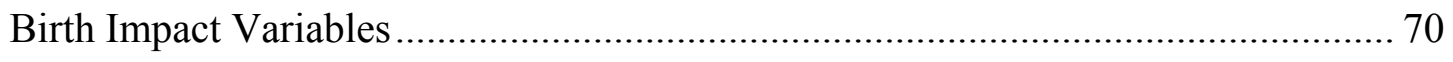

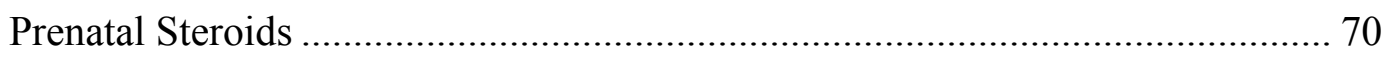

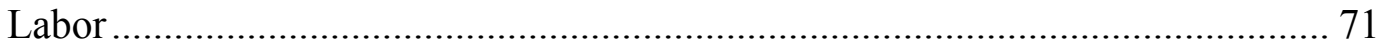

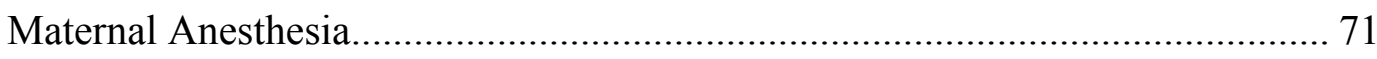

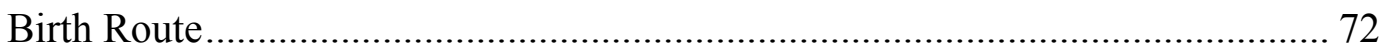

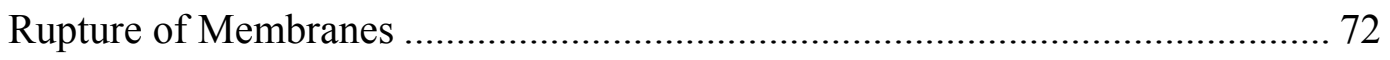

Neonatal Physiologic Variables............................................................................ 73

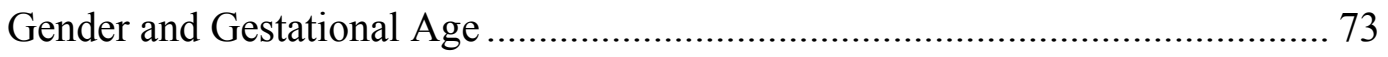

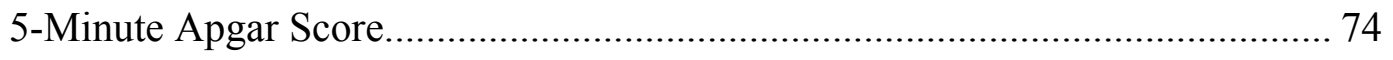

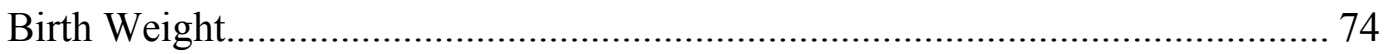

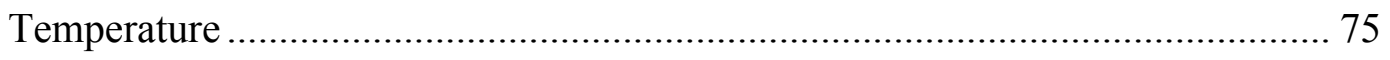

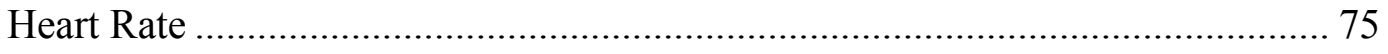

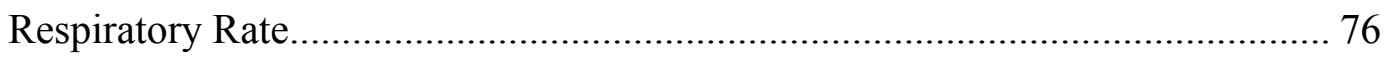

Lowest Mean Blood Pressure …………………………................................ 77

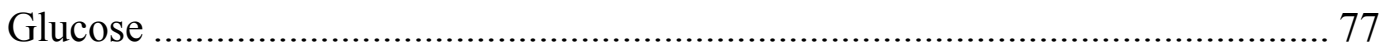




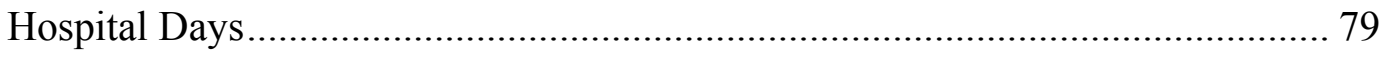

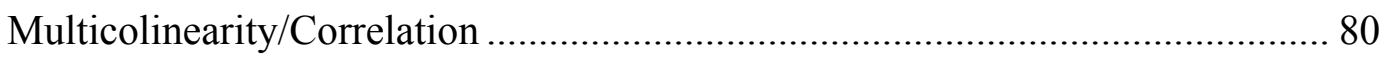

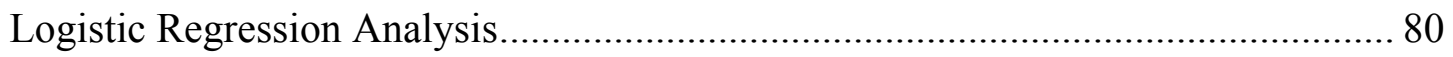

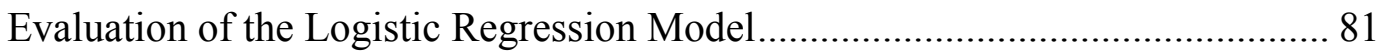

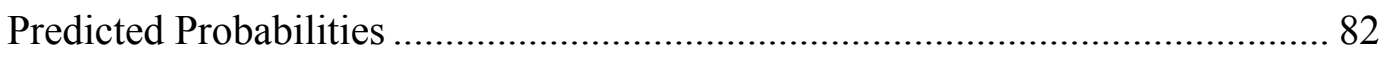

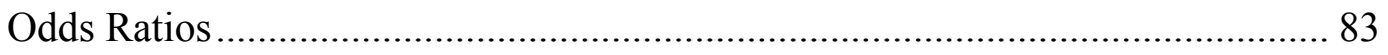

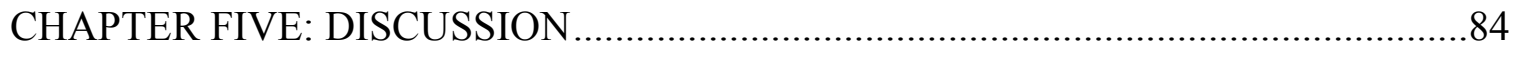

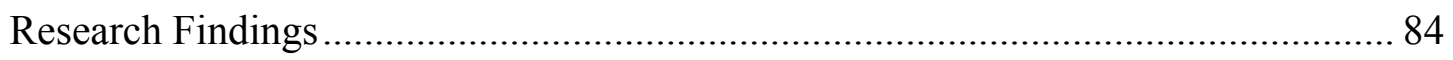

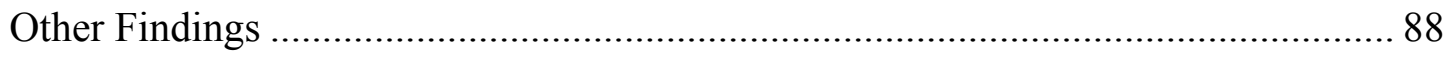

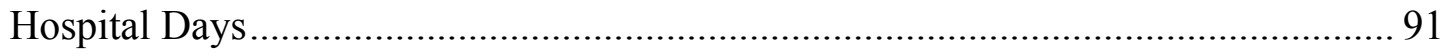

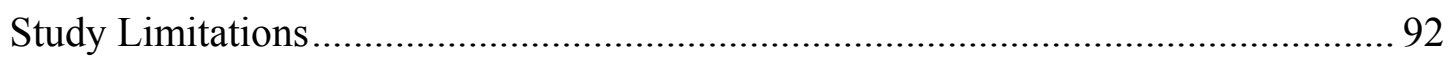

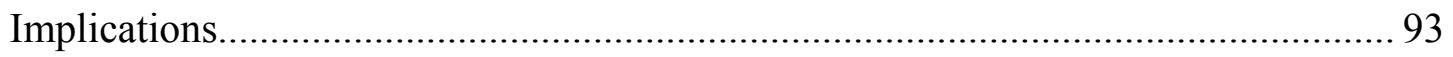

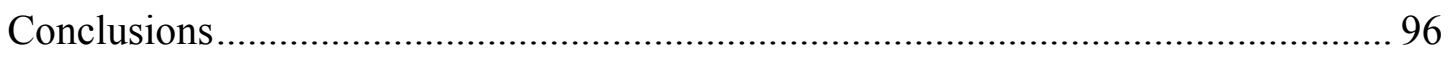

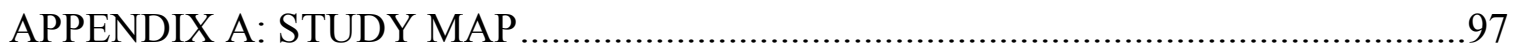

APPENDIX B: DATA COLLECTION SHEET (FROM SURVEYMONKEY),..............99

APPENDIX C: UNIVERSITY OF CENTRAL FLORIDA IRB APPROVAL ...............104

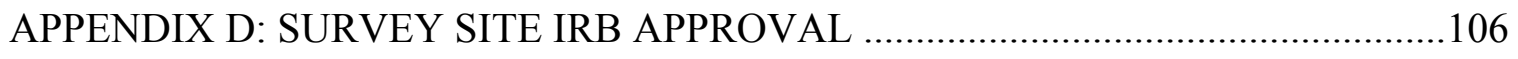

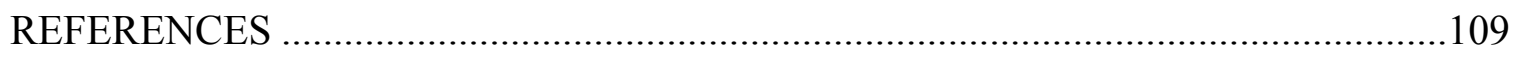

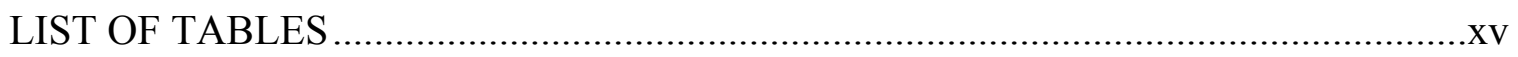

CHAPTER ONE: FACTORS RELATED TO BIRTH TRANSITION SUCCESS OF LATE-PRETERM INFANTS...............................................................

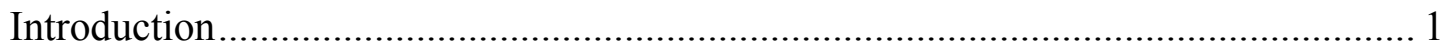

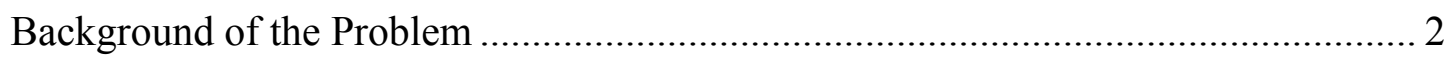

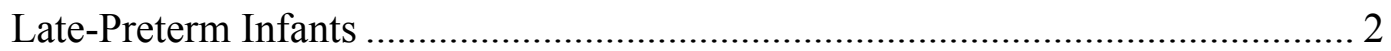




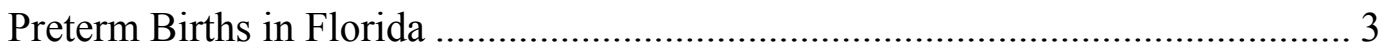

Physiology of and Factors in Neonatal Birth Transition ............................................. 5

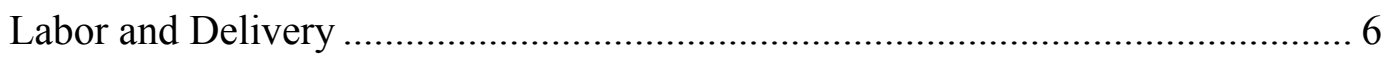

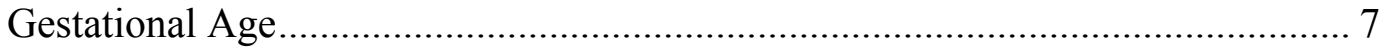

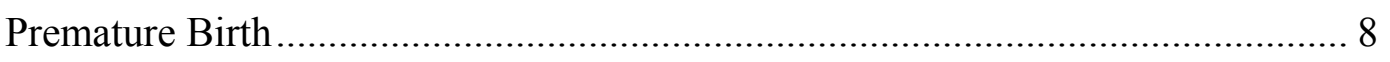

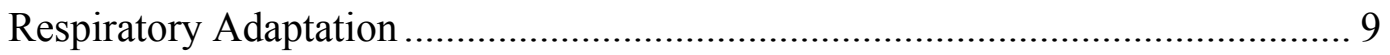

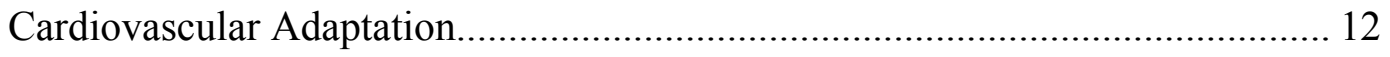

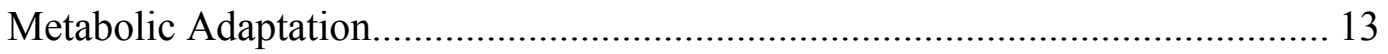

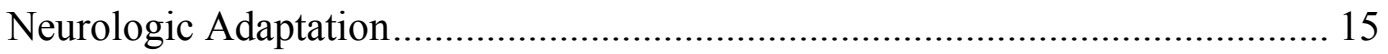

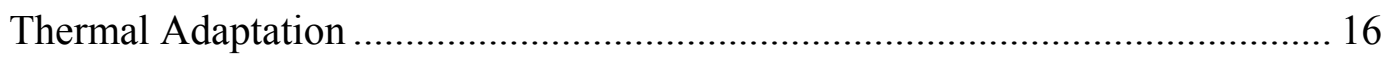

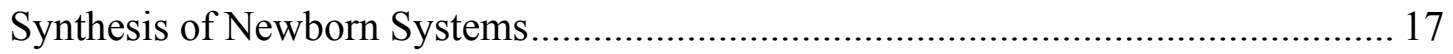

Statement of the Problem and Significance …………………................................... 18

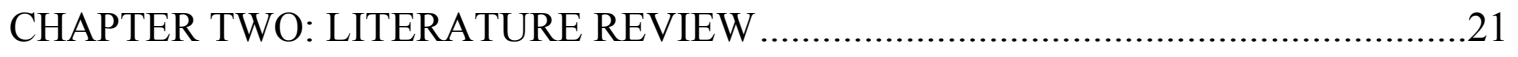

Birth Transition, Transition Variables, and Late-Preterm Infants ............................... 22

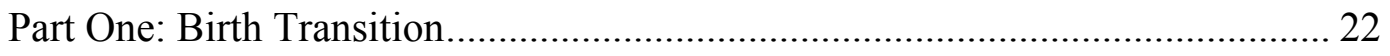

Part Two: Transition Variables ....................................................................... 25

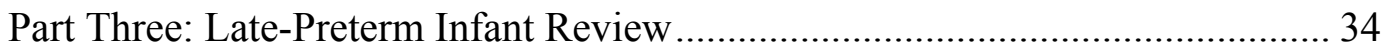

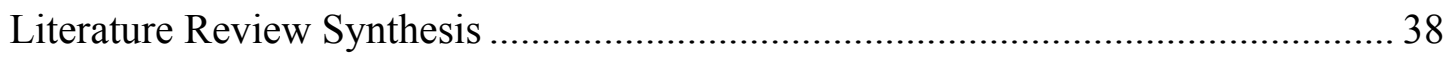

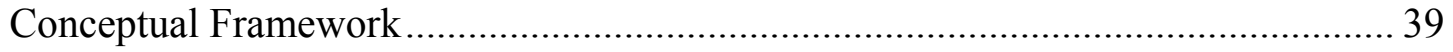

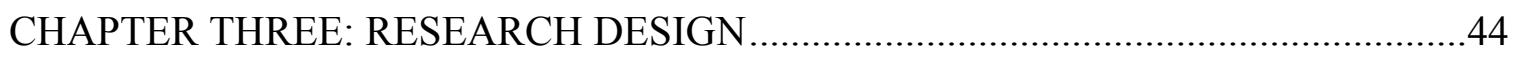

Case and Control Group Selection........................................................................ 44

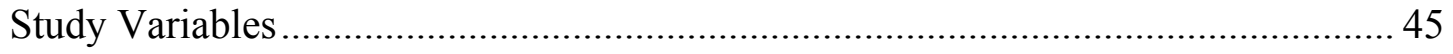

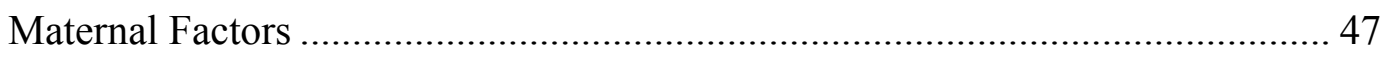

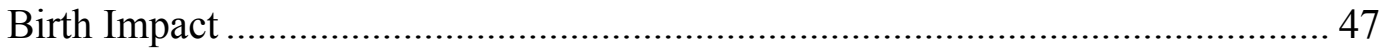


Neonatal Physiologic Maturity ………….......................................................... 48

Study Site, Population, Sampling Frame, and Sample ………………..................... 52

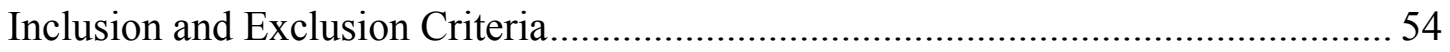

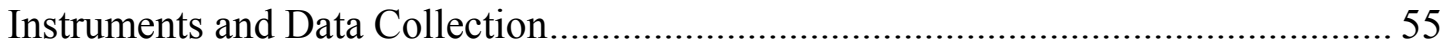

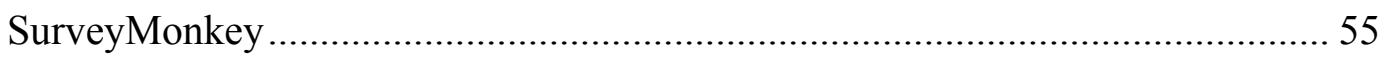

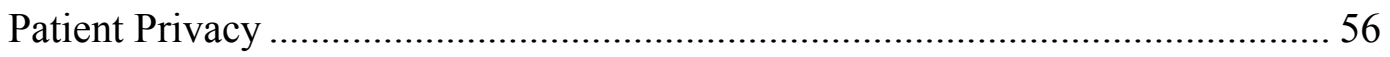

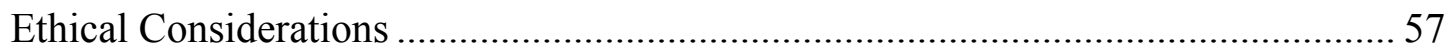

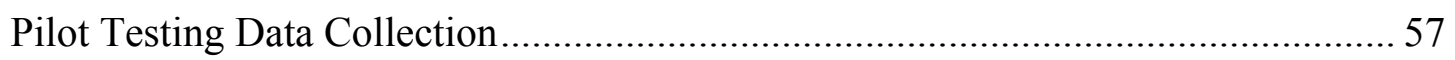

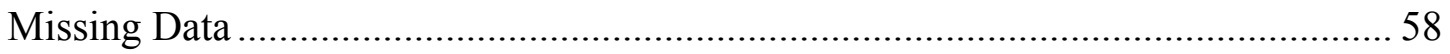

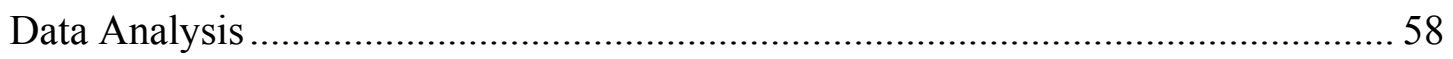

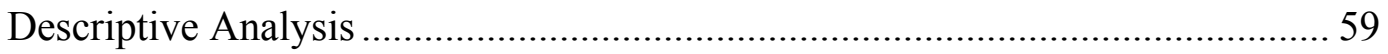

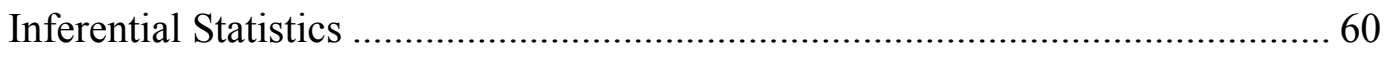

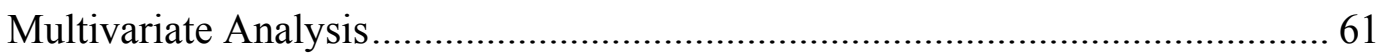

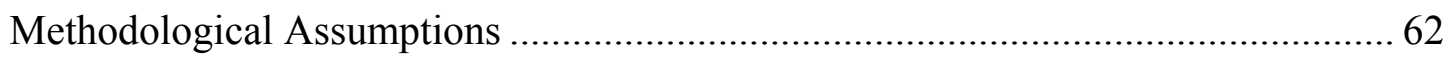

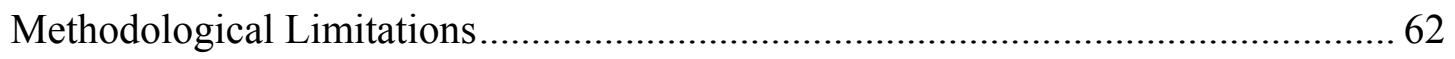

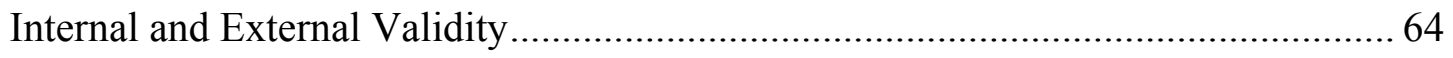

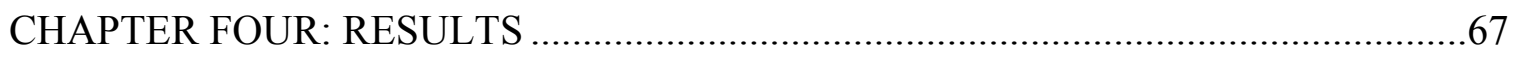

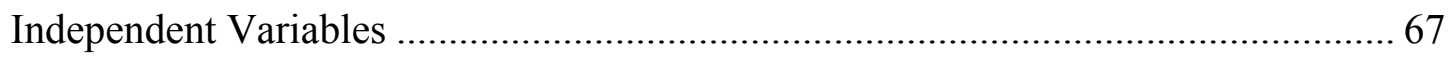

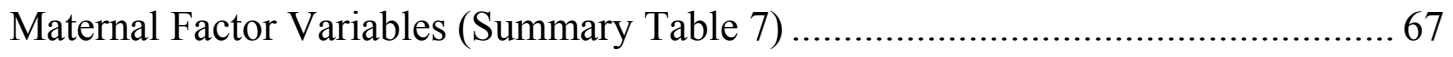

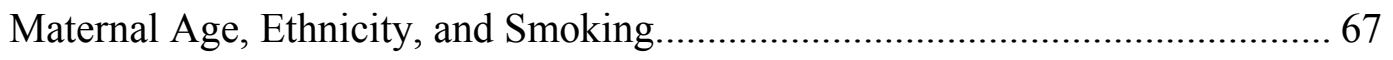

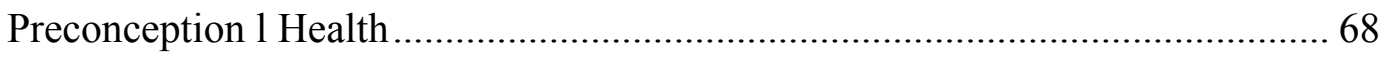

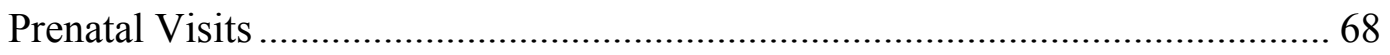

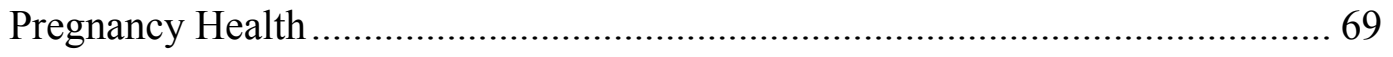

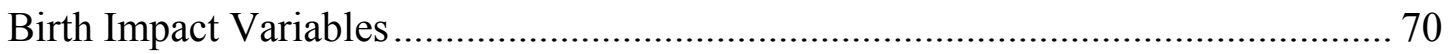




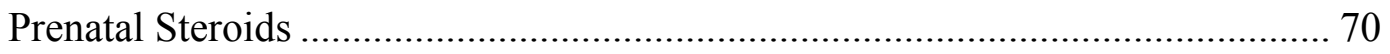

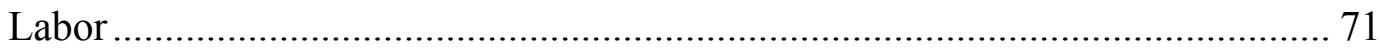

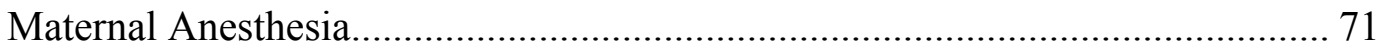

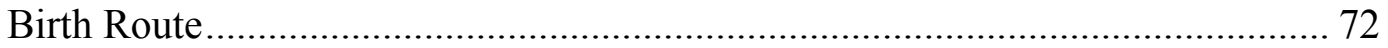

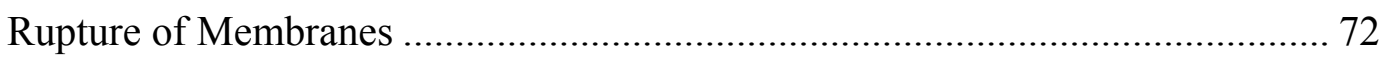

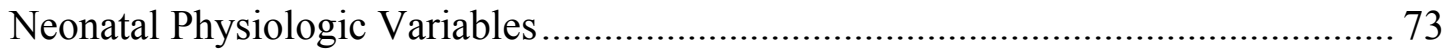

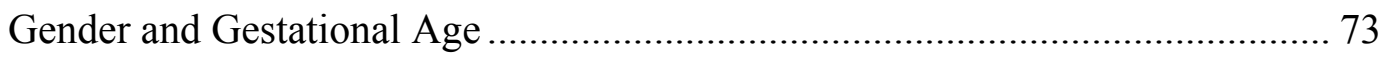

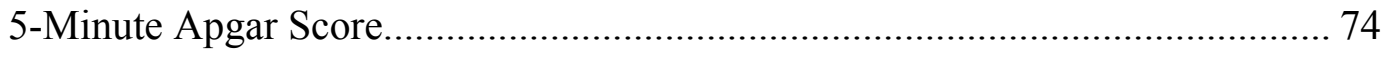

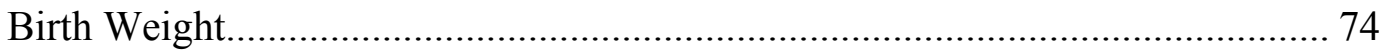

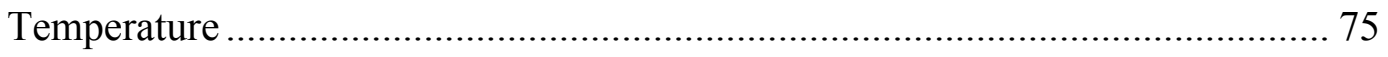

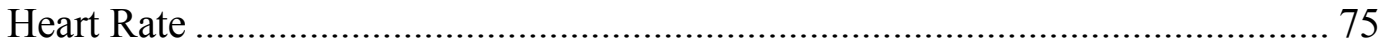

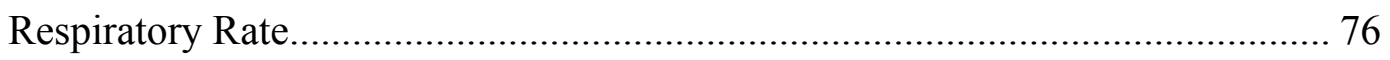

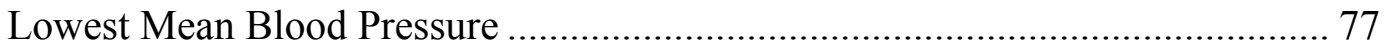

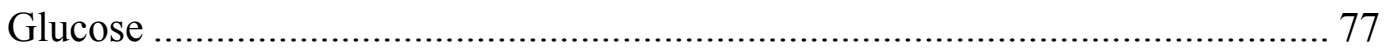

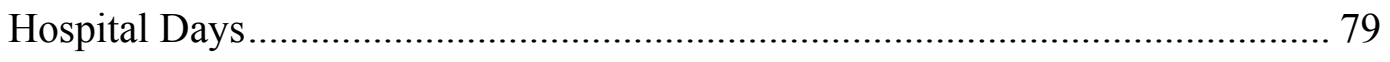

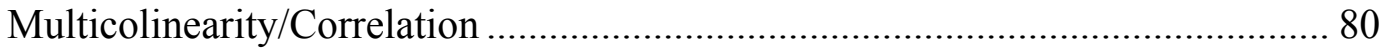

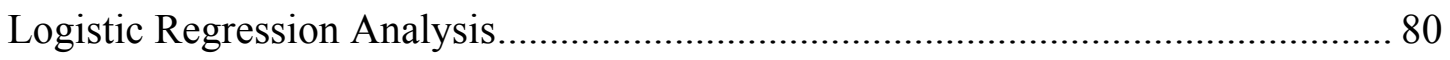

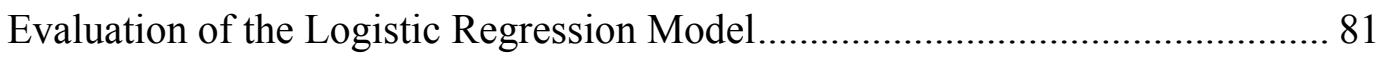

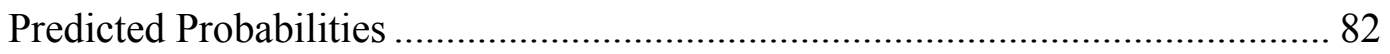

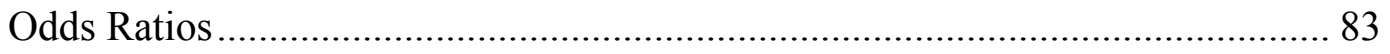

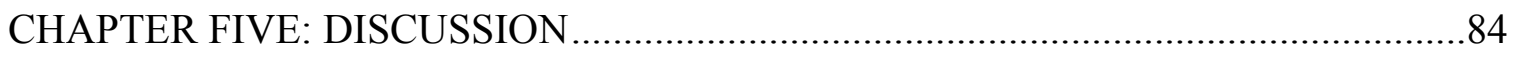

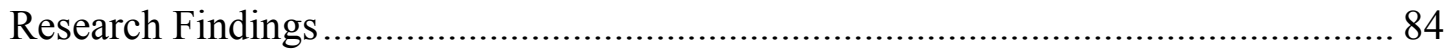

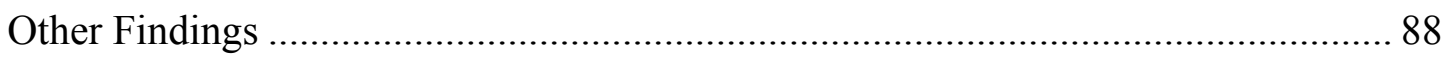

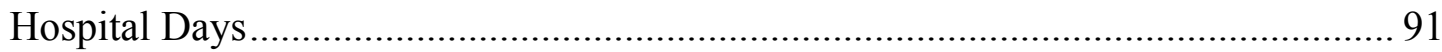




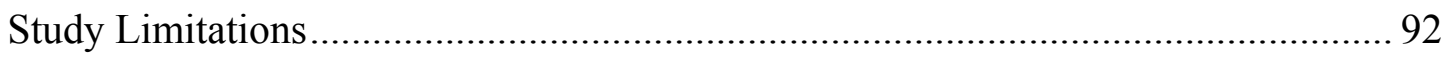

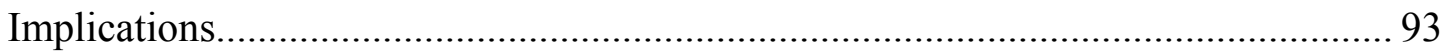

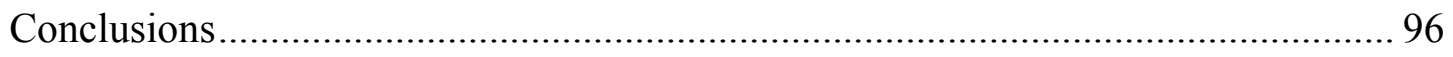

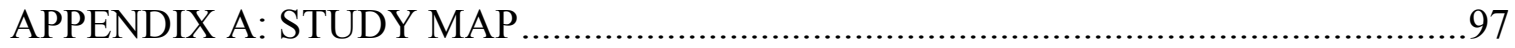

APPENDIX B: DATA COLLECTION SHEET (FROM SURVEYMONKEY).............99

APPENDIX C: UNIVERSITY OF CENTRAL FLORIDA IRB APPROVAL ..............104

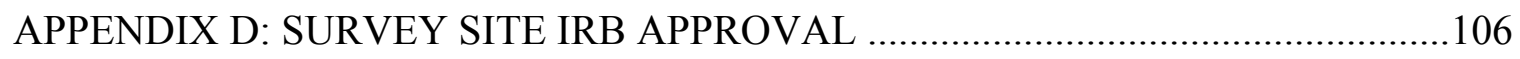

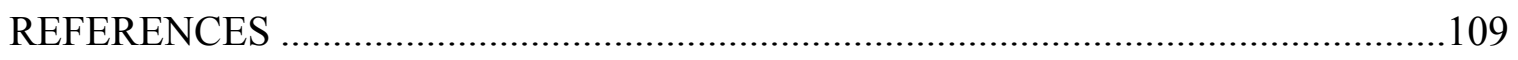




\section{LIST OF TABLES}

Table 1 Adaptive Physiologic Challenges and Subsequent Symptoms of Common Latepreterm Newborn Transition............................................................................ 18

Table 2 Composite Outcome Variables from Study by Bastek et al. (2008).................... 36

Table 3 Summary of Literature Review Synthesis ........................................................... 40

Table 4 Conceptual and Operational Definitions of the Dependent Variable ................... 46

Table 5 Independent Variables, Related Construct Conceptual Definition, Operational Definition, and SPSS Code........................................................................ 49

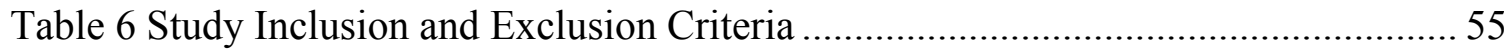

Table 7 Maternal Demographic Characteristics ................................................................ 69

Table 8 Chi-Square $\left(\chi^{2}\right)$ Test, Dichotomous Variables Among Demographic and Study Variables, Babies With Transition Success and Failure (Frequency \% of

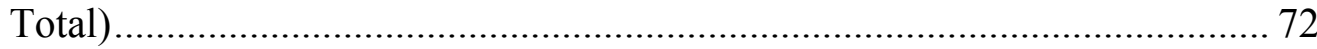

Table 9 Chi-square $\left(\chi^{2}\right)$ Tests for Dichotomous Neonatal Physiological Variables (Frequency \% of Total) ............................................................................... 74

Table 10 Cross-tabulation Results of Transition Success and Highest Transition Respiratory Rate, Recoded into Categorical Variable splitresprate................ 76

Table 11 Summary of $t$ Tests and Descriptive Statistics of Continuous Variables .......... 77 


\section{CHAPTER ONE: FACTORS RELATED TO BIRTH TRANSITION SUCCESS OF LATE-PRETERM INFANTS}

The transition from fetal life to neonatal life is a period of time involving consequential physiologic adaptation. The overall response of late-preterm infants to birth is uncertain and may be due to specific maternal and birth factors, as well as physiologically immaturity. As the first physiologic challenge of newborn life, birth transition success begins the process of the expectation of wellness, whereas birth transition failure results in admission to intensive care and possible illness. This chapter examines the physiology of birth transition and late-preterm infants, and discusses factors that place late-preterm infants at risk for illness.

\section{Introduction}

Although chronologically near term, late-preterm infants are most prevalent group of premature infants; they are, by definition, preterm (34 - 37 weeks' gestation) (Raju, 2006). Although this subgroup of infants has always been included among all preterm infants, these babies have recently been bracketed as a unique subpopulation of premature infants due to their uncertain outcomes and large numbers (Raju, 2006). Latepreterm infants are preterm and, by definition, are physiologically immature, but they are the same size as term babies, and not observably immature. The uncertainty surrounding late-preterm infants may be attributed to their resemblance to term infants, creating a higher expectation of wellness at birth for caregivers following birth. These infants present a challenge to determine where and how best to care for them following birth. 
While term babies are expected to complete transition with little event, extremely premature infants are expected to fail transition because of physiological challenges shortly after birth. In contrast, late-preterm infants face uncertain birth transition outcomes. An analysis of the factors associated with the birth transition success may provide insight into the level of care that may be anticipated by health care providers, as well as the background and physiologic aspects of birth transition and late-preterm infants. In addition, a description of the relevant developmental physiological events of the fetus prior to delivery is presented.

\section{Background of the Problem}

\section{Late-Preterm Infants}

Late-preterm infants are specifically defined as those infants delivered between the first day of the 34th week of gestation (day 239 of pregnancy) and just prior to the end of the 36th week of gestation (day 259 of pregnancy) (American Academy of Pediatrics and the American College of Obstetricians and Gynecologists, 2007). This subpopulation of preterm infants was initially recognized in 2006 and coined latepreterm infants because the timing of their birth is late in gestation and near term (Raju, 2006).

Although the mortality rate for these infants is fairly low $(0.9 \%)$ (Tomashek, Shapiro-Mendoza, Davidoff, \& Petrini, 2007), the incidence of moderate morbidities is increased in this population (Kramer et al., 2000). In addition, overall infant mortality has remained static in the United States for the past several years (Goldenberg, Culhane, Iams, \& Romero, 2008), whereas the mortality rates of late-preterm infant are rising (Shapiro-Mendoza et al., 2008). Because of the large number of infants in this 
population, any increase in morbidity will have a relatively large impact on overall mortality.

Based on a study of U.S. natality files and birth certificate data, Davidoff et al. (2006) determined that of more than four million annual live births, about 360,000 occur during the late-preterm period of gestation. This number indicates that one of every 11 births in the United States is of a late-preterm infant. Long-term outcomes for latepreterm infants are concerning. A retrospective cohort study from California indicated that newborns delivered as late-preterm's were found to be 3 times more likely to have a recognizable developmental delay including cerebral palsy, and had a moderately increased risk of intellectual disability (hazard ratio 1.25, $95 \%$ CI 1.01-1.54) (Petrini et al., 2009). Chyi, Lee, Hintz, Gould, and Sutcliffe (2008) found that children who were delivered as late-preterm infants had lower reading scores from kindergarten until the fifth grade. In Norway, a population-based study of late-preterm infants delivered without congenital anomalies between 1967 and 1983 were much more likely to have cerebral palsy (RR 2.7, 95\% CI 1-1.7), intellectual disability (RR 1.6, 95\% CI 1.4-1.8), schizophrenia (RR 1.3, 95\% C.I. 1-1.7), and disorders in psychological and emotional development, as well as major disabilities such as blindness, hearing loss, and seizures (RR 1.5, 95\% CI 1.2-1.8) (Moster, Lie, Markestad, \& 2008). These studies, along with the rising population of late-preterm infants, spotlight the importance of understanding the nature of the transition impediments encountered by late-preterm infants.

\section{Preterm Births in Florida}

Annually, the March of Dimes (2009a) premature birth report card documents the comparative rate of preterm births per state relative to the national goal based on Healthy 
People 2010. As reported by the National Center for Health Statistics and the March of Dimes (2009b), the incidence of the preterm births in Florida was 13.8\% for years 2005, 2006, and 2007, well exceeding the national average of 7.5\% (Hamilton, Martin, \& Ventura, 2009). Based on the estimation of 239,143 live births in Florida in 2007, 33,002 births were preterm and 23,436 births were late preterm.

In 2009, Florida was awarded the grade of F by the March of Dimes (2009a) relative to the national goal based on Healthy People 2010. This failing grade is attributed to the unchanging status of uninsured women $(27 \%)$ and rate of late-preterm births $(9.8 \%)$, as well as an increase in women smoking $(.01 \%)$ in Florida for the same time period. Increasing cesarean section rates are related to the increase in preterm births in Florida. In 2006, 36.1\% of Florida live births were cesarean deliveries and $63.9 \%$ were vaginal deliveries (March of Dimes, 2009b). In 2007, the caesarean section rate in Florida climbed to $37.2 \%$ versus the national average of $31.8 \%$ (American Congress of Obstetricians and Gynecologists, 2009). National trends possibly contributing to the increasing number of late-preterm births in Florida include the broadening use of assisted reproductive technology, which raises the likelihood of multiple-gestation births, and the prevalence of maternal obesity (Raju, 2006).

Although analysis of risk factors for delivery of a late-preterm infant has yielded beneficial insight, these relationships are not completely understood. Racial disparities in premature birth rates remain largely unexplained. In the United States, African American women are 3 to 4 times more likely to deliver a preterm infant than are other ethnicities. Caucasian women are more likely to deliver prematurely due to spontaneous labor and 
African American women are more likely to deliver prematurely due to preterm premature rupture of membranes (Fiscella, 1996).

At least $20 \%$ of pregnant women in the United States are reported to smoke tobacco. Maternal smoking increases the possibility of preterm birth twofold, but has not yet been studied. Nicotine and carbon dioxide are known vasoconstrictors that decrease placental blood flow. Of the remaining 3,000 chemicals found in cigarette smoke, the direct effect on the fetus is unknown. Smoking is related to systemic inflammatory response in pregnant women (Cnattingius, 2004).

Mild or moderate alcohol use is not associated with preterm birth, but studies have linked cocaine and heroin use to preterm delivery. Other risk factors associated with preterm labor include lower or higher maternal age, lower socioeconomic status, lowers educational status, and single marital status. Additional related contributing factors include lack of insurance — which equates to lack of prenatal care — and lack of social and economic support during pregnancy (Iams, Romero, Culhane, \& Goldenberg, 2008).

\section{Physiology of and Factors in Neonatal Birth Transition}

Newborn transition or birth transition is defined as the period of time beginning at the initial moment of birth and continuing until 6 hours of age (Askin, 2002). Successful or unsuccessful physiological transition experienced by the infant is demonstrated by observation and measurement of the adaptive processes following birth. As a series of physiological events, birth transition describes the newborn's adaptive ability to successfully establish respiratory, cardiovascular, thermal, and neurological processes that are independent of the mother and the placenta. Specific physiological events include increased blood flow to the lungs to support ventilation, an increase in 
systemic blood pressure for perfusion, redirection of blood flow away from anatomic shunts, establishment of independent metabolism, and exposure of the infant's body surface area to environmental (thermal) elements. Overall, newborns who fail to transition successfully may demonstrate observable and measurable physiological symptoms related to the system of failure.

\section{Labor and Delivery}

Newborn birth may or may not include labor. Methods of possible delivery include spontaneous vaginal delivery, assisted vaginal delivery, or cesarean delivery. Assisted vaginal deliveries may include use of vacuum extractors or forceps. No studies have been conducted to indicate a benefit of cesarean delivery over vaginal delivery for late-preterm infants (Dobak \& Gardner, 2006). Following delivery, neonatal respiratory maladaptation may be due to the absence of the beneficial effects of labor (Dobak \& Gardner, 2006; Fuchs \& Wapner, 2006). The complex processes of labor influence the production of fetal lung fluid. Absence of the labor process may contribute to continued production of fetal lung fluid, resulting in respiratory distress at birth (Jain \& Eaton, 2006).

The definitive effect of labor on the newborn is unknown. Labor contractions have been demonstrated to facilitate respiratory adaptation in the newborn. The experience of labor contractions elicits a catecholamine response by the adrenal glands in the fetus, a response also found in infants delivered by cesarean section following labor. Infants delivered by elective cesarean section without the impact of labor do not experience this rise in epinephrine and norepinephrine. These effects are considered protective because infants born without the benefit of labor have a higher respiratory 
morbidity rate. Without these strategic catecholamines, infants have poorer lung function, lower dynamic lung compliance, decreased protection from oxidative stress, and a much higher likelihood of persistent pulmonary hypertension (Ronca, Abel, Ronan, Renner, \& Alberts, 2006).

\section{Gestational Age}

A physiological consideration of neonatal birth transition success is gestational age. The purpose of gestational age assessment is to gauge fetal maturity to anticipate the clinical problems commonly associated with the particular gestational age. Infants born at 34 weeks' gestational age are assumed to be immature and are admitted directly to the neonatal intensive care unit (NICU) at birth. Gestational aging is not a perfect science. Gestational age is mapped throughout prenatal visits as a standard component of maternal prenatal care. Considered to be the strongest determinant of gestational age, fetal ultrasound is conducted at approximately 20 weeks (Campbell, Warsof, Little, Cooper, 1985).

In the absence of prenatal care, the determination of gestational age falls to physical examination of the newborn for neurological and physiological evidence of maturity by Ballard exam. The Ballard exam, although helpful, has been found to have a margin of error of \pm 2 weeks' gestational age (Rosenberg et al., 2009). Rosenberg et al. (2009) reviewed methods of gestational age assessment in low-resource settings compared to 20-weeks' gestational age ultrasound measurement. Comparing the results of external physical exam with calculation by last menstrual period, Rosenberg et al. (2009) found that, of 355 preterm infants, the last menstrual period was the most accurate 
$(W=0.878)$. Because of its accuracy, in the absence of an early-gestation ultrasound, the last menstrual period is used to calculate gestational age.

Complicating the phenomenon of birth transition is the immature physiology of the late-preterm infants, who have the size and appearance of healthy, term infants. Because they are near-term premature infants, the specific scope of physiological ability of each infant is individualized and possibly subject to factors influencing fetal life, as well as the gestational age of the infant at birth. A common consequence of failed transition for the late-preterm infant is admission to the NICU, resulting in an increased length of hospital stay and parental separation. Identification of the maternal, birth, and physiological characteristics that have an impact on the transition success of late-preterm infants will provide knowledge, add to the understanding of transition, and possibly guide future studies of predicting transition outcomes. The specific developmental physiological processes relevant to the care and outcome of late-preterm infants make up the physiological model of birth transition.

\section{Premature Birth}

Preterm or premature labor is defined as the presence of regular contractions accompanied by cervical changes prior to 37 weeks' gestation (Goldenberg et al., 2008). The circumstances under which infants are delivered prematurely include (a) spontaneous labor with intact membranes, (b) preterm premature rupture of membranes, and (c) elective labor induction or cesarean section. Spontaneous preterm births are now considered to be due to a syndrome complicated by maternal infection and inflammation, vascular disease, and uteroplacental ischemia or hemorrhage, uterine overdistention, stress, and/or immunologically mediated responses (Goldenberg et al., 2008). Goldenberg 
et al. (2008) reported the primary risk factors for preterm birth include women who have delivered a premature infant previously, are African American, have periodontal disease, and have a low body mass index (BMI).

\section{Respiratory Adaptation}

Embryonic fetal lung development, fetal lung fluid activity, fetal breathing movements, and surfactant synthesis are integral for optimal respiratory adaptation at birth. These processes are interrelated and crucial for determining the respiratory ability of the newborn at birth. Fetal lung development is a continuous process and occurs in five stages: embryonic, pseudoglandular, canalicular, saccular, and alveolar. These stages are overlapping and continue throughout fetal life. The embryonic stage lasts from 3 to 7 weeks' gestation and is characterized by the primal formation of the tracheal tree with 10 rudimentary bronchopulmonary segments on the right and left division. During the embryonic stage, thickened airway tubes lined with epithelial cells form, causing a glandular-like appearance to the lungs. By the end of the pseudoglandular stage, cartilage, connective tissue, muscle, blood vessels, and lymphatics are rudimentary but identifiable (Blackburn, 2007).

The canalicular stage lasts until 26 weeks' gestation and is characterized by the formation of terminal air sacs appearing at the terminal bronchioles. From this incremental milestone begins the formation of multiple terminal air sacs, a process that continues until 30 weeks' gestation. During the overlap of this saccular stage, lung surface area and volume increase dramatically. The alveolar stage begins at 36 weeks, with primitive alveoli with transitional ducts and saccules with primitive septa. By term gestation, only $15 \%$ of alveoli are formed. The true alveoli are formed postnatally 
following the occurrence of gas exchange. During the alveolar phase, microvascular maturation occurs and a single capillary network is formed (Blackburn, 2007). Infants born during late-preterm gestation are delivered prior to the end of the saccular stage and at the beginning of or prior to the alveolar stage (Blackburn, 2007).

The fetal lung is composed of two cell types: Type I and Type II pneumatocyte cells. Type I cells facilitate respiration and cover $93 \%$ of the alveolar surface. Type II cells appear at 20-24 weeks' gestation; these cells are found over $5 \%$ of alveolar surface and are more differentiated than Type I cells. Type II pneumatocytes have more organelles and larger mitochondria, with Golgi apparatus, rough endoplasmic reticulum, ribosomes, lamellar bodies, and glycogen lakes than Type I cells. The design of Type II cells supports their function of surfactant secretion with production and secretion by lamellar bodies. A final function of Type II cells is alveolar repair (Blackburn, 2007).

Functional development of the lung is primarily related to the biochemistry of surfactant, a lipoprotein. Surfactant has multiple classic functions as well as specific chemical functions. In its typical role, surfactant is primarily responsible for decreasing surface tension relative to surface area, preventing lung collapse, maintaining gas exchange, and supporting overall lung mechanics. In its nonclassical role, surfactant exhibits antioxidant activity, alters cytokine/inflammatory mediator release, has antibacterial and antiviral activity, and performs a variety of nonspecific host defenses. Maintaining a surfactant film across the surface of the lung also provides a stable barrier against pathogens (Blackburn, 2007).

Synthesis of surfactant is an intricate interaction of hormones and growth factors. The primary hormones that stimulate or accelerate lung maturity are glucocorticoids. 
Stimulation of glucocorticoids results in an increase in glycogen depletion, which results in thinning of the intralveolar septa and an increase in the size and surface area of the alveoli. Glucocorticoids also enhance the production of elastin and collagen in the lung, which improves lung compliance. Glucocorticoids protect cells from damage during transition from lower to higher oxygen levels by producing antioxidant enzymes in the lung. Near term, there is an increase in the fetal level of glucocorticoids, resulting in lung maturation. Administration of antenatal steroids to preterm fetuses just prior to delivery simulates this effect, thereby decreasing the prevalence of respiratory distress syndrome caused by surfactant deficiency (Blackburn, 2007).

Fetal breathing begins as early as 10 weeks' gestation and is rapid, irregular, and intermittent during early gestation. Later in gestation, fetal breathing increases to 30-70 breaths per minute with frequent gasping. Fetal breathing accomplishes stretching of the lung tissue and results in lung growth. As delivery approaches, fetal breathing becomes organized with increased breathing during the daytime. The components surrounding the initiation of fetal breathing are unknown but thought to be related to maternal inhalation of carbon dioxide, adrenergic and cholinergic compounds, and prostaglandin inhibitors. Initiation or failure of initiation of fetal breathing may also be related to maternal glycemic level, nicotine, alcohol ingestion, and absence of labor (Blackburn, 2007).

Just prior to birth, the formation of true alveoli is beginning, and blood flow to the lungs via narrowed pulmonary arteries remains at $10-20 \%$ of cardiac output. As birth nears, the volume of fetal lung fluid is approximated to be 10-30 milliliters per kilogram of body weight; this fluid must be replaced with air and forced out following birth. Surfactant within the alveoli retains air and prevents atelectasis, increasing alveolar size 
and perfusion. At this point, fetal lung fluid production must move from secretion to absorption (Blackburn, 2007).

\section{Cardiovascular Adaptation}

The first functioning system of the fetus is the cardiovascular system, consisting of the heart and blood vessels. As the fetus grows exponentially, the cardiovascular system is necessary for delivery of substrates and nutrients essential for fetal growth and development. The process of cardiovascular development lasts 6-8 weeks prenatally. Cardiovascular development involves transformation of scattered cells into a plexus of endothelial vessels. These vessels fuse to create two longitudinal cellular strands known as cardiac cords. These cords cannulate, forming two endocardial heart tubes that fold into a fused single tube. Cardiac gelatinous connective tissue separates the mesenchymal tube from the endothelial tube as they become a tube within a tube. From the inner tube, the endocardium is derived, while the myocardium and epicardium are derived from the outer tube. Septation begins while the heart is pumping blood and is completed by week 6 of life (Blackburn, 2007).

Fetal circulation is characterized by multiple physiologic factors related to placental blood flow. Blood flow is optimized from the placenta to the newborn's vital organs by the presence of three anatomic shunts. The ductus venosis is an extracardiac shunt that carries blood oxygenated at the placenta through the liver and into the inferior vena cava. Blood is then introduced in the right atrium and passes through the second shunt, the foramen ovale, which is intracardiac and located between the right and left atria. The final shunt carries blood from the aorta into the pulmonary artery, allowing for optimal upper body circulation. The pulmonary bed is bypassed primarily due to 
vasoconstriction by decreased fetal oxygen levels, endothelium, arachidonic acid metabolites, and hypoxia. An equalization of pressures between the heart chambers and parallel circulation within the heart results from these processes (Blackburn, 2007).

At birth, pulmonary blood flow is increased by breathing, and cardiac output is redistributed. Pulmonary vascular resistance decreases, allowing blood flow to the lungs and increasing systemic blood flow. As air enters the lungs with air breathing, oxygen levels in the blood rise, facilitating the closure of the anatomic shunts. A rise in epinephrine and norepinephrine at birth mediates cardiac output and contractility. This surge begins 4 hours prior to birth and continues for 6 hours following birth. Decreasing levels of these catecholamines ultimately affect heart rate. Baseline heart rate is based on the intrinsic depolarization rate of the sinoatrial node because sympathetic innervation is incomplete. Maturation of the parasympathetic system results in lowering the resting heart rate (Blackburn, 2007).

\section{Metabolic Adaptation}

Transition of the metabolic process from fetal life to post delivery life is multifactorial. This process is based on the balance of energy requirements, substrate requirements, and maturation of hormonal, neuronal, and enzymatic systems. Ability of the newborn to accomplish glucose homeostasis is affected by gestational age, health status, and intake (Blackburn, 2007). Balance of these glucose levels after delivery is also influenced by the environment (Klaus \& Fanaroff, 2001).

The fetus is maintained in an anabolic state with $80 \%$ of energy consumption provided by glucose. Glucose is supplied transplacentally by passive diffusion, maintained by a gradient whereby fetal blood sugar levels are two-thirds that of the 
mother's (Garg \& Devaskar, 2006). During the last week prior to birth, the fetus increases fuel storage of glycogen and lipids to maintain glucose homeostasis at birth. At birth, the constant supply of maternal glucose is lost with placental separation, requiring quick metabolic adaptation to meet the energy demands of cellular adenosine triphosphate. During transition, the newborn's circulating glucose drops to one third of the maternal concentration, or 40-60 mg/dL (Garg \& Devaskar, 2006). This fall in neonatal glucose reaches its nadir at 60 minutes of life, with a subsequent increase in glucose values and stabilization at 2-4 hours of life. Stabilized values range between 50 and $60 \mathrm{mg} / \mathrm{dL}$. Gluconeogenesis increases after birth, contributing to available systemic glucose after birth. The liver metabolizes substrates to produce glucose, including glycerol, lactate, alanine, and pyruvate. By 3 days of life, blood glucose regulation is dominated by glucose levels, and gluconeogenesis is decreased (Blackburn, 2007).

Neonatal hypoglycemia may be neurologically detrimental to the newborn. Hypoglycemia results when neonatal glycogen stores are insufficient to fuel transition or the newborn is unable to mobilize glycogen stores. The definition of hypoglycemia according to an actual level of glucose is controversial in the literature (Blackburn, 2007). In newborns, glucose levels of $<40 \mathrm{mg} / \mathrm{dL}$ are considered to indicate hypoglycemia (Verklan \& Walden, 2004). Clinical signs of hypoglycemia are primarily neurologic and include jitteriness, tremors, irregular respiration, hypotonia, apnea, cyanosis, high-pitched cry, lethargy, irritability, hypothermia, and eventually seizures (Jorgensen, 2008). Infants with hypoglycemia may also be asymptomatic (Garg \& Devaskar, 2006). 


\section{Neurologic Adaptation}

Fetal neurologic development is a complex process; it is one of the earliest systems to develop but the last to mature. The nervous system begins development approximately 18 days after fertilization. Primary neurulation involves the development of the neural plate, neural folds, and the neural tube, and occurs on the dorsal surface of the embryo. The process of neurulation results in formation of the brain and spinal cord. The neural tube is an open invagination until cephalid and caudal closure at 23 to 26 days of life. Neurectodermal cells on the neural plate migrate into neural folds, forming neural crest cells that migrate into the developing embryo to form facial and spinal structures. From these neural crest cells come connective tissue and neurons, the peripheral nervous system, Schwann cells, pigment cells, the pia and arachnoid layers of the meninges, and the peripheral nerves. Ventral induction leads to facial and forebrain structures. Closure of the rostra neural tube completes formation of the brain (Blackburn, 2007).

Fetal neurodevelopment at the beginning of gestation involves growth of the basal ganglia, thalamus, midbrain, and brainstem. Neuronal proliferation is continuous but is maximized between 12 and 18 weeks' gestation. Neuronal migration is mediated by proteins, receptors, surface molecules such as fibronectin and chondroitin (Volpe, 2008). After formation, neurons migrate from the germinal layer into the gray matter to be further differentiated into the subependymal region. Organization begins at 6 months' gestation and continues into adulthood. Myelinization of the central and peripheral nervous systems begins during the second trimester and continues into adulthood (Blackburn, 2007). 
At birth, environmental change challenges the newborn neurologic system. Motor control is emerging to manage motor activities that include muscle tone, motor abilities, and reflexes. Term babies normally demonstrate an increase in muscle tone during birth transition. Flexion demonstrates innervation of flexor muscles and assists the newborn to conserve energy. Hypotonicity is indicative of poor muscle tone and may provide observable delayed responses to light, impact, suck, movement, noise, and stimulation (Blackburn, 2007). Neurologic manifestations such as the absence of basic reflexes of rooting and sucking may signal underlying disease (Askin, 2002) but may have multiple origins, such as maternal medications, placental events, or congenital malformation. Neurologically, infants establish flexion and tone to conserve heat, and cry to facilitate ventilation (Blackburn, 2007).

\section{Thermal Adaptation}

Prior to delivery, fetal temperature is entirely maintained by the maternal-fetal thermal gradient. Exposure to this gradient means newborns cannot control their postbirth temperature independently. Fetal core temperature is similar to amniotic fluid temperature but must be higher than maternal temperature to maintain the gradient. The heat generated by the fetus is transmitted to the uterine wall or by way of the umbilical cord to the maternal blood in the placental intervillous spaces. Because the placenta has a large surface area, a thin membrane barrier, and an enormous blood-flow rate, thermal exchange is enhanced. Maternal fever directly affects the fetus but the effect may be delayed by amniotic fluid, which acts as an insulator for the fetus. During labor, the maternal-fetal temperature gradient exists as long as blood flow is maintained (Blackburn, 2007). 
After delivery, thermoregulation is critical to optimal neonatal physiology. The larger relative surface area of the infant, decreased body fat, and increased skin permeability to water can result in rapid heat loss. Falling temperatures after birth trigger compensatory oxidative metabolic process, including nonshivering thermogenesis triggering the release of norepinephrine, which increases heat-producing metabolic activity requiring oxygen consumption and glucose metabolism (Blackburn, 2007). At birth, newborns lose heat rapidly, primarily through evaporation and radiation. Other methods of newborn heat loss include conductive losses and losses due to convection. Without thermal intervention, a newborn's temperature may fall up to $1{ }^{\circ} \mathrm{C}$ per minute. In response to cold stress, term infants can increase their metabolic rate by $200-300 \%$ but this response is delayed in late-preterm infants (Verklan \& Walden, 2004).

In newborns, body temperature and the consumption of oxygen are inversely proportional. Provision of a neutral thermal environment decreases oxygen consumption to a minimal level. When a newborn is in a thermoneutral state, heat and oxygen are neither lost nor gained. A neutrothermal environment is provided after birth by the use of radiant warmers with skin probe sensors. The radiant warmer monitors the infant's skin temperature constantly and maintains skin temperature within the normal range based on data associated with birth weight. The lower the infant birth weight, the lower the range is for maintaining neutrothermality (Verklan \& Walden, 2004).

\section{Synthesis of Newborn Systems}

Understanding the health status of the newborn first begins with a comprehensive view. Prior to birth, the newborn is considered based on maternal health factors prior to and during pregnancy. The events of labor and delivery also contribute to knowledge 
about the newborn. Gestational aging contributes to this knowledge when prenatal care has occurred. Following birth, the neonate is monitored for transitional challenges that signal the possibility of illness, beginning with the Apgar score. Vital signs are obtained periodically and the newborn is assessed for transitional challenges including respiratory, cardiovascular, metabolic, neurologic, and thermal changes. Overall, infants who fail to transition successfully may demonstrate observable and measurable symptoms related to the system of failure. The neonatal physiological indicators of adaptive challenge and resulting clinical characteristic of the infant are presented in Table 1.

Table 1

Adaptive Physiologic Challenges and Subsequent Symptoms of Common Late-preterm Newborn Transition

\begin{tabular}{ll}
\hline \multicolumn{1}{c}{ Adaptive challenge of transition } & \multicolumn{1}{c}{ Symptoms of challenge } \\
\hline Respiratory adaptation & Tachypnea, apnea \\
Cardiovascular adaptation & Hypotension \\
Thermal adaptation & Hypothermia, hyperthermia \\
Metabolic adaptation & Hypoglycemia \\
Neurologic adaptation & Absent or poor rooting \\
\hline
\end{tabular}

\section{Statement of the Problem and Significance}

To date, no systematic evaluation of birth transition outcomes in term or in latepreterm infants has been conducted to document the prevalent, clinical, and epidemiological factors surrounding transition success and failure. Studies linking possible individual or collective contributing factors to infant transition failure do not specifically address late-preterm infants. Although it is known late-preterm infants are premature infants with immature physiology and a higher frequency of transition 
challenges than term infants (Raju, Higgens, Stark, \& Leveno, 2006), it is not known which specific factors affect the transition outcomes of late-preterm infants in particular. How individual factors surrounding mother, birth, and physiology affect late-preterm wellness following birth is also not well known (Raju et al., 2006). Why do some latepreterm infants do well while others transition poorly? Finally, what magnitude of this population is admitted to the NICU?

Based on the need for recognizable collective information of the factors surrounding transition of the late-preterm infant, the following research questions emerge:

1. How many late-preterm infants are admitted to the NICU at or prior to 6 hours of life?

2. What are the risk factors related to maternal factors, birth impact, and neonatal physiologic maturity that are associated with late-preterm infants who fail and do not fail transition?

3. Of the risk factors determined to be related to transition success, are any of these factors predictive of transition success or failure?

The purpose of the study is to determine the prevalence, clinical-epidemiological characteristics, and predictive factors for failed birth transition in late-preterm infants. The study provides descriptive information of the maternal, birth, and neonatal physiological factors and the possible impact of these factors on the transition success of late-preterm infants. From this descriptive information, a determination may be made regarding how policy, education, and research initiatives might be shaped by the findings. 
Analysis provides information regarding common maternal, birth, and neonatal physiologic characteristics of infants related to their transition outcome.

A presentation of a comprehensive literature review of the research phenomenon of birth transition, particularly related to the population of late-preterm infants is offered in Chapter Two. A summary of what it known is offered as well as a physiologic framework to guide this study is presented.

The method by which the study's research was conducted is discussed in detail in Chapter Three. Providing detail will facilitate replication of the study, if warranted. Methods are a reflection of the stated research problems and input from the literature review. The variables for study, setting, specific population, sample size, and sampling plan, as well as inclusion and exclusion criteria, are explained. An instrument constructed for data collection is presented, including information related to reliability, validity, and standardization. The procedure for data analysis, methodological assumptions, and limitations is described are also in Chapter Three.

Chapter Four details the results of data analysis including description of the sample and findings based on the methods identified in Chapter Three. The results section includes the presentation of information sufficient to answer the stated research questions based on the stated study method. Chapter Five includes a discussion of the conclusions as related to the research question, literature review, and study findings. The implications for nursing practice, policy, and education are stated, as are recommendations for further research. 


\section{CHAPTER TWO: LITERATURE REVIEW}

For a comprehensive and complete review of the literature for the study, the concept of transition as an overall process must be considered first. A review focusing on the study of identified variables affecting transition is included to determine possible independent variables for consideration with processes already identified as related to transition. A third focus of this review is the late-preterm infant. As a subpopulation first identified in the literature in 2006 (Raju, 2006), there have been many publications since that time related to developing knowledge and understanding of this window of gestational age.

At issue is determining what events define successful and unsuccessful transition, and at what point does delayed transition become illness requiring admission to a higher level of care, such as an NICU. What are the identifiable factors related to newborns and their successful or unsuccessful birth transitions? Could identification of these characteristics assist caregivers to identify infants with risk of delayed transition and illness? Finally, has transition related to the late-preterm infant been explored in the literature?

For explanatory purposes, the literature review is presented in three parts. A review of articles on the collective processes of birth transition is offered in Part One. Articles documenting the possible variables surrounding birth transition that are related to maternal circumstance, labor and delivery, and neonatal physiologic system findings of 
newborns and birth transition are reviewed in Part Two. A summary of the emerging literature surrounding multiple aspects of late-preterm infants is presented in Part Three.

\section{Birth Transition, Transition Variables, and Late-Preterm Infants}

A literature review of neonatal birth transition and associated variables, and of late-preterm infants was performed on English-language publications from 2000 onward (the past 10 years). The synonymous keywords fetal, newborn, and infant, as well as adaptation, birth and transition and late-preterm infant were searched as complete and truncated terms using CINAHL, MEDLINE, and the Cochrane databases.

\section{Part One: Birth Transition}

In 2002 and again in 2009, Askin provided an overview of the physiology of birth transition regarding the normal and abnormal possible outcomes of birth transition of term infants. Presented in two parts, Askin (2009a, 2009b) synthesized the event of successful and unsuccessful birth transition from a systems perspective and assigned duration to transition as lasting from birth until 6 hours of life. The phases of birth transition described by Askin (2009a, 2009b) identify the red flags of transition failure:

(a) symptoms persisting greater than 2 hours of life; (b) worsening distress; (c) congenital anomalies; (d) abnormal muscle tone; (e) central cyanosis; and (f) moderate to severe respiratory distress characterized by grunting, flaring, retractions, and oxygen need. Tachypnea is not listed as a red flag for transition (Askin, 2009a, 2009b) but the severity of symptoms and duration of symptoms, including tachypnea, is noted as a possible signal of more significant disease. Finally, Askin (2009a, 2009b) identified risk factors for transition of term infants related to maternal factors (e.g., diabetes, hypertension, cardiac or respiratory disease, severe anemia, shock, febrile infection), antepartum factors 
(e.g., intrauterine growth restriction, placenta previa or abruption, fetal-maternal hemorrhage, malpresentation, multiple gestation, pregnancy-induced hypertension, illicit or prescription drug exposure), intrapartum complications (e.g., chorioamnionitis, fetal distress, prolapsed cord, premature or prolonged rupture of membranes, shoulder dystocia, vacuum delivery, forceps delivery, caesarian section, presence of meconium), and neonatal complications (e.g., prematurity, congenital anomaly, postmaturity, birth trauma).

Sinha and Donn (2006) stated the incidence of transition difficulties in term babies is $1-2 \%$ and described birth as a "test" of physiologic systems maturity (p. 166). Regarding the physiological processes, Sinha and Donn agreed difficulties with maladaption may signal further illness involving respiratory, cardiovascular, metabolic, and neurological systems. Labor is essential to the prevention of excessive lung fluid production, and respiratory distress syndrome may prevent the sequelae of maladaptation in very preterm infants. Activation of nitric oxide is essential to preventing pulmonary hypertension in term infants, but is unknown in preterm infants (Sinha \& Donn, 2006).

Aylott (2006a, 2006b) identified a new conceptual framework to the approach of transition assessment of newborns at delivery by describing an integrated physiological theory of the neonatal energy triangle that involves hypoglycemia, hypothermia, and hypoxia as the primary problems of transition. Transition is not described in usual contexts, but is regarded as an ongoing process for premature infants who have been admitted to the NICU at birth. Aylott's neonatal energy triangle theory relates to understanding birth transition by considering transition may be an ongoing process for preterm infants, whereas it is a more temporary process for term infants. Aylott 
considered the transition period for preterm infants to be a minimum of 6 hours following birth, theorizing that for preterm infants, the variables of hypoglycemia, hypothermia, and hypoxia are closely related and, when combined with breathing, crucial for survival.

Although the purpose of Aylott's (2006a, 2006b) neonatal energy theory was to identify and support infant transition in an intensive care unit, it is unclear if this theory relates to the late-preterm infant. Because the infants considered were admitted to the NICU, Aylott may have been more directly addressing infants who were 23-34 weeks and would normally receive a higher level of care. The neonatal energy theory offers an understanding of the altered physiology of preterm infants and the interrelationship of hypoglycemia, hypothermia, and hypoxia, which may prove relative to transition challenges of late-preterm infants.

In 2007, Mercer, Erikson-Owens, Graves, and Haley reviewed and summarized many practices related to birth transitional care, including skin-to-skin care, cordclamping practices, suctioning, and resuscitation. Of particular interest, the authors investigated findings related to thermoregulation and maternal anesthesia. The reviewed effects of maternal anesthesia proved the most pertinent to transition success or failure. Specifically regarding newborn transition, the authors assessed three Cochrane reviews, nine systematic reviews, six randomized controlled trials, a case-control study, one retrospective cohort study, and three observational studies. Multiple neonatal outcomes were evaluated in these studies but of interest to the proposed study's focus are Apgar scoring, respiratory depression, neurobehavioural outcomes, and admission to the NICU.

The studies reviewed by Mercer et al. (2007) considered term newborns and varying methods of maternal delivery anesthesia. Based on their review, the authors 
determined results were inconclusive and inconsistent. Although an extensive review was conducted, the authors were unable to draw a conclusion between maternal anesthesia and any of the stated outcomes. Of significance to the present study, the articles reviewed by Mercer et al. related to well newborns and not specifically to preterm or late-preterm infants.

Overall, the literature available regarding the process of birth transition is primarily descriptive of physiological adaptation. Quantitative or qualitative studies related to birth transition as well as transition challenges related to late-preterm infants were not found.

\section{Part Two: Transition Variables}

\section{Respiratory Adaptation}

Zelenina, Zelenin, and Aperia (2005) discovered microscopic water channels known as aquaporins (AQPs) are responsible for regulating water transport across cell membranes. From this discovery, the processes of fetal lung fluid reabsorption as a process of homeostatic adaptation could be better understood. Zelenina et al. found AQPs are related to the use of antenatal steroids and their previously mysterious benefit. The researchers postulated the depth and composition (acidity) liquid layer covering the airways is critical to maintaining gas exchange and preventing infection. Transport of water from the lungs through the AQPs is important for clearance of lung water and prevention of atelectasis at birth. When AQPs — specifically AQP3s - are depleted, transcapillary osmotic water permeability is reduced. The use of perinatal corticosteroids increases the level of AQPs (Zelenina et al., 2005). 
Most of the articles regarding respiratory transition addressed the effects of labor and cesarean section on respiratory outcome. Dudell and Jain (2006) documented the detrimental effects of elective cesarean without labor on the neonatal respiratory system. Jain and Dudell (2006) reaffirmed the biggest challenge faced by infants at birth is respiratory transition from fluid to air breathing. The authors found the physiologic mechanisms underlying fetal lung fluid absorption, including the processes set forth by labor, lessen the effect of the "vaginal squeeze" on the minimization of fetal lung fluid (Dudell \& Jain, 2006, p. 803). Bland (2001) discussed from a biochemical perspective the loss of fluid from the lung lumen during labor. Jain coauthored three additional articles describing the physiology of fetal lung fluid and alveolar fluid clearance (Dudell \& Jain, 2006; Jain \& Eaton, 2006; Ramachandrappa \& Jain (2008).

\section{Exposure to Maternal Antidepressants}

Moulsdale and Hermann (2008) reviewed the literature on the effect of in-utero exposure to selective serotonin reuptake inhibitors ([SSRIs] i.e., Lexapro, Zoloft, Prozac, Paxil) and serotonin norepinephrine reuptake inhibitors, and their interference with postnatal transition. The authors' intention was to identify a syndrome or withdrawal cascade of symptomatology present after exposure to these drugs because these drugs are the most commonly used antidepressants during pregnancy, demonstrated by a $20 \%$ incidence of depression during the last trimester of pregnancy. The authors reviewed six prospective cohort studies and found half of these studies demonstrated an in-utero SSRI and neonatal adaptation, specifically neurobehavioral problems, and two other studies were statistically significant for respiratory depression in newborns following maternal administration of SSRIs. 
An important revelation of the study by Moulsdale and Hermann (2008) was that maternal psychiatric history is not always considered in newborn care. The authors could not determine if the effects on neonates were not the result of maternal depression. Many of the studies were not controlled for maternal comorbidities. Moulsdale and Hermann commented studies on the need for supportive measures for newborns following delivery of mothers receiving SSRIs have not been conducted.

\section{Persistent Pulmonary Hypertension}

Persistent pulmonary hypertension of the newborn (PPHN) is a complication of failed transition associated with hypoxia due to failure of the pulmonary vessels to dilate due to hypoplastic pulmonary vasculature, increased muscularization of pulmonary arterioles, or idiopathic factors. During fetal life, regulatory hormones influence the high vascular resistance, directing blood through fetal anatomic shunts. Respiratory distress after delivery is worsened by the presence of PPHN, a cause of newborn morbidity.

Hernández-Díaz, van Marter, Werler, Louik, and Mitchell (2007) conducted a large sample study of possible risk factors for pulmonary hypertension by multivariate analysis. During a 5-year period, the authors enrolled 377 mothers of infants with PPHN and matched them with 836 control mothers. The researchers interviewed the mothers 6 months following delivery to obtain demographic and obstetrical information.

Hernández-Díaz et al. found the antenatal risk factors for PPHN were maternal Asian or African American ethnicity and a prepregnancy BMI of greater than 27. Smoking was not found to be associated with newborn PPHN. Through analysis of perinatal factors, Hernández-Díaz et al. reported elective cesarean delivery was predictive of PPHN even 
in term infants, calculating the risk of PPHN to be 7 times higher after cesarean deliveries.

Other perinatal factors noted by Hernández-Díaz et al. (2007) included a higher incidence of PPHN in late-preterm infants and postterm infants, as well as male infants. Of the maternal factors examined, maternal ethnicity and BMI were the strongest independent predictors for PPHN. Hernández-Díaz et al. found that when compared to Caucasian women with a BMI $<20$, the odds of delivering and infants that developed PPH forAfrican American and Asian women with BMI > 27, were 6.1 (2.9-13.2) and 7.0 (2.0-24.8) respectively. The investigators found smoking at any time during pregnancy was not associated with PPHN risk but was related to an odds ratio of 1.9 (95\% CI: 1.32.9).

According to research by Hernández-Díaz et al. (2007) regarding perinatal risk factors, infants who were delivered after 41 weeks' gestation or between 34 and 37 weeks' gestation and were large for gestational age were at the greatest risk for pulmonary hypertension. More infants with PPHN were delivered by caesarian section (61.3\%) than in the control group (19.4\%), with an odds ratio of 7.4\% (95\% CI: 5.210.4). The authors concluded that although the predictors were not demonstrated to have causal relationships, the overall risk for PPHN is increased with caesarean section of late preterm infants and infants delivered after 41 weeks, by mothers with BMIs greater than 27, who are of African American or Asian ethnicity, and have diabetes or asthma.

Of the respiratory adaptation literature reviewed, relevance to birth transition was found in all. The physiological adaptation processes described by Jain and others (Dudell \& Jain, 2006; Jain \& Dudell, 2006; Jain \& Eaton, 2006; Ramachandrappa \& Jain, 2008) 
are valuable for their identification of the pertinence of the presence of labor, the importance of labor, and the route of delivery. Literature related to pulmonary hypertension demonstrated the relevance of the maternal factors of maternal health, BMI, race/ethnicity, and delivery route.

\section{Cardiovascular Adaptation Review}

Beat-to-beat variability has been used for monitoring fetal changes and labor response. This method of data acquisition is also used in the heart rate observation system as a predictive technology for neonatal sepsis (Griffin et al., 2004). In 2002, Verklan published a description of the physiological variability of newborns during transition to extrauterine life. As indicated by heart rate observational system monitoring, Verklan demonstrated subtle changes in neonatal heart rate may be predictive of physiological change. Verklan examined heart rate during the transition period using spectral analysis to monitor for subtle frequency changes that may be indicative of transition challenges. Normative data is still needed to establish spectral analysis as a predictive pathway to newborn transition success or failure (Verklan \& Padhye, 2004).

\section{Metabolic Adaptation Review}

Platt and Deshpande (2005) provided a descriptive article regarding specific changes in neonatal glucose metabolism occurring with placental separation. The authors described the differences in glucose metabolism for preterm infants and growth-restricted infants. Although the gestational age at which these infant processes occurred was not identified with great specificity, this article notes glucose metabolism in preterm and smaller infants differs from that in term infants. The endocrine stress response during transition requires the preterm infant to adapt rapidly to catabolism and enteral feedings. 
Platt and Deshpande contended the newborn's blood glucose reaches nadir at 1 hour of age and stabilizes by 3 hours of age. Preterm infants experience a greater fall in glucose at birth than do term infants; their limited supply of liver glycogen and enzymatic pathways result in slower conversion to glucose (Platt \& Deshpande, 2005).

Laptook and Jackson (2006) considered metabolic and thermal adaptation in latepreterm infants as related processes. The authors related transition success or failure as a biological phenomenon based on multiple variables and contended these infants may have been ill at birth and had the potential to develop problems after birth. Risk variables described in this review included birth without labor, delivery route, biochemical lung maturation, lung fluid clearance, presence of infection, maternal anesthetic or analgesics, and fetal Potenz power plus hydrogen $(\mathrm{pH})$. Late-preterm infants are at greater risk for respiratory distress, hypothermia, and hypoglycemia, which often drive the level of care provided to the late-preterm infant. Laptook and Jackson identified hypoglycemia as a problem that may possibly reappear after transition is completed because of cold stress, poor feeding, and energy expenditure from tachypnea.

Hawdon (2008) investigated the management of impaired neonatal glucose metabolism as a review of physiologic processes and management strategies of neonatal hypoglycemia. Garg and Devaskar (2006) explained the detrimental effects of hypoglycemia on late-preterm infants, noting neuronal cell death and, later, adverse neurodevelopment. The lowest glucose nadir cited by Garg and Devaskar was from 30 to 90 minutes. Garg and Devaskar described the processes of labor as preemptive to the beginning of enzymatic processes for the prevention of hypoglycemia as an observational 
finding that has not yet been researched. Garg and Devaskar cited the lack of substantive research on late-preterm infant hypoglycemia and specific brain injury.

\section{Thermal Adaptation Review}

Laptook and Jackson (2006) reviewed the literature on thermal adaptation processes of transitioning late-preterm infants, providing a physiologic overview of the process. Considering physiological immaturity, the efficiency and thermal adaptive processes in late-preterm infants is inadequate. According to the authors, if hypothermia is not prevented, it has negative consequences for all infants.

Sherman, Greenspan, St. Clair, Touch, and Shaffer (2006) reviewed devices used to provide thermal support to preterm newborns and the process of newborn thermal adaptation. The authors noted preterm infants have less brown fat storage than full-term infants and this shortcoming may be the reason why it is more difficult to maintain a neutral thermal environment for preterm infants than for full-term infants. Infants have 3 times more surface area than an adult. Heat loss is 4 times greater in a low-birth weight infant than an adult, based on body surface area. Sherman et al. discussed the concept of hyporthermia as a source of morbidity and mortality in newborns and described the positive impact of emerging technologies for providing precise warmth as applicable to transition success. Mance (2008) presented an overview of hypothermia and methods of prevention primarily focused on delivery room care.

Of the articles reviewed regarding birth transition, thermal adaptation is generally included in physiological overviews or as a component of hypoglycemia. In the literature review, only descriptive reviews of thermal adaptation were found. 


\section{Neurologic Adaptation Review}

Aydin, Coskun, Sahin, and Aypar (2008) reported their study of the influence of two maternal anesthetic agents on neurological and adaptive capacity scores of newborns following birth. The randomized, prospective, blinded study was conducted in 2003 and included 102 patients randomized into two groups according to maternal general anesthesia administered: One group received desflurane and the other received seroflurane. The researchers considered maternal and neonatal covariates of maternal bleeding, umbilical arterial blood gases, delivery methods, delivery intervals, Apgar scores, and neuromuscular scores at intervals of 15 minutes, 2 hours, and 24 hours.

These criteria considered by Aydin et al. (2008) were used to assess the five general areas of (a) adaptive capacity; (b) passive tone; (c) active tone; (d) primary reflexes; and (d) alertness, crying, and motor activity (general observations). The researchers looked at short-term neurological observations of newborns in transition whose mothers had received one of the two different anesthetic agents. Based on a comparison of maternal age, blood loss, induction time, pulse oximetry, and blood pressure, as well as neonatal gestational age, Apgar scores, birth weight, and umbilical arterial blood gases, results indicated no significant differences between the desflurane and seroflurane groups. Comparison of the neurological and adaptive capacity scores between neonatal groups were significant in favor of desflurane ( $p=0.044$ and $p=0.035$, respectively) (Aydin et al., 2008).

A study by Bell, White-Traut, and Medoff-Cooper (2010) looked at newborn neurobehavioral organization following delivery using maternal epidural anesthesia. Bell et al. organized a prospective, comparative design using a sample of 52 low-risk 
maternal-infant dyads. The subjects were primarily of African American and Latino ethnicity who were delivering term infants. One group received epidural anesthesia by standardized dosing, using bipivicaine and fentanyl, and one group labored without anesthesia. Newborn suckling ability and pressure of suck were measured with the first feeding at 1 hour of age; a video recording of the infant before and after feeding supplemented the quantitive data. Sucking was measured with a nutritive sucking apparatus.

Bell et al. (2010) determined that total number of sucks and quantified sucking pressure were not related to epidural exposure except for female infants, who had more sucks than male infants. Female infants in the unmedicated groups sucked more than the epidural group. The researchers concluded female infants may have enhanced neurobehavioural organization as compared to male infants $(p<0.042)$, and longer labor was related to an increase in alertness $(p<0.003)$.

In 2004, Judith Littleford conducted a review of the literature involving the effects of obstetrical anesthesia on the fetus and newborn. Littleford's extensive search was conducted using the Cochrane Collaboration, MEDLINE, and Embase databases with the aim of determining the published effects of maternal anesthetics and analgesics on the fetus and newborn. Her computerized literature search did not support determination that any one test separates the effects on the newborn. Absence of determination is partly attributed to the lack of human study of transplacental passage of medications, limiting knowledge resulting from this methodology. The overall findings were that infant well-being is an important factor in determining maternal anesthesia (Littleford, 2004). 
The studies of literature on transition variables were beneficial because they provided evidence supporting the observation of neurologic responses during birth transition.

\section{Part Three: Late-Preterm Infant Review}

In December 2006, in response to research revealing an increase in morbidities, an entire issue of Clinics in Perinatology was dedicated to the topic of late-preterm infants (Jain \& Raku, 2006). The first articles were a discussion of the epidemiology of late-preterm infants (Raju, 2006) and the effect of elective cesarean section and induction on the late-preterm infant (Fuchs \& Wapner, 2006). Dudell and Jain (2006) contributed information on transition regarding hypoxic respiratory failure in the late-preterm infant. In their descriptive estimate, Dudell and Jain reported $15 \%$ of 35 -week infants and $8 \%$ of 36-week infants were admitted to the NICU. Severe respiratory distress demography reveals late-preterm infants with severe lung disease take longer to recover and require lengthier advanced therapies for survival than do term infants. Survival overall for latepreterm infants with advanced respiratory illness is $74 \%$, as compared to term infants at 87\% ( $p<.0001)$ (Dudell \& Jain, 2006).

Another article on birth transition in the December 2006 issue of Clinics in Perinatology (Jain \& Raju, 2006) discussed metabolism of glucose in late-preterm infants. Garg and Devaskar (2006) specifically addressed transition at birth as an adaptation challenge of the late-preterm infant regarding production of endogenous glucose. The authors related this challenge to a catecholamine surge accompanied by immaturity of $\beta$-islet insulin production, resulting in a hypoglycemic response (Garg \& Devaskar, 2006). Glucose levels in late-preterm infants are suspected to fall to the lowest 
nadir between 30 and 90 minutes following birth. During transition, $8 \%$ of term babies develop hypoglycemia but the extent of this condition in late-preterm infants is unknown (Garg \& Devaskar, 2006).

Bastek et al. (2008) examined the risk of adverse neonatal outcomes, comparing term infants (37 weeks and greater), late-preterm infants (34-36 6/7 weeks), and preterm (32-33 6/7 weeks) infants from one large treatment center. The authors used a retrospective chart review to contribute to the paucity of data on outcomes of late-preterm infants, bracketing nearby gestational age groups. Their review examined 264 infants delivered after 32 weeks' gestation relative to adverse outcomes. Exclusion criteria were multiple gestation, adverse maternal pregnancy events, cervical insufficiency, abruption, preeclampsia, premature rupture of membranes, intrauterine fetal demise, unknown outcome, and congenital anomalies.

Charted information on the newborns was extensive and included all diagnoses made during the newborns' entire hospital stay (Bastek et al., 2008). Of the 264 infants enrolled, $23.1 \%$ were preterm, $26.1 \%$ were late preterm, and $50.7 \%$ were term. The researchers constructed two composite variables to summarize acute neonatal morbidities found to lengthen hospital stay (COMP 1) and a set of variables thought to be associated with long-term morbidities and adverse neurodevelopment (COMP 2). The researchers found COMP 1 was pertinent in $46.2 \%$ of infants, and COMP 2 was pertinent in $36.7 \%$ of the infants. All infants with COMP 1 outcomes were also in the COMP 2 group.

Overall, Bastek et al. (2008) found infants delivered at 34 weeks' gestation had a sevenfold increase $(p<.001)$ in risk of COMP 1 outcomes, compared to infants born at 35 weeks' (threefold increase, $p<.012$ ). Delivery at 35 weeks was found to be associated 
with a 56\% reduction in COMP 1 outcomes (RR 0.44, $p<.003,95 \%$ CI, 0.26-0.75).

When compared with newborns delivered at 34 weeks, those delivered at 35 weeks were found to have a reduction of $75 \%$ in COMP 2 outcomes (RR $0.25, p<.002,95 \% \mathrm{CI}$, 0.11-0.60) (Bastek et al., 2008). A summary of the identified composite variables is shown in Table 2.

Table 2

Composite Outcome Variables from Study by Bastek et al. (2008)

\begin{tabular}{|c|c|c|}
\hline System & $\begin{array}{l}\text { Composite } 1 \text { variables } \\
\text { (COMP1) }\end{array}$ & $\begin{array}{l}\text { Composite } 2 \text { variables } \\
\text { (COMP 2) }\end{array}$ \\
\hline $\begin{array}{l}\text { Central nervous } \\
\text { system/neurologic }\end{array}$ & $\begin{array}{l}\text { Intraventricular hemorrhage } \\
\text { (grades 1-4) } \\
\text { Witnessed seizures } \\
\text { Treatment of apnea/ } \\
\text { bradycardia }\end{array}$ & $\begin{array}{l}\text { Intraventricular hemorrhage } \\
\text { Seizures } \\
\text { Treatment for apnea and } \\
\text { bradycardia } \\
\text { Home apnea monitoring }\end{array}$ \\
\hline Pulmonary & Respiratory assistance & $\begin{array}{l}\text { Longer than } 21 \text { days } \\
\text { ventilator therapy }\end{array}$ \\
\hline Gastrointestinal & $\begin{array}{l}\text { Necrotizing enterocolitis } \\
\text { Reflux } \\
\text { Hypoglycemia } \\
\text { Delayed feeding }\end{array}$ & Necrotizing enterocolitis \\
\hline Infectious disease & $\begin{array}{l}\text { Antibiotics for presumed } \\
\text { sepsis }\end{array}$ & $\begin{array}{l}\text { Antibiotics for confirmed } \\
\text { sepsis }(>7 \text { days })\end{array}$ \\
\hline Hematologic & $\begin{array}{l}\text { Hyperbilirubinemia } \\
\text { Blood transfusion }\end{array}$ & $\begin{array}{l}\text { Hyperbilirubinemia } \\
\text { Blood transfusion }\end{array}$ \\
\hline General & Temperature instability & None \\
\hline
\end{tabular}

Wang, Dorer, Fleming, and Catlin (2004) completed a chart review of 7,474 newborns, comparing term and late-preterm infants. Their retrospective review determined late-preterm infants had an increased risk of more costly hospitalization and 
varied hospital lengths of stay regardless of vaginal or cesarean birth. They found latepreterm infants had an increase in significant temperature instability ( $10 \%$ versus $0 \%)$, low blood sugar (hypoglycemia) (15.6\% versus 5.3\%), respiratory distress (28.9\% versus $4.2 \%$ ), septic workup (36.7\% versus $12.6 \%$ ), intravenous infusions ( $26.7 \%$ versus $5 \%$, and apnea and bradycardia (4.4\% versus 0\%) (Bakewell-Sachs, 2007; Wang et al., 2004).

Escobar, Clark, and Greene (2006) reviewed data published in the United States and England to analyze short-term hospital outcomes among 35 and 36 weeks' gestational age infants delivered between 1998 and 2004. The authors constructed three multivariate models looking at oxygen need, Score for Neonatal Acute Physiology scores less than 9, and the need for assisted ventilation during the newborn transition period. They found preterm infants born as late preterms had greater mortality and morbidity than babies born at term, and that these babies were delivered with an increased need for oxygen and other hospital therapies. Preterm infants were also found to be at much greater risk for re-hospitalization following discharge. When compared with their more premature counterparts, late-preterm infants are better off but do have a higher mortality rate than do infants born at term at 7.7 per 1,000 live births, compared with 2.5 per 1,000 live births (Escobar et al., 2006).

The descriptive review by Escobar et al. (2006) emphasized the possible significance of this infant population in terms of morbidity, mortality, and potential health care costs. Escobar et al. suggested an alternative method for future studies of latepreterm infants that would involve inclusion of infants of all gestations. By including infants of all gestational ages, the data considered as key predictors might be analyzed as 
continuous variables instead of arbitrary bracketing. This method would improve stratification by more clearly defining the populations represented (Escobar et al., 2006).

Shapiro-Mendoza et al. (2008) examined late-preterm morbidity risk relative to maternal illness. The authors examined birth and death certificates in the Boston area and assessed maternal medical conditions with gestational age, both independently and collectively, by calculating risk ratios. Shapiro-Mendoza et al. created a new measure of newborn morbidity that was based on a composite score of discharge diagnosis, hospital stay, and transfer status as a method of identifying newborns according to the presence or absence of life-threatening conditions. The researchers compared this score with eight maternal medical conditions including vascular complications (hypertensive disorders of pregnancy, antepartum hemorrhage), diabetes, respiratory disease, infection (bacterial and viral, including herpes), heart disease, and renal disease, and related these findings to newborn morbidity. A population of 26,170 late-preterm infants and 377,638 term infants was studied. Late-preterm infants were found to be 7 times more likely to experience newborn morbidity than were term babies. The incidence of late-preterm infant morbidity reported by Shapiro-Mendoza et al. was $22 \%$ versus $3 \%$ in term infants.

\section{Literature Review Synthesis}

The literature review confirms the lack of a simultaneous, multisystem evaluation of the variables surrounding birth transition, or of birth transition outcomes in term or preterm infants. Although the descriptive review and epidemiologic resources are available, a comprehensive quantitative analysis to determine which specific variables associated with birth transition contributed to success and the determination of whether these variables are quantitatively predictable of transition outcome does not exist. The 
present study could assist in differentiation of transition from illness. This study could also facilitate analysis of a collective study of the variables occurring during birth transition by identifying if there are any statistically significant factors related to birth transition success of the late-preterm infant.

Missing from the existing literature is the differentiation of the effects of transition variables on infants of various gestational ages, specifically late-preterm infants. Emerging literature details the adaptive difficulties of these infants who, despite their appearance as term infants, experience challenges with birth transition. Descriptive literature reveals this population of newborns is more vulnerable, demonstrating an increase in morbidity and mortality when contrasted with term infants. This vulnerability is noted in the literature to be related to maternal and delivery circumstances, and physiologic maturity established by the time of birth. Although specific literature and the possibility of related variables have been discussed, it is unknown whether there are collective variables that determine vulnerability to transition failure. What happened, and how is the resulting morbidity and mortality preventable? The most pressing research question resulting from the literature review is "What set of risk factors best explain birth transition success or failure in late preterm infants?"

\section{Conceptual Framework}

The framework guiding the present study is based on the physiological model of newborn birth transition versus the unknown model of birth transition of late-preterm infants. Based on the literature review, it is hypothesized that a relationship exists between the factors surrounding the mother's health and pregnancy-related health, the factors surrounding labor and birth, and the physiologic properties unique to late-preterm 
infants. Research exploring these relationships could determine if there are positive and negative effects of transition success of late-preterm infants and possibly if physiological outcomes are influenced by maternal and birth factors.

The most prevalent concept of newborn birth transition in the literature is that it is a complex, multisystem physiological event that may be impacted by individual but unclear variables. Specific correlations of variables related to birth transition are inferred in the literature but only maternal anesthesia, maternal SSRIs, prenatal steroids, and pulmonary hypertension are specifically studied from the perspective of birth impact. The pertinent information obtained from the literature review is presented in Table 3.

Table 3

Summary of Literature Review Synthesis

The process of transition

- The overall process and difficulties of transition is well described and understood

- Birth transition is unsuccessful in 1-2\% of all newborns

- For premature infants, the primary problems of transition may be viewed as a triangle of hypoglycemia, hypothermia, and hypothermia

- The specific effects of maternal anesthesia on birth transition are unclear

Specific transition variables

- Prenatal steroids enhance water channel activity in the lungs

- Labor is associated with successful respiratory adaptation in newborns

- More infants delivered by cesarean section have respiratory difficulties than those delivered vaginally 
Specific transition variables

- African American and Asian women, overweight women, late-preterm and post term gestation, male infants, and infants exposed to SSRIs are more likely to develop pulmonary hypertension

- Maternal anesthesia affects neurologic adaptation and Apgar scores

- There is a presumptive relationship between maternal depression and SSRI use and newborn perinatal depression, but the nature of the relationship is unclear

- Subtle heart rate changes have been observed in newborns with transition difficulties

- Glucose levels in uncomplicated term infants reach nadir in 1-2 hours

- Labor is described as a preemptive event preventing hypoglycemia

- Newborns are less affected by desflurane than serofluane

- Girls may be have enhanced neurobehavioral organization compared to boys and longer labor was related to an increase in newborn alertness

Late-preterm infants

- The incidence of late-preterm infants continues to rise

- Morbidity and mortality is increased

- $15 \%$ of 35 -week infants and $8 \%$ of 36 -week infants are admitted to the NICU at birth

- Hypoglycemia in late-preterm infants is physiologic with unknown incidence

- Glucose levels in late-preterm infants is lowest between 30 and 90 minutes of age

- There is a significant difference in outcomes between 34-, 35-, and 36-week infants

- Late-preterm infants have a longer length of stay, increased morbidity and mortality, and higher hospital costs than term infants

The physiological connection between mother and infant implies a relationship. Labor and delivery are experienced by both the mother and newborn. The physiological state of the newborn at the time of delivery determines the newborn's adaptive ability at birth. Factors analyzed surrounding labor and delivery of the newborn are pertinent, as described in the literature. Physiological maturity is a factor related to prematurity and 
critical to transition success but varies between infants. Because the specific components of late-preterm birth transition have not been studied relative to transition success, identification of the variables that may be related to transition outcome would be beneficial. As a vulnerable population increasing in size, the study of transition of latepreterm infants relative to maternal, birth, and delivery variables could be especially useful to nursing science.

The maternal variables related to the construct of the relationship between mother and infant are maternal age, ethnicity, health, and prenatal care. In the present study, maternal age was defined as the age of the mother at the time of delivery. Ethnicity was defined by the determination of the documented race of the mother. Prenatal care was defined by the number of prenatal visits prior to delivery. Maternal health included all preexisting and current diagnoses found on the prenatal record, including maternal depression and use of SSRIs.

Variables related to delivery and newborn transition were prenatal steroid administration, method of delivery, presence or absence of labor, type of maternal anesthesia, and the length of the rupture of membranes prior to delivery. Method of delivery was either vaginal or cesarean birth. Labor was defined as the presence of labor contractions prior to delivery or no labor as the absence of labor contractions prior to delivery. Contractions documented in the electronic medical record or progress noted were considered evidence of labor. Maternal anesthesia route and duration of ruptured membranes were extracted from the delivery record.

The face value of physiological maturity was the documented estimation of gestational age. Gestational age was defined by the obstetrical determination of 
gestational age on admission for delivery, adjusted from the time of admission. The gestational age was rounded down to the nearest week of gestation. The physiological variables of temperature, pulse, respiration, and mean blood pressure were determined as the lowest and highest values documented during the first 6 hours of life. Axillary temperatures falling out of normal range were considered abnormal. Heart rate values ranging above 180 and below 80 beats per minute were defined as tachypnea and bradycardia, respectively. Respiratory rate greater than 70 breaths per minute was defined as tachypnea. Blood pressure was recorded as the lowest mean blood pressure obtained and recorded during the first 6 hours of life. Glucose measurement is not obtained on every newborn but was assessed when available; it was considered abnormal if the measurement was below $40 \mathrm{mg} / \mathrm{dL}$ by point of care measurement.

The timeframe of birth until 6 hours of life was used as the transition period. Transition outcome was limited to progression of the infant to the nursery (successful transition), transition care (unsuccessful transition), or admission to the NICU (unsuccessful transition). 


\section{CHAPTER THREE: RESEARCH DESIGN}

A descriptive, ex post facto, retrospective chart review, case-control design was used to compare the characteristics of preterm infants who had not experienced successful birth transition with similar infants who had birth transition success. Use of this design permitted examination of factors surrounding the phenomena of birth transition as they have naturally occurred and provided a description of the documented characteristics of this sample for further analysis. Ninety-six case infants were 35- or 36week infants admitted to the NICU unit during the first 6 hours of life, which was defined for the purposes of the present study as failing transition. A control group, also of 96 infants, was selected based on demonstrating similarity with case infants based on birth month and birth time (see Neonatal Physiologic Maturity). Because a nonexperimental design was used, the research results are considered noncausal but more descriptive of the relationship between the variables.

\section{Case and Control Group Selection}

Case and control infants were found by examination of the NICU and nursery logbooks of all infants admitted during calendar year 2007 with the recorded gestation age of 35 weeks or 36 weeks. Data from all newborns identified in the logbook satisfying study criteria were recorded for further analysis of inclusion and exclusion criteria. The study was hospital-based in that all infants had experienced delivery and birth transition in the same hospital and their births were recorded into the same admission logbook. The sampling method was based on the population of 35- and 36-week infants admitted 
within 6 hours of birth to the NICU in 2007 (case group) compared to a similar group not admitted to the NICU during transition (control group). Diagnostic criteria for cases were admission to the NICU for any reason other than exclusion criteria during the first 6 hours of life, regardless of clinical criteria.

Identification and selection of the control group were of infants drawn from the same overall population as the case group, regarding gestational age, setting, and time period. The matching criteria for pairing control group members to case group members was based on birth date and time. The control group infants selected were late-preterm infant (35 or 36 weeks' gestation) delivered closest to the time of the case group infant, but that has not been previously selected as a control group member. Selection bias was addressed by selecting control infants retrospectively from the same case group sampling frame, occurring after selection of the failed transition sample, and with the fewest extraneous variables involving the relationship between the newborn and transition outcome. In other words, the case control group would have had the same possibility of case group selection as part of the same population and sampling frame as the case group.

\section{Study Variables}

The dichotomous dependent variable of transition success was suggested by the literature based on the identified time span of transition of 6 hours following birth (Askin, 2002). In this study, the dependent variable was a binary $(0,1)$ variable: transition success, transition failure. By operationalization of this variable, infants who failed transition were admitted into the NICU prior to 6 hours of life, indicating transition failure (1), whereas transition success means that the infant had not been admitted to the 
NICU (0). A summary of codes related to the dependent variable is presented in Table 4.

Details on the independent variables are presented in Table 5.

Table 4

Conceptual and Operational Definitions of the Dependent Variable

\begin{tabular}{|c|c|c|c|}
\hline \multirow{2}{*}{$\begin{array}{l}\text { Dependent } \\
\text { variable/level }\end{array}$} & \multicolumn{2}{|c|}{ Definition } & \multirow[b]{2}{*}{ SPSS code } \\
\hline & Conceptual & Operational & \\
\hline $\begin{array}{l}\text { Transition success/ } \\
\text { nominal }\end{array}$ & $\begin{array}{l}\text { Birth transition is } \\
\text { successful by } 6 \\
\text { hours of age }(0)\end{array}$ & $\begin{array}{l}\text { Infant is not admitted } \\
\text { to the NICU by } 6 \\
\text { hours of age }\end{array}$ & sickno \\
\hline $\begin{array}{l}\text { Transition failure/ } \\
\text { nominal }\end{array}$ & $\begin{array}{l}\text { Birth transition is } \\
\text { not successful (1) }\end{array}$ & $\begin{array}{l}\text { Admitted to the } \\
\text { NICU by } 6 \text { hours of } \\
\text { age }\end{array}$ & sickyes \\
\hline
\end{tabular}

The independent variables were a combination of the factors surrounding birth that might be related to transition and the variables identified by literature review (see also Table 5). The categorical variables were ethnicity, maternal health, gestational age, maternal anesthesia route, birth route, and gender. These variables are related to the conceptual framework of the relationship between maternal factors and birth transition outcome. A schematic depiction of the present study representing the relationship of the variables to the constructs of the study is presented in Appendix A. The literature review presented in Chapter Two revealed these factors are ultimately risk factors related to newborn well-being. Although comprehensive, the literature review did not address the relationship of these factors to late-preterm infants or transition specifically.

The physiological variable of temperature indicates the highest and lowest axillary infant temperature obtained and documented from birth until 6 hours of life. In 
keeping with current documentation standards, the Fahrenheit scale of measurement was used.

Although gestational age is continuous, it was treated as a categorical variable, based on the inclusion criteria of the study, allowing only 35- and 36-week participants.

\section{Maternal Factors}

The maternal factors for the study were maternal age, ethnicity, health, and prenatal care. Maternal age represents a ratio level variable, which was stratified for data analysis. Maternal age was defined as the age of the mother at the time of delivery. Ethnicity was defined as that recorded in the electronic record based on maternal report. Maternal health refers to preexisting or pregnancy illnesses such as diabetes, hypertension, and depression. Maternal health was considered a nominal variable that has been reported in the medical record as a diagnosis prior to delivery. Prenatal care refers to the exposure of the mother to prenatal care. For the present study, prenatal visits were recorded as the raw number of visits documented prior to delivery.

\section{Birth Impact}

Birth impact variables reflect the construct of the theorized relationship between birth circumstance and transition outcome. The birth impact variables included labor, prenatal steroids, type of maternal anesthesia, duration of ruptured membranes, and delivery route. The presence of labor was defined as absent labor, such as in a primary cesarean section, and induction or spontaneous labor in hours. Maternal anesthesia was a nominal variable defined by the type of anesthesia the mother received for delivery, such as epidural, spinal, local, or none. The anesthetic type or route was determined by chart review and reported. Ruptured membrane duration refers to the length of time for which 
membranes were ruptured prior to delivery. Delivery route includes vaginal, cesarean, assisted, or not assisted.

\section{Neonatal Physiologic Maturity}

Neonatal physiological maturity refers to the specific maturation of the latepreterm infant at birth and during transition as measured by gestational age, 5-minute Apgar scoring, vital signs (e.g., axillary temperature, heart rate, respirations, mean blood pressure), and glucose. The newborn gestational age was defined as the age of the newborn in weeks at the time of delivery. Gestational age, for the purposes of this study, was determined by documentation in the maternal chart of an 18-20 weeks' gestation ultrasound. In the absence of an early prenatal ultrasound, last menstrual period was used to categorize the infant by gestational age.

Apgar scoring for this study was the number assigned at 5 minutes of life, reflecting the quantitative delivery room score associated with color, heart rate, respirations, tone, and grimace. Birth weight included was the initial weight recorded in kilograms the soonest following birth. Vital signs included were the highest and lowest values to determine extreme values. Heart rate is related to ventilation and conductivity. Elevation or decline of heart rate may lead to admission to the NICU for monitoring. Respiratory rate is an indicator of multiple systemic disorders. Measurements of greater than 60 respirations per minute may warrant investigation and further monitoring.

The lowest mean blood pressure was defined as the lowest mean blood pressure value documented during the transition period as a reflection of cardiac output. Glucose is a ratio value measured by bedside heel-stick testing and was recorded as the value closest to 1 hour of life. 
Table 5

Independent Variables, Related Construct Conceptual Definition, Operational Definition, and SPSS Code

\begin{tabular}{|c|c|c|c|}
\hline \multirow[b]{2}{*}{ Variable (construct) } & \multicolumn{2}{|c|}{ Definition } & \multirow[b]{2}{*}{ SPSS code } \\
\hline & Conceptual & Operational & \\
\hline \multicolumn{4}{|c|}{ Maternal factors } \\
\hline Age (maternal) /ratio & Chronological age of the mother. & Age in years of mother on the date of delivery & age, agerang \\
\hline Ethnicity (maternal)/nominal & Classification of humans by descent & Documented race/ethnicity of mother & ethni \\
\hline $\begin{array}{l}\text { Preconceptual health } \\
\text { (maternal)/nominal }\end{array}$ & Health prior to conception of this pregnancy & $\begin{array}{l}\text { Documentation of health conditions prior to } \\
\text { pregnancy such as diabetes, hypertension, } \\
\text { depression) }\end{array}$ & $\begin{array}{l}\text { prehealth } \\
\text { no issues (0) } \\
\text { diabetes (1) } \\
\text { hypertension (2) } \\
\text { depression (3) }\end{array}$ \\
\hline $\begin{array}{l}\text { Prenatal care } \\
(\text { maternal)/nominal \& ratio }\end{array}$ & $\begin{array}{l}\text { Health care visits during pregnancy for the purpose } \\
\text { of monitoring pregnancy and fetal health }\end{array}$ & $\begin{array}{l}\text { Documented number of prenatal visits on the } \\
\text { prenatal record, including zero }\end{array}$ & $\begin{array}{l}\text { pnc1-yes }(1) / n o(0) \\
\text { pnc2-visits }\end{array}$ \\
\hline $\begin{array}{l}\text { Maternal health } \\
\text { (maternal)/nominal }\end{array}$ & Wellness of mother during pregnancy & $\begin{array}{l}\text { Documentation of ongoing maternal illness } \\
\text { during pregnancy not including labor events } \\
\text { (e.g., diabetes, preeclampsia, depression) }\end{array}$ & $\begin{array}{l}\text { mahealth } \\
\text { no issues (0) } \\
\text { diabetes (1) } \\
\text { pre-eclampsia (2) } \\
\text { depression (3) }\end{array}$ \\
\hline \multicolumn{4}{|c|}{ Birth impact } \\
\hline Prenatal steroids & Administration of antenatal steroids prior to delivery & $\begin{array}{l}\text { Documented steroids received prenatally at least } \\
24 \text { hours prior to delivery }\end{array}$ & $\begin{array}{l}\text { steroid } \\
\text { yes }(1), \text { no }(0)\end{array}$ \\
\hline $\begin{array}{l}\text { Labor } \mathrm{y} / \mathrm{n} \text {, spontaneous or } \\
\text { induced (birth) /nominal \& } \\
\text { ratio }\end{array}$ & The process of expulsion of the fetus from the uterus & Documented contractions for great than 1 hour & $\begin{array}{l}\text { labor1- } \\
\text { yes }(1) / \text { no }(0) \\
\text { labor2-hours }\end{array}$ \\
\hline $\begin{array}{l}\text { Smoking } y / n \text { (maternal), } \\
\text { nominal }\end{array}$ & Inhalation of tobacco during pregnancy. & $\begin{array}{l}\text { Documentation of maternal report of smoking } \\
\text { during pregnancy }\end{array}$ & $\begin{array}{l}\text { smoke } \\
\text { yes (1), no (0) }\end{array}$ \\
\hline
\end{tabular}




\begin{tabular}{|c|c|c|c|}
\hline \multirow[b]{2}{*}{ Variable (construct) } & \multicolumn{2}{|c|}{ Definition } & \multirow[b]{2}{*}{ SPSS code } \\
\hline & Conceptual & Operational & \\
\hline \multicolumn{4}{|c|}{ Birth impact } \\
\hline $\begin{array}{l}\text { Maternal anesthesia } \\
\text { (maternal)/nominal }\end{array}$ & $\begin{array}{l}\text { Agent provided during labor and/or delivery for } \\
\text { relief of pain during childbirth }\end{array}$ & $\begin{array}{l}\text { Documentation of type of maternal anesthetic or } \\
\text { no anesthetic used }\end{array}$ & $\begin{array}{l}\text { anesthet none (0) } \\
\text { epidural (1) } \\
\text { spinal (2) } \\
\text { general (3) }\end{array}$ \\
\hline $\begin{array}{l}\text { Ruptured membranes } \\
(\text { maternal)/ratio }\end{array}$ & $\begin{array}{l}\text { Length of time membranes are ruptured prior to } \\
\text { delivery }\end{array}$ & $\begin{array}{l}\text { Documentation of length of time in hours that } \\
\text { membranes are ruptured prior to delivery; } \\
\text { includes zero hours (not ruptured) }\end{array}$ & $\begin{array}{l}\text { membra } \\
\text { non-rupt (0) } \\
\text { rupt }(1)\end{array}$ \\
\hline $\begin{array}{l}\text { Birth route } \mathrm{C} / \mathrm{S} \text { or vaginal } \\
\text { (birth), nominal }\end{array}$ & Process by which an infant is delivered & $\begin{array}{l}\text { Documented route of delivery including } \\
\text { caesarian or vaginal birth }\end{array}$ & $\begin{array}{l}\text { Route } \\
\operatorname{vag}(0) / c / s(1)\end{array}$ \\
\hline \multicolumn{4}{|c|}{ Neonatal physiologic maturity } \\
\hline $\begin{array}{l}\text { Gestational age } \\
\text { (maturity)/ratio }\end{array}$ & Duration from conception to delivery & $\begin{array}{l}\text { Documented age in weeks of gestational age of } \\
35 \text { or } 36 \text { weeks }\end{array}$ & $\begin{array}{l}\text { gage } \\
35 \text { weeks (0) } \\
36 \text { weeks (1) }\end{array}$ \\
\hline Birth weight & Initial weight of infant & Initial documents weight in grams & bweight \\
\hline $\begin{array}{l}\text { Gender (physiologic)/ } \\
\text { nominal }\end{array}$ & Assigned sex based on physical characteristics & $\begin{array}{l}\text { Documented gender-male, female, or } \\
\text { ambiguous }\end{array}$ & $\begin{array}{l}\text { gender } \\
\text { female (0)/male (1) }\end{array}$ \\
\hline $\begin{array}{l}\text { Apgar score (physiologic)/ } \\
\text { ratio }\end{array}$ & $\begin{array}{l}\text { Numeric score from } 0 \text { to } 10 \text { regarding newborn at a } \\
\text { specific time }\end{array}$ & $\begin{array}{l}\text { Documented Apgar score at } 5 \text { minutes of age }(0- \\
\text { 10) }\end{array}$ & $\begin{array}{l}\text { apgar } \\
8,9(0) \\
7 \text { or less }(1)\end{array}$ \\
\hline Glucose $($ physiologic)/ratio & Level of available glucose for metabolic processes & $\begin{array}{l}\text { Documented lowest glucose during first } 6 \text { hours } \\
\text { of life }\end{array}$ & $\begin{array}{l}\text { glucose } \\
>40(0) \\
39 \text { or }<(1)\end{array}$ \\
\hline $\begin{array}{l}\text { Respiratory rate } \\
(\text { physiologic)/ratio }\end{array}$ & $\begin{array}{l}\text { Numeric value of respirations observed for one } \\
\text { minute }\end{array}$ & $\begin{array}{l}\text { Documented highest and lowest respiratory rate } \\
\text { during first } 6 \text { hours of life }\end{array}$ & respers \\
\hline
\end{tabular}




\begin{tabular}{|c|c|c|c|c|}
\hline \multirow[b]{2}{*}{ Variable (construct) } & \multicolumn{2}{|c|}{ Definition } & \multirow{2}{*}{\multicolumn{2}{|c|}{ SPSS code }} \\
\hline & Conceptual & Operational & & \\
\hline \multicolumn{5}{|c|}{ Neonatal physiologic maturity } \\
\hline Heart rate (physiologic)/ratio & Numeric value of heartbeats observed for 1 minute & $\begin{array}{l}\text { Documented highest and lowest heart rate } \\
\text { closest during first } 6 \text { hours of life }\end{array}$ & hrate & \\
\hline $\begin{array}{l}\text { Temperature (physiologic)/ } \\
\text { interval }\end{array}$ & Axillary measurement of body temperature & $\begin{array}{l}\text { Documented highest and lowest temperature } \\
\text { during first } 6 \text { hours of life }\end{array}$ & temp & \\
\hline $\begin{array}{l}\text { Mean blood pressure } \\
\text { (physiologic)/ ratio }\end{array}$ & $\begin{array}{l}\text { Peripheral measurement of blood pressure; reflects } \\
\text { cardiac output }\end{array}$ & $\begin{array}{l}\text { Documented lowest mean blood pressure } \\
\text { during first } 6 \text { hours of life }\end{array}$ & lowpress & \\
\hline \multicolumn{5}{|c|}{ Neonatal physiologic maturity } \\
\hline Hospital days & $\begin{array}{l}\text { Number of days infant is hospitalized prior to } \\
\text { discharge }\end{array}$ & $\begin{array}{l}\text { Documented number of hospital days prior to } \\
\text { discharge }\end{array}$ & $\begin{array}{l}\text { hosdays } \\
(0) \\
\text { more (1) }\end{array}$ & $\begin{array}{l}<5 \\
5 \text { or }\end{array}$ \\
\hline
\end{tabular}




\section{Study Site, Population, Sampling Frame, and Sample}

The setting for this study was a large tertiary-care center in Florida. This center was chosen because of the large delivery service offered by this facility and the large population of late-preterm infants. As the third largest delivery center in the United States, nearly 13,000 infants are delivered at this facility yearly. The site and city chosen for this study is representative of a diverse population of approximately five million residents. The defined population for this study was late-preterm infants determined to have been delivered between 35 weeks and 0 days' gestational age and 36 weeks and 6 days' gestational age at a large urban, tertiary-care center during calendar year 2007. Infants were identified by the obstetrical logbook, completed on every patient admitted to labor and delivery and delivered between 35 weeks' gestation and 36 weeks' completed gestational age.

The year 2007 was chosen because it was prior to an internal practice initiative and the Association of Women's Health, Obstetric, and Neonatal Nurses late-preterm infant initiative, which increased awareness of late preterm infants. In 2008, an emphasis was placed on late-preterm infants in this facility, charging the assessment and care provided to these infants by caregivers. By sampling infant data prior to the national and international focus on late-preterm births, there was no influence on the transition care provided to these infants and internal validity of the study was strengthened.

By using the documented method of participant selection, all late-preterm infants delivered at the center in 2007 were identified regardless of outcome. The resulting list was then cross-referenced with the year 2007 NICU admission logbook of infants admitted with the gestational age of 35 or 36 weeks. Infants on this list were individually 
matched with an infant from the control group of infants according to corresponding birth date and closest possible birth time. The matched infants served as the control group for the failed transition group. All infants' charts were then reviewed using the data collection sheet represented in Appendix B. A master list of infant medical record numbers was kept in a concealed book, and maintained in a locked office cabinet when not in use and accessible only by the investigator.

The sample size of this study was dependent on the number of 35- and 36-weeks' gestation infants admitted to the NICU, plus the number of control infants available in calendar year 2007. Tabachnick and Fidell (1996) recommended a ratio of 10:1 minimum observations-to-predictor for logistic regression, with a sample size of 50 or 100. Considering the sample size of 96 , this recommendation would be representative of an adequate sample size for up to nine predictor variables.

The exact sampling frame was from January 1, 2007, at 12 midnight until December 31, 2007, at 12 midnight. The estimated sample size was based on the delivery rate (approximately 13,000 infants per year) at a large mother-and-baby hospital in 2007. Based on the reported late-preterm singleton birth rate in Florida in 2006 of $8.85 \%$ (Martin, Kirmeyer, Osterman, \& Shephard, 2009), the estimated number of late-preterm infants delivered at the study site in 2007 was 1,274 infants. This number included infants who were 34 weeks' gestation, but by policy automatically admitted to the NICU regardless of transition success or failure. Considering exclusion of infants delivered at 34 weeks' gestation, the sample size of this study was reduced by one third, to a possible total of 850 infants. It was unknown, at the outset of the study, exactly how many of these 850 infants would be birth transition cases. The largest sample size available without 
violation of the inclusion and exclusion criteria was chosen to strengthen the external validity, power, and applicability of this study.

\section{Inclusion and Exclusion Criteria}

In addition to the exclusion of 34-weeks' gestation infants, infants who weigh less than 2,200 grams (4.6 pounds) are automatically admitted to the NICU. Although 34week gestational age infants are sometimes reclassified as older by application of the Ballard exam, the validity of this exam varies by \pm 2 weeks (Lynch \& Zhang, 2007). Infants who have not had prenatal care may be considered by Ballard exam as the best available means of assigning gestational age. For this reason, infants identified prior to delivery as 35 weeks' gestation or those without prenatal care who have been classified as less than 35 weeks by Ballard exam were excluded. Other exclusion criteria included multiple-gestation infants. These infants may experience challenges after birth based exclusively on lower birth weight.

Exclusion criteria included infants who had not been delivered or had not been cared for at the study site during the first 6 hours of life, as well as those babies who were transferred in or out of the study site during the first 6 hours of life. Complete documentation is not always available for these infants. These babies may have been exposed to extraneous variables related to transfer that may make determination of factors of transition success unclear. Infants with obvious congenital anomalies were excluded because of the possibility that the congenital anomaly may have had an impact on transition success. A final exclusion criterion was of infants with ambiguous genitalia, preventing matching by gender with opposite group members. The inclusion and exclusion criteria are summarized in the Table 6. 
Table 6

Study Inclusion and Exclusion Criteria

\begin{tabular}{|c|c|}
\hline Inclusion & Exclusion \\
\hline $\begin{array}{l}\text { Documented gestational age of } 35 \text { weeks } \\
\text { and } 0 \text { days' gestational age until } 36 \text { weeks } \\
\text { and } 6 \text { days' gestational age }\end{array}$ & $\begin{array}{l}\text { Documented gestational age less than } 35 \\
\text { weeks' and greater than } 37 \text { weeks' } \\
\text { gestational age }\end{array}$ \\
\hline \multirow[t]{6}{*}{ Documented delivery at study site in 2007} & Documented delivery outside of study site \\
\hline & $\begin{array}{l}\text { Documented birth weight less than 2,200 } \\
\text { grams }\end{array}$ \\
\hline & $\begin{array}{l}\text { Documented congenital anomalies such as } \\
\text { cleft lip and palate and Down Syndrome }\end{array}$ \\
\hline & $\begin{array}{l}\text { Documented multiple gestations, such as } \\
\text { twins or triplets }\end{array}$ \\
\hline & $\begin{array}{l}\text { Documentation of transfer to or from } \\
\text { another facility during the first } 6 \text { hours of } \\
\text { life }\end{array}$ \\
\hline & Documented ambiguous genitalia \\
\hline
\end{tabular}

\section{Instruments and Data Collection}

\section{SurveyMonkey}

The instrument for data collection was a 30 -item survey built using the program SurveyMonkey ${ }^{\mathrm{TM}}$ (n.d.). This program was chosen as the platform for data collection and storage based on its versatility, compatibility, and security. Using this platform eliminated the need for paper data collection. The data collection instrument was built into SurveyMonkey as a single survey per subject. Each survey was completed by the investigator and numbered based on birth date and birth sequence. At no time were medical record numbers or identifiers entered into SurveyMonkey. Use of SurveyMonkey strengthens data integrity by minimizing data entry error. 
Each infant was assigned a 4-digit study number comprised of group and sequence. For example, the first case group infant was assigned the number 1001, indicating 1 (case group), and 001 designating the first infant in the group. The second case group baby was assigned the number 1002 .

Infants for the control group were randomly selected from the same sampling frame. The control group babies were designated by the leading number 0 followed by the selection sequence number. For example, the first control group infant selected for the study was designated by the leading number 0 followed by the sequence number 001 . The data collection sheet, including the assigned study number as constructed in SurveyMonkey ${ }^{\mathrm{TM}}$ (n.d.), is presented in Appendix B.

\section{Patient Privacy}

Although the present study posed no immediate patient risk, accessing the electronic medical records of mother and baby did pose a threat to privacy. The protection of patient privacy and data security was a priority of this study. Personal identifiers were not be used in any way. Although SurveyMonkey (n.d.) states on its website that data stored on its site is confidential, at no time were these data linked in any way by which a patient might be identified or privacy compromised.

SurveyMonkey (n.d.) has completed the requirements for the designation of a Safe Harbor company and is considered a secure site. SurveyMonkey offers secure sockets layer (SSL) encryption as Verisign certificate Version 3, with 128-bit encryption coding available, if required by the Institutional Review Board (IRB). Data collection was conducted exclusively by the investigator and accomplished online. The investigator's computers were password-protected by a unique login and password 
known only by the investigator. Access to SurveyMonkey was password-protected with the investigator's private login and password. Data collection at all times occurred in a private setting with the computer screen oriented to prevent visibility by others.

SurveyMonkey ${ }^{\mathrm{TM}}$ has been previously approved by the University of Central Florida and the study site's IRB.

\section{Ethical Considerations}

As a requirement of the University of Central Florida and the study site IRBs, the investigator has completed certification in the National Institute of Health's education program. In accordance with both institutions' IRB requirements, a financial disclosure form was completed, indicating no financial interest in or gain from the results.

Prior to conducting the study, written permission to conduct the study was obtained from the investigator's dissertation committee, the University of Central Florida's IRB, and the study site's nursing research committee and IRB. Permission to complete the study was granted by the university's IRB on August 18, 2008 (UCF IRB \# SBE.10.07064), the study site's Nursing Research Council on August 12, 2010, and the study site's IRB on August 24, 2010 (APMC IRB \# 1009008) (see Appendix C and Appendix D, respectively). Verbal approval was obtained from the chief nursing officer and director of newborn services of the study site. The study presented minimal risk and important benefits regarding the knowledge and characterization of this population.

\section{Pilot Testing Data Collection}

Following approval to conduct the study, a trial of data collection using SurveyMonkey was conducted by the investigator on the first 10 records reviewed to determine whether the data collection plan was manageable and available. Pilot data were 
also imported into Microsoft ${ }^{\circledR}$ Office Excel ${ }^{\circledR}$ Version 2007 and then IBM’s Statistical Package for Social Services (SPSS) Version 16.0 to validate the constructed survey results were usable. The pilot was successful, and permission to use the pilot data as a part of the study was granted by the dissertation advisory committee chair. Following completion a successful pilot, the remainder of the data collection was completed.

\section{Missing Data}

The only variable found to have missing data was prenatal visits ( 13 cases $=$ $13.5 \% ; 14$ controls $=14.5 \%)$. The systematic missing data was assigned the code 99 , indicating that the data that was not found in the medical record and that the values were not known. The difference of missing prenatal care visit data was $1 \%$ between groups, but noteworthy for the overall sample. Because the variable prenatal visits was found to have less than 5\% missing data between groups, no data procedures or substitutions were necessary (D. F. Polit, 2010).

\section{Data Analysis}

Data was initially imported directly from SurveyMonkey ${ }^{\mathrm{TM}}$ into Microsoft ${ }^{\circledR}$ Office Excel® by secure connection and then imported from Excel into SPSS for analysis. During the preanalysis phase, two separate data files were constructed, one each for the case group and the control group. Columns were constructed in spreadsheet fashion using the abbreviated variable names as column labels and entered into the SPSS data editor, and the data level assigned to each variable. The extended name of the variable was also entered into SPSS for clarity, as well as an explanation of each of the numerical codes assigned to the data. Code 99 was assigned to missing data values. After data were entered into the computer file, these data were inspected for outliers and 
irregularities, such as extreme values. The medical records of outliers were reviewed to check for accuracy of data.

\section{Descriptive Analysis}

A preliminary exploratory assessment of these data was conducted to assess for missing values. Missing data were inspected and determined to be omitted during collection or systemic omitted data. Data omitted during collection resulted in a second chart review to supply missing data. Data that were omitted because they were not available due to system design were determined during the pilot and the variable omission discussed with the dissertation chair and a substitution variable determined. Preliminary actions were taken to address missing values by repeating the chart review of the corresponding document. The distributions of interval and ratio level variables were inspected for normality. Appropriate data transformation was completed and the variables recoded as needed to reduce outliers.

Initial principal data analysis involved the use of descriptive statistics to summarize the data for each group. A frequency distribution of all ratio and nominal variables was completed to determine the frequency of male infants and female infants, 35-week and 36-week infants, and so forth for each of the groups. Mean or median values were reported for interval and ratio level variables, such as the highest and lowest mean heart rate, respiratory rate, and temperature, depending upon whether these variables were skewed or normally distributed.

Considering the physiological data for analysis, the possibility of a positively skewed distribution existed relative to glucose and temperature in the case group. Respiratory rate may have been high and displayed a negative skew. In the case of 
skewness, statistical analysis which did not require a normal distribution was conducted, or the variables transformed. For skewed continuous variables, a Mann-Whitney $U$ test was used to test the scoring ranks between the groups.

Calculation of central tendency described the research sample by determining the means and standard deviations of the ratio variables of maternal age, prenatal care, labor, Apgar score, heart rate, respiratory rate, temperature, and glucose between groups.

\section{Inferential Statistics}

To identify the variables to be used as predictors in a logistic regression analysis, a series of chi-square and $t$-test analyses were conducted. Comparisons between the case and control groups on nominal level variables (i.e., ethnicity, prenatal care, maternal health, prenatal steroids, labor, smoking, maternal anesthesia, birth route, gender, rooting) were conducted using chi squares. From the initial frequency distributions, the sample was identified by number of male infants and female infants, and 35- and 36week infants in both groups. Chi squares between the case and control group, as well as between the male infants and female infants within each group, and the 35- and 36-week infants of each group, were conducted and displayed in a contingency table for a particular variable, such as maternal smoking or maternal anesthesia. Multiple analysis of the dichotomous study variables (i.e., transition outcome, ethnicity, prenatal care, maternal health, labor, smoking, maternal anesthesia, birth route) were possible for a more in-depth description of the sample.

Chi squares were used to compare the association between two variables such as gender and gestational age group, gestational age and smoking, and transition success and labor duration. The use of chi squares may facilitate analysis of multiple aspects of this 
sample. Some examples of analysis that might benefit from chi square analysis included "What is the proportion of infants with smoking mothers who transitioned successfully?", "What is the proportion of infants with teen mothers who transitioned unsuccessfully?", and "How many of these infants of mothers who did not labor were able to transition successfully?".

Absolute risk, relative risk, and relative risk reduction were estimated to describe differences between the case and control groups based on transition success. Exposure to risk was assessed. Odds ratios were computed using the dependent variable crosstabulated with independent variables.

To test differences between the case and control group means, two sample $t$ tests were conducted on the independent variables that measure interval- and ratio-level data. Using multiple $t$ tests determined the probability of observed differences between two group means. A Bonferroni correction for multiple $t$ tests would be used if indicated to avoid a higher than desired risk of a Type I error. The primary use of $t$ tests was for selection of the independent interval and ratio variables for multivariate analysis.

\section{Multivariate Analysis}

Possible predictive variables of birth transition success identified in the preliminary analysis used to address Question 2 was entered into a logistic regression to estimate the probability of transition success or failure in the present study's sample of late-preterm infants. This analysis was applicable because the variables represented multiple levels of data and the dependent variable was categorical. Descriptive analysis of the significant relationship between the independent variables and transition outcome was selected as predictive variables for logistic regression. By application of binary 
logistic regression, coefficients, standard errors, and significance levels may be applied to predict a logit transformation of the likelihood or natural odds that the dependent variable will be present (Pampel, 2000). Transformation of the dependent variable into a logit provided structure for an algorithmic model for testing the independent variables.

Logistic regression used maximum estimation to determine which set of the independent variables best predict transition success or failure. The odds of transition success relative to the predictive variables was determined based on the generated ratio of the probability that transition would be successful or unsuccessful (D. F. Polit, 2010).

\section{Methodological Assumptions}

The methodological assumption of the present study was that explanatory information regarding the specificities of birth transition success may be accurately determined by chart review. One of the functional antecedents related to this assumption was that data contained in the patient data record is accurate. A second assumption was that the criteria used for matching the case and control group hold constant extraneous factors and allow transition outcome differences to be credible.

\section{Methodological Limitations}

Findings from the present study of the factors related to the identification of antecedent factors positively associated with transition success of late-preterm infants are best viewed in light of the methodological limitations of the study. First, the study was a retrospective review of documented events from a single study site. To balance that limitation, the population of the target site's locale (Orlando, Florida) has been demonstrated to be a fairly diverse, similar cross-sectional representation of the United States. Second, data from the present study were gathered from documentation by 
multiple caregivers representative of multiple departments involving late-preterm infants. Because of the independent variables presumed to be possibly predictive of transition success, the matching characteristics chosen must not interfere with the true relationship between the independent variables and the dependent variable. A final methodological limitation is that examination of the independent variables retrospectively did not allow for the determination of direct cause and effect.

The primary threats to construct validity of the present study involved the variables of gestational age and 5-minute Apgar. Gestational age is generally considered the most valid when determined based on a maternal ultrasound obtained at 20 weeks' gestation (Engle, 2006). In the absence of prenatal ultrasound, the reported last menstrual period was used to determine gestational age at the time of delivery (Davidoff et al., 2006). Without accepting this possible limiting factor, infants of mothers without prenatal care would be inadvertently excluded.

Apgar scores have been used in nearly every delivery center since 1958. During the determination of the 1-minute Apgar score, newborn resuscitation may progress and the infant's immediate adaptive ability is uncertain. By 5 minutes of life, a complete cycle of neonatal resuscitation is completed and the 5-minute Apgar score assigned, projecting a more accurate picture of initial transition success (Kattwinkle, 2000). Although the 5-minute Apgar score is considered a valid reflection of newborn wellness by multiple studies (Casey, McIntire, \& Leveno, 2001), the Apgar score may be considered an issue of interrater reliability, as identified by Pinheiro (2009). Because Apgar scoring is the only quantified, indexed measurement currently used to document 
newborn wellness and due to its standardized use, 5-minute Apgar scoring was identified as a valid variable in the present study.

\section{Internal and External Validity}

This study attempted to maximize control over the related factors by concise definition of the independent variables. In this research design, the independent variable values have already occurred naturally and were studied ex post facto. This study sample encompassed the majority of 35- and 36-weeks' gestational age infants representative of a calendar year's worth of births of late-preterm infants. All cases fulfilling the inclusion and exclusion criteria were selected for review.

Causation was not established with a retrospective review because the groups were not random, and the amount of control was decreased (Hess, 2004). Although internal validity was weakened by lack of causal conclusion, the rationale for retrospective data collection was an advantage because the Hawthorne effect was eliminated. This design was also selected because it allowed for use of the most recent available information regarding this population prior to practice changes and a heightened clinical awareness of this population by site and national exposure in 2008 .

As a further issue of validity, data in the health care record may or may not portray an accurate clinical picture. Luck, Peabody, Dresselhaus, Lee, and Glassman (2000) found clinical circumstance may be underestimated by chart review. The type of data that was collected 3 years ago for use in the present study is primarily objective information that is either numeric or nominal. More recent studies have determined chart review of objective data is more reliable (Eder, Fullerton, Benroth, \& Lindsay, 2005). 
To minimize the influence of extraneous variables, matching was used to establish a comparison group (control group) to the case group. Matching birth date and time was used to strengthen the internal validity by controlling for extraneous variables influenced by different days and nursing shifts. Matching case and control group infants should improve the detection and understanding of relationships (J. F. Polit \& Beck, 2008).

Regarding external validity, generalizability of the study results is limited based on the selection of a single study site for data collection and by use of a nonexperimental design. However, a clearly defined study population derived from a diverse, urban setting of the study site represents a similar stratification of the U.S. population. Use of an accepted, standardized definition of the independent variables is designed to add precision to the data collected.

This study also used a case control design to strengthen the conclusions of the study. The possibility of missing data exists and is reported in the study results, affecting reliability and validity (Wu \& Ashton, 1997). Crucial chart details may also be missing, which may have an adverse impact on sample size if charts are found to be unusable. Another possibility is that a chart may be restricted for use by the study institution. Information may also be documented in a different place, affecting data extraction.

Reliability is strengthened by the use of the principle investigator only for data extraction from the medical record. The parameters chosen for measurement are supported by the literature review. The neonatal physiologic data represent the information obtained during the assessment of newborns during transition, but in the medical record have been obtained by multiple caregivers. 
An issue of weakness of a retrospective chart review is causation. Causation is difficult to establish with a retrospective review because the groups are not random, and the amount of control is decreased (Hess, 2004). To strengthen reliability, the data were collected by the primary investigator only. 


\section{CHAPTER FOUR: RESULTS}

Chapter Four presents the application of the statistical analysis of the data related to the research questions. The sample of late-preterm infants is described then the answer to each research question is reported. The first research question was "How many latepreterm infants are admitted to the NICU at or prior to six hours of life?" The logbooks indicated that of 13,855 newborns delivered at the study site in 2007, 201 late-preterm infants (35 and 36 weeks' gestation) were admitted to the NICU in 2007 prior to 6 hours of life.

\section{Independent Variables}

The second research question, "What are the risk factors related to maternal factors, birth impact, and neonatal physiologic maturity that are associated with latepreterm infants who fail and do not fail transition" resulted in measurement and analysis of the independent variables related to the constructs of the study. The description and significance of maternal, birth, and physiologic variable relationships were analyzed.

\section{Maternal Factor Variables (Summary Table 7) \\ Maternal Age, Ethnicity, and Smoking}

The maternal age range of this study was fairly wide. The average maternal age for this study was 28.81 years $(S D=6.5)$, with the minimum age of 15 years and the maximum age of 42 years. There were 22 teenage mothers $(<20$ years old $)$ distributed evenly between the two groups. Of the 192 newborns, babies were primarily identified as Caucasian (52.6\%), followed by Hispanic (24.5\%), and African American (17.7\%). The 
remainder of the newborns were identified as Asian, Asian Indian, or Filipino infants $(5.2 \%)$. No significant relationship was found $\left(\chi^{2}(3)=.352, p>.05\right)$ between birth transition outcome and ethnicity.

Ninety-one percent of the mothers reported that they were nonsmokers, while $8.9 \%$ reported smoking during pregnancy. A chi-square test of independence found no association between maternal smoking and birth transition success $\left(\chi^{2}(1)=.799\right.$, $p>.05)$.

\section{Preconception l Health}

Most mothers had no health issues reported (88\%), and there was no significant association between transition success and maternal health for individual health issues, $\left(\chi^{2}(6)=.529, p>.05\right)$, or for having at least one preconception health problem $\left(\chi^{2}(1)=\right.$ $.824, p>.05)$. The most frequent health issue reported was chronic hypertension $(4.7 \%)$, followed by hypothyroidism (4.7\%), asthma (2.1\%), diabetes (1.6\%), and depression (1\%) (See Table 7).

\section{Prenatal Visits}

Of the available prenatal visit information the mean number of prenatal visits for this population was 8.35 overall, 8.49 for the case group $(S D=2.97, \mathrm{n}=82)$, and 8.20 for the control group $(S D=2.91, \mathrm{n}=83)$ pregnancy visits, ranging from 0 to 13 prenatal visits. No significant relationship was found between having one or more prenatal visits and transition outcome $\left(\chi^{2}(2)=307, p>.05\right)$. Of the six pregnancies without prenatal care, four of these babies failed transition. Three failed transition babies had four or fewer prenatal visits versus seven babies in the transition success group. Of the babies receiving 
five or more prenatal visits, 41 of these babies transitioned successfully versus 44 who did not.

\section{Pregnancy Health}

Most of the mothers (108) did not experience pregnancy health complications.

The most common pregnancy complications of the mothers with pregnancy health issues (84) were pregnancy-induced hypertension (24.5\%), followed by diabetes (10.9\%), complete placenta previa (4.2\%), complete abruption (1.6\%), partial placenta previa $(0.5 \%)$, and depression (1.6\%). To further explore pregnancy health, the variable pregnancy complications was redefined into extended categories: none (0), diabetes (1), vascular (2), and depression (3). The category of vascular is representative of the broad category of pregnancy-induced hypertension, preeclampsia, eclampsia, and abruptions. Comparing transition success with pregnancy complications, the group that failed transition had fewer infants of diabetic mothers but twice as many infants with pregnancy-induced hypertension and placenta previa. However, the differences between groups was not significant $\left(\chi^{2}(1)=.146, p>.05\right.$.). A summary of the maternal demographic characteristics is presented in Table 7.

\section{Table 7}

Maternal Demographic Characteristics

\begin{tabular}{lcc}
\hline Characteristic & Transition success(count) & Transition failure (count) \\
\hline \multicolumn{3}{c}{ Ethnicity } \\
\hline Caucasian & $46.9 \%(45)$ & $58.3 \%(56)$ \\
Hispanic & $28.0 \%(25)$ & $22.9 \%(22)$ \\
\hline African American & $21.9 \%(21)$ & $13.5 \%(13)$ \\
Other & $5.2 \%(5)$ & $5.2 \%(5)$ \\
\hline
\end{tabular}


Maternal age

\begin{tabular}{|c|c|c|}
\hline \multicolumn{3}{|c|}{ Maternal age } \\
\hline \multicolumn{3}{|l|}{ Range $15-42$ years } \\
\hline Mean & 29 years & 28 years \\
\hline SD & 6.63 years & 6.484 years \\
\hline \multicolumn{3}{|c|}{ Preconception health } \\
\hline No issues & $88.5 \%(85)$ & $87.5 \%(84)$ \\
\hline Diabetes & $0 \%(0)$ & $3.1 \%(3)$ \\
\hline Hypertension & $4.2 \%(4)$ & $5.2 \%(5)$ \\
\hline Depression & $1.0 \%(1)$ & $1.0 \%(1)$ \\
\hline Hypothyroidism & $2.1 \%(2)$ & $2.1 \%(2)$ \\
\hline Asthma & $3.1 \%(3)$ & $1.0 \%(1)$ \\
\hline Total Colectomy & $1.0 \%(1)$ & $0.0 \%(0)$ \\
\hline \multicolumn{3}{|c|}{ Pregnancy health } \\
\hline No issues & $68.6 \%(66)$ & $60.4 \%(58)$ \\
\hline Diabetes & $14.6 \%(14)$ & $7.3 \%(70$ \\
\hline Vascular* & $16.7 \%(16)$ & $32.3 \%(31)$ \\
\hline
\end{tabular}

\begin{tabular}{|c|c|c|}
\hline Characteristic & Transition success(count) & Transition failure (count) \\
\hline \multicolumn{3}{|c|}{ Smoking } \\
\hline Yes & $8.3 \%(8)$ & $9.4 \%(9)$ \\
\hline No & $91.7 \%(88)$ & $90.6 \%(90)$ \\
\hline \multicolumn{3}{|c|}{ Prenatal visits } \\
\hline \multicolumn{3}{|c|}{ Range $0-12$ visits } \\
\hline Mean & 8.20 & 8.49 \\
\hline$S D$ & 2.916 & 2.977 \\
\hline
\end{tabular}

Note. * Vascular includes abruption, pregnancy-induced hypertension, and preeclampsia

\section{Birth Impact Variables}

\section{Prenatal Steroids}

Most of the mothers $(91.1 \%)$ did not receive prenatal steroids versus those who did $(8.9 \%)$. Note in Table 8 that within the case and control groups, the distribution of 
mothers that did not receive prenatal steroids between the case and control groups was similar. However, in the failed transition group, only $6 \%$ received prenatal steroids while in the success group, twice as many babies received prenatal steroids prior to delivery. However, this difference was not statistically significant. $\left(\chi^{2}(1)=.204, p>.05\right)$.

\section{Labor}

Twice as many mothers represented by this sample were reported to be in preterm labor prior to delivery, versus not in preterm labor (Table 8). The length of labor was not quantifiable from the medical record and therefore became a categorical yes (in premature labor for any length of time) or no (not in premature labor) variable. A secondary implication of newborns without labor is that delivery by cesarean section is implied. In the transition success group, about 18\% more newborns were delivered after labor versus the failed transition group. But of the late-preterm infants delivered without labor, the failed transition group included nearly twice as many newborns than the transition success group (see Table 8). Late-preterm infants delivered without labor were significantly more likely to fail transition than not fail in this sample $\left(\chi^{2}(1)=.017\right.$, $p<.05)$.

\section{Maternal Anesthesia}

The distribution of the maternal anesthesia route were nearly equal between both

groups (see Table 8 ). In the case and control groups, the mothers predominantly received epidural anesthesia, followed by spinal, then general anesthesia. A small percent received no anesthesia prior to deliver implying vaginal birth following labor. Although general anesthesia is a direct risk factor of respiratory depression in newborns, three newborns delivered with general anesthesia experienced transition success versus two 
babies that failed transition. An overall comparison between groups however found no significant relationship $\left(\chi^{2}(3)=.495, p>.05\right)$ between the type of maternal anesthesia given and transition success.

\section{Birth Route}

Most of the late-preterm infants in this sample were delivered by cesarean section (54.2\%) as opposed to vaginal birth (45.8\%). Comparing transition success to birth route, just over half of the babies who failed transition were delivered by cesarean section versus 43 who were delivered vaginally. These numbers were nearly identical for the newborns who did not fail transition (see Table 8). Consequently, there was no significant relationship between birth route and transition success $\left(\chi^{2}(1)=.772, p>.05\right)$.

\section{Rupture of Membranes}

The mean length of time for which membranes were ruptured prior to delivery of this population was 6.81 hours $(S D=15.00)$, ranging from zero hours to 72 hours. The case group had a slightly higher mean ruptured membrane length of 7.40 hours $(S D=$ $15.94)$ versus the control group mean of 6.23 hours $(S D=14.06)$. The ruptured membrane duration prior to delivery was not significantly different between the groups $(t(190)=.538, p>.05)$.

Table 8 Chi-Square $\left(\chi^{2}\right)$ Test, Dichotomous Variables Among Demographic and Study Variables, Babies With Transition Success and Failure (Frequency \% of Total)

\begin{tabular}{lcccc}
\hline Variable & $\begin{array}{c}\text { Transition } \\
\text { success }\end{array}$ & $\begin{array}{c}\text { Transition } \\
\text { failure }\end{array}$ & Total & $p$ \\
\hline No & \multicolumn{3}{c}{ Prenatal steroids } \\
Yes & $85(44.3 \%)$ & $90(46.9 \%)$ & $91.1 \%$ & .310 \\
\hline
\end{tabular}




\begin{tabular}{lcccc}
\hline Variable & $\begin{array}{c}\text { Transition } \\
\text { success }\end{array}$ & $\begin{array}{c}\text { Transition } \\
\text { failure }\end{array}$ & Total & $p$ \\
\hline Spinal & \multicolumn{3}{c}{ Anesthesia } & \\
Epidural & $8(4.2 \%)$ & $14(7.3 \%)$ & $11.5 \%$ & .495 \\
General & $75(39.1 \%)$ & $73(38 \%)$ & $77.1 \%$ & \\
\hline None & $3(1.6 \%)$ & $2(1.0 \%)$ & $2.6 \%$ &. \\
\hline No labor & $10(5.2 \%)$ & $7(3.6 \%)$ & $8.9 \%$ & .017 \\
Yes labor & $20(10.4 \%)$ & $36(18.8 \%)$ & $29.2 \%$ & .442 \\
\hline & $76(39.6)$ & $60(31.2)$ & & \\
\hline Vaginal & & Birth route & \\
Cesarean & $51(23.4 \%)$ & $43(22.3 \%)$ & $45.8 \%$ & \\
\hline
\end{tabular}

\section{Neonatal Physiologic Variables}

\section{Gender and Gestational Age}

The percentage of male infants in this population was $54.2 \%$, and $45.8 \%$ were female. In the case group, over half of the newborns were male gender versus female gender, whereas the control group had 43 male newborns and 53 female newborns. Of the babies who failed transition, approximately one-third were female and the remainder were male. In the group that transitioned successfully, just over half of the newborns were females with slightly fewer males. As shown in Table 9, in this population, male infants were more likely to fail transition than female infants $\left(\chi^{2}(1)=.009, p<.05\right)$.

The distribution of gestational ages ( 35 or 36 weeks) was nearly identical in the case and control group as was the frequency of gestational ages (either 35 or 36 weeks). Note in Table 9 the only exception is that $5 \%$ more 35 week infants were found in the 
failure group versus the transition success group. However, the difference was not found to be statistically significant $\left(\chi^{2}(1)=.247, p>.05\right)$.

Table 9

Chi-square $\left(\chi^{2}\right)$ Tests for Dichotomous Neonatal Physiological Variables (Frequency \% of Total)

\begin{tabular}{lcccc}
\hline Variable & $\begin{array}{c}\text { Transition } \\
\text { success }\end{array}$ & $\begin{array}{c}\text { Transition } \\
\text { failure }\end{array}$ & Total & $p$ \\
\hline Female & $53(27.8 \%)$ & $35(18.2 \%)$ & $45.8 \%$ & .009 \\
Male & $43(22.2 \%)$ & $61(31.8 \%)$ & $54.2 \%$ & \\
\hline & & Gender & \\
\hline 35 weeks & $41(21.4 \%)$ & $49(25.5 \%)$ & $90(46.9 \%)$ & .247 \\
36 weeks & $55(28.6 \%)$ & $47(24.5 \%)$ & $102(53.1 \%$ & \\
\hline
\end{tabular}

\section{5-Minute Apgar Score}

The five minute Apgar score range was the same for both groups, 6-10. A significant difference was found $(t(190)=3.35, p<.05)$ between the average five minute Apgar scores between the case and the control groups. The mean Apgar score of the case group was $8.36(S D=1.21)$, which was significantly less than the transition success group $(M=8.82, S D=.58)$, and the population mean $(M=8.59, S D=.977)$, indicating that the case group had 5-minute Apgar scoring that was significantly lower than that of the control group.

\section{Birth Weight}

The mean birth weight for this sample was 2848.20 grams (6.4 pounds), with a maximum weight of 4,620 grams (10.2 pounds), and a minimum weight of 2,200 grams (4.9 pounds). The average birth weight between groups was nearly the same as noted in 
Table 11. A comparison of birth weights between the case and control group and transition failure indicated that birth weight and transition outcome are not related in this sample $(t(190)=-2.105, p>.05)$.

\section{Temperature}

The highest average transition temperature found in this sample was $98.57^{\circ} \mathrm{F}$ $(S D=.4741)$, with the maximum value of $101.0^{\circ} \mathrm{F}$ and the minimum value of $97.6^{\circ} \mathrm{F}$.

The average temperatures found in the case and control groups were nearly identical (Table 11). An analysis comparing the highest transition temperatures of the case and the control group $\mathrm{T}$ was not significant $(t(190)=1.087, p>.05)$, indicating that the highest transition temperature and transition success or failure are not related in this sample.

The average low transition temperature for both groups was the same $-96.99^{\circ} \mathrm{F}$ $(S D=.69)$. The temperature range for both groups was $3.7^{\circ} \mathrm{F}$. The minimum case group temperature was one degree lower than for the control group (see Table 11). Because both groups averages were low, the difference between groups was not significant $(t$ $(190)=-1.792, p>.05)$.

\section{Heart Rate}

The highest mean heart rate for the transition success group was $152 \mathrm{bpm}$ ( $S D$ $=.11 .25)$ and was $154 \mathrm{bpm}(S D=12.68)$ for the transition failed group. The ranges were similar for both groups and without significant difference between groups $(t(190)$ $=1.097, p>.05)$.

A between-groups comparison of the lowest mean heart rate was also not significant $(t(189)=-1.72, p>.05)$. The mean of the case group and of the control group were nearly identical. The statistical analysis of highest and lowest transition heart rates 
between groups indicates that in this sample, heart rate and transition success are not related (see Table 11).

\section{Respiratory Rate}

The case group had a significantly higher respiratory rate than the control group $(t$ $(190)=-1.126), p<.05)$. The average respiratory rate of the case group $(M=71 \mathrm{rpm}, S D$ $=15.5)$ was significantly higher than that of the control group $(M=62 \mathrm{rpm}, S D=11.8)$. The difference in the lowest respiratory rate, however, was not statistically significant $(t$ $(190)=-2.258, p>.05)$. However, the difference between the highest respiratory rate was found to be significant $(t(190)=-2.258, p<.05)$.

For further analysis, the variable highresp was redefined as a categorical variable (splitresprate) and redefined as: $0=<60 \mathrm{rpm}, 1=60-69 \mathrm{rpm}$, and $2=>70 \mathrm{rpm}$. These strata allowed classification of the variable ranges into normal respiratory rate $(<60$ rpm), slightly abnormal respiratory rate (60-69 rpm), and abnormal and tachypneic respiratory rate $(>69 \mathrm{rpm})$. The transition failed group was found to have more newborns with abnormal respiratory rates (48) than the transition success group (19), with a significant difference found between the groups $\left(\chi^{2}(2)=20.256, p<.05\right)$. A summary of the cross-tabulation between groups is presented in Table 10.

Table 10

Cross-tabulation Results of Transition Success and Highest Transition Respiratory Rate, Recoded into Categorical Variable splitresprate

\begin{tabular}{lcccc}
\hline $\begin{array}{l}\text { Transition } \\
\text { outcome }\end{array}$ & Code & Success & Failure & Total \\
\hline \multicolumn{1}{c}{ splitresprate } & .00 & .00 & 1.00 & \\
& 1.00 & 46 & 18 & 71 \\
\hline
\end{tabular}




\begin{tabular}{ccccc}
\hline $\begin{array}{l}\text { Transition } \\
\text { outcome }\end{array}$ & Code & Success & Failure & Total \\
\hline Total & 2.00 & 19 & 48 & 67 \\
& & 96 & 96 & 192 \\
\hline
\end{tabular}

Note. splitresprate variable: $.00=\mathrm{rpm}<60,1.00=\mathrm{rpm} 60-69,2.00=\mathrm{rpm}>69$.

\section{Lowest Mean Blood Pressure}

. The mean blood pressure for the case group $(39 \mathrm{mmHg}, S D=10.1)$ was nearly the same as for the control group $(38 \mathrm{mmHg}, S D=5.8)$. The difference in mean blood pressures between the groups was not found to be statistically significant $(t(190)=-.867$, $p>.05$ ), indicating that the lowest mean blood pressure and transition outcome are not related in this sample.

\section{Glucose}

The lowest glucose of the control group of newborns was $58.25 \mathrm{mg} / \mathrm{dL}(S D=$ 12.68) versus the case group mean of $60.87 \mathrm{mg} / \mathrm{dL}(S D=21.15)$ and were not significantly different $(t(190)=-1.042, p>.05)$ in this population. Lower glucose and transition success are not related in this sample. The glucose of the control group had a narrower range (32-97 mg/dL) than the case group (20-129 mg/dL). See Table 11 for a summary of t-tests of the continuous variables.

Table 11

Summary of $t$ Tests and Descriptive Statistics of Continuous Variables

\begin{tabular}{lcccc}
\hline Variable & $\begin{array}{c}\text { Transition success } \\
(n=96)\end{array}$ & $\begin{array}{c}\text { Transition failure } \\
(n=96)\end{array}$ & $\begin{array}{c}\text { Total } \\
(N=192)\end{array}$ & $p$ \\
\hline Mean & 29.07 & Maternal age \\
\hline
\end{tabular}




\begin{tabular}{|c|c|c|c|c|}
\hline Variable & $\begin{array}{c}\text { Transition success } \\
(n=96)\end{array}$ & $\begin{array}{c}\text { Transition failure } \\
(n=96)\end{array}$ & $\begin{array}{c}\text { Total } \\
(N=192)\end{array}$ & $p$ \\
\hline$S D$ & 6.63 & 6.48 & 6.50 & .583 \\
\hline Range & $15-42$ & $15-41$ & $15-42(27)$ & \\
\hline \multicolumn{5}{|c|}{ Prenatal visits } \\
\hline Mean & 8.2 & 8.49 & 8.35 & \\
\hline$S D$ & 2.91 & 2.97 & 2.94 & .516 \\
\hline Range & $0-12$ & $0-13$ & $0-13$ & \\
\hline Missing & $14(14.6 \%)$ & $13(13.5 \%)$ & $27(16.36 \%)$ & \\
\hline \multicolumn{5}{|c|}{ ROM duration } \\
\hline Mean & 7.40 & 6.23 & 6.81 & \\
\hline$S D$ & 15.94 & 14.06 & 15 & .531 \\
\hline Range & $0-70$ & $0-70$ & $0-72$ & \\
\hline \multicolumn{5}{|c|}{ 5-minute Apgar } \\
\hline Mean & 8.82 & 8.36 & 8.59 & \\
\hline$S D$ & .58 & 1.21 & .97 & .001 \\
\hline Range & $6-10$ & $6-10$ & $6-10$ & \\
\hline \multicolumn{5}{|c|}{ Birth weight (grams) } \\
\hline Mean & 2831.10 & 2865.30 & 2848.20 & \\
\hline$S D$ & 445.6 & 497.6 & 470.2 & .377 \\
\hline Range & $2200-4112$ & $2200-4620$ & $2200-4620$ & \\
\hline \multicolumn{5}{|c|}{ Highest transition temperature $\left({ }^{\circ} \mathrm{F}\right)$} \\
\hline Mean & 98.6 & 98.5 & 98.5 & \\
\hline$S D$ & .47 & .47 & .47 & .274 \\
\hline Range & $97.6-99.8$ & $97.6-101.0$ & $97.6-101.0$ & \\
\hline
\end{tabular}

Lowest transition temperature $\left({ }^{\circ} \mathrm{F}\right)$

\begin{tabular}{llcll}
\hline Mean & 96.9 & 97.0 & 96.9 & .085 \\
$S D$ & .77 & .58 & .69 & \\
Range & $95.7-98.3$ & $94.6-98.3$ & $94.6-98.3$ & \\
\hline \multicolumn{5}{c}{ Highest transition heart rate } \\
\hline Mean & 15.2 & 154.2 & 153.2 \\
\hline
\end{tabular}




\begin{tabular}{|c|c|c|c|c|}
\hline$S D$ & 11.24 & 12.68 & 11.99 & .262 \\
\hline Range & $124-180$ & $128-186$ & $124-186$ & \\
\hline \multicolumn{5}{|c|}{ Lowest transition heart rate } \\
\hline Mean & 126.4 & 126.1 & 126.2 & \\
\hline$S D$ & 11.72 & 11.43 & 11.55 & .867 \\
\hline Range & $86-152$ & $90-150$ & $86-152$ & \\
\hline \multicolumn{5}{|c|}{ Highest transition respiratory rate } \\
\hline Mean & 62.5 & 71.13 & 66.86 & \\
\hline$S D$ & 11.88 & 15.56 & 14.46 & $<.001$ \\
\hline Range & $40-98$ & $34-120$ & $34-120$ & \\
\hline \multicolumn{5}{|c|}{ Lowest transition respiratory rate } \\
\hline Mean & 41.7 & 44.6 & 43.2 & \\
\hline$S D$ & 8.13 & 9.57 & 8.98 & .085 \\
\hline Range & $20-70$ & $27-73$ & $20-73$ & \\
\hline \multicolumn{5}{|c|}{ Lowest transition blood pressure } \\
\hline Mean & 38.03 & 37.84 & 37.93 & \\
\hline$S D$ & 5.86 & 5.18 & 5.52 & .387 \\
\hline Range & $23-54$ & $24-55$ & $23-55$ & \\
\hline \multicolumn{5}{|c|}{ Lowest transition glucose } \\
\hline Mean & 58.25 & 60.87 & 59.53 & \\
\hline$S D$ & 12.69 & 21.15 & 17.59 & .299 \\
\hline Range & $32-97$ & $20-129$ & $20-129$ & \\
\hline
\end{tabular}

\section{Hospital Days}

. The control group had a mean hospital stay of 2.6 days $(S D=.92)$, which was significantly lower than that of the case group, staying an average of 8.6 days $(S D=9.9)$. The mean number of hospital days for the case and control groups were compared by calculating an independent-samples $t$ test and found to be significantly different. The difference between the mean value of the two groups was statistically significant $(t(190)$ 
$=-5.8, p<.05)$. The hospital stay of the failed transition group was significantly longer than that of the successful transition group.

\section{Multicolinearity/Correlation}

The study variables were measured for the strength of linear relationships prior to further statistical analysis. The statistically significant variables (5-minute Apgar, respiratory rate,) were evaluated by calculating the Pearson correlation coefficient. Pearson correlation coefficients were calculated by examining the relationship between the ratio level variables between the case and control group infants. Of these, a weak correlation that was not found to be significant existed between highest transition respiratory rate and lowest transition respiratory rate $(r(2)=.518, p>.05)$.

\section{Logistic Regression Analysis}

The third research question, "Of the risk factors determined to be related to transition success, are any of these factors predictive of transition success or failure?". A four-predictor logistic model was fitted to describe and test the relationships between transition for the four significant variables (labor, gender, 5-minute Apgar score, highest respiratory rate) identified in the previous univariate analyses.

The distribution of gender is noted to be nearly even (male newborns $=54.2 \%$, female newborns $=45.8 \%$ ). According to the model, the log of the odds of a successful birth transition were negatively related to the labor $(p<.05)$ indicating that in the absence of labor, the newborn is more likely to fail transition (See Table 12). Lower 5-minute Apgar scores $(p<.05)$ were also related to transition failure. A higher respiratory rate 
was positively related to transition failure $(p<.05)$. The relationship to gender was not significant $(p=.073)$.

\section{Evaluation of the Logistic Regression Model}

A logistic model may be evaluated for an improved fit by surpassing the null (intercept only) model (Peng, Lee, \& Ingersoll, 2002). Based on the omnibus test of model coefficients, the overall model was significantly $(p<.05)$ capable for jointly predicting the dependent variable response, demonstrating improvement above the benchmark of the null model. The Wald chi-square statistic was used to test the regression coefficients of the individual predictors. The conditions were satisfied for the goodness-of-fit to be evaluated by using the Hosmer-Lemeshow (H-L) test calculated from a table of observed and expected frequencies. The H-L statistical test resulted in $\chi^{2}$ $(7)=7.72$, demonstrating insignificance $(p>.05)$. An insignificant result indicates that the model was a good fit to the data (Peng et al., 2002) (see Table 12).

Table 12

Significance and Odds Ratios for Final Logistic Regression Model

\begin{tabular}{lccccccc}
\hline Variable & Beta & $S E$ & $\chi^{2}$ & $d f$ & $p$ & $\begin{array}{c}\text { Odds ratio } \\
\text { Exp (B) }\end{array}$ & $\begin{array}{c}\text { 95\% CI for } \\
\text { Exp (b) }\end{array}$ \\
\hline Labor & -.864 & .353 & 5.985 & 1 & .014 & .421 & $\begin{array}{c}.207- \\
.825\end{array}$ \\
Gender & -.756 & .251 & 9.078 & 1 & .003 & .470 & $.288-$ \\
& & & & & & & .770 \\
$\begin{array}{l}\text { 5-minute } \\
\text { Apgar }\end{array}$ & .584 & .326 & 3.217 & 1 & .043 & 1.793 & $.956-$ \\
score & & & & & & & \\
Resp. rate & .706 & .212 & 11.142 & 1 & .001 & 2.026 & $1.349-$ \\
\hline
\end{tabular}




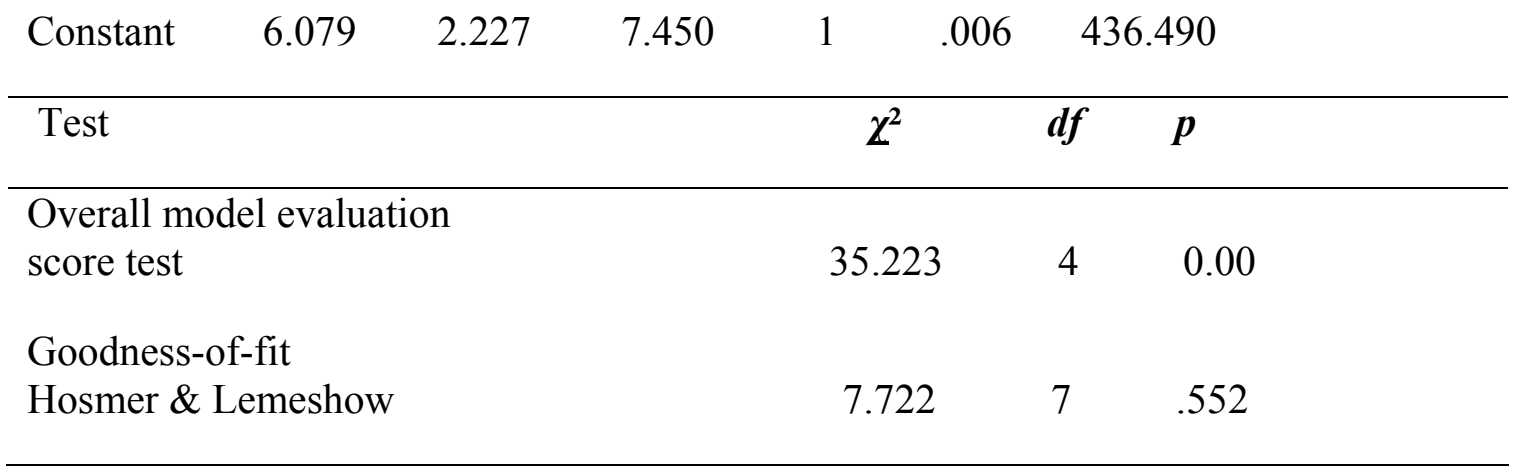

\section{Predicted Probabilities}

The classification table (see Table 13) based on this model indicates that the correct classification was slightly higher for transition success (74\%) than for transition failure (66.7\%). The number of control babies who were both predicted and observed to transition successfully was 71 , indicating that the model classification was correct for these newborns. Twenty-five control babies were predicted to fail transition but were observed as babies who transitioned successfully, indicating that the model classification was incorrect for these newborns. In the case group, the number of cases that were both correctly predicted and observed as babies that failed transition was 64 . The false positives, or cases that were predicted to pass transition, yet were observed to fail transition (false positives) numbered 32 . 
Table 13

Classification Table for Logistic Regression

\begin{tabular}{lccc}
\hline \multicolumn{1}{c}{ Observed } & Predicted controls & $\begin{array}{c}\text { Predicted transition } \\
\text { failure cases }\end{array}$ & Predicted \% correct \\
\hline $\begin{array}{l}\text { Transition success } \\
\text { (controls) (coded as }\end{array}$ & 71 & 25 & 74.0 \\
$.00)$ & 32 & 64 & 66.7 \\
$\begin{array}{l}\text { Transition failure } \\
\text { (cases) (coded as }\end{array}$ & & & \\
$1.00)$ & & & 70.3 \\
Overall percentage & & & \\
\hline
\end{tabular}

Note. The cut value is .500 .

\section{Odds Ratios}

The odds ratio compares the likelihood of an event occurring between two groups and indicates strength between the independent variable and the dependent variable. Based on the results of the logistic regression, the group that transitioned successfully was 2.84 times more likely to transition successfully than to fail transition. The group that failed transition was twice as likely to fail transition as to not fail transition. Four of the independent variables (see Table 12) were significantly associated with transition failure. Because high respiratory rate is one of the most important physiological features of neonatal illness, a high odds ratio was expected. As the most significant predictor, respiratory rate $(p<.01)$, had an odds ratio of 2.085 , indicating that newborns with an elevated respiratory rate greater than 59 were twice as likely to fail transition as those who do not have this level of elevated respiratory rate. 


\section{CHAPTER FIVE: DISCUSSION}

The purpose of this study was to determine the prevalence, clinicalepidemiological characteristics, and predictive factors related to failed and successful birth transition in a sample of late preterm infants. The focus of this chapter is to discuss the study findings and the potential implications of these finding for practice, policy, education, and future research.

\section{Research Findings}

The independent variables that were found to be statistically associated with transition outcome were labor, gender, five minute Apgar score, and respiratory rate. These variables represent to conceptual framework of the study and the hypothesized relationship between birth, neonatal physiology, and birth transition outcome. The independent variables representing the construct of maternal impact were not found to be statistically significant regarding prediction of transition failure in this study.

Based on the literature review, an expected finding was that late preterm birth without labor is statistically associated with transition outcome. The expected positive effects of labor on the production and clearance of fetal lung fluid was physiologically described by Jain and Eaton (2006) and Sinha and Donn (2006) as a perceived benefit of labor by decreasing the incidence of respiratory distress, as well as the detriment of the absence of labor. In this study, labor was analyzed as a dichotomous variable based on the available consistent information documented found in the medical record. The operational definition of labor that was either spontaneous or induced and with duration 
greater than one hour. Consistent with the literature review (Dudell \& Jain, 2006; Jain \& Eaton, 2006; Ramachandrappa \& Jain, 2008), late preterm infants delivered without any labor benefit (cesarean section), nearly twice as many newborns in the case group failed transition (64.3\%) than did not fail transition (35.7\%). Of the newborns that did experience labor prior to delivery, the number of newborns represented by the case and control groups were nearly even, indicating that the presence of labor alone is not consistently predictive of transition outcome. A consideration of this finding is that the absence of the availability of the documented length and intensity of labor is a limitation of this study. However the identification of labor as a risk factor if present at in any amount prior to delivery versus no labor and the positive effect on transition outcome implies that any labor is positively significant in the transition outcome of this population, whereas the absence of labor implies risk of transition failure.

Gender was the second variable which was found to be statistically significant in this study. The overall sample demonstrated a slightly higher distribution of males (54.2\%) than females (45.5\%). A between groups comparison of the case and control groups found that nearly two thirds as many male infants (39.8\%) failed transition than did female infants (58.7\%), indicating that in this sample, late preterm males are nearly twice as likely to fail birth transition than late preterm females. Likewise is the transition success group, females represented over half of the preterm infants that successfully transitioned (60.2\%) while fewer males (41.3\%) transitioned successfully. This is a significant finding as it identifies gender as a potential risk factor for birth transition failure. Prior to this study, this finding was not evident in the literature review but as an informal observation of neonatal caregivers. 
An expected finding based on the literature review was that more 35 week gestational age infants would fail transition than 36 weeks gestational age infants. In this sample, nearly the same number of 35 weeks gestational age infants $(46.9 \%)$ were admitted to the NICU as 36 weeks gestational age infants (53.1\%). This finding was inconsistent with the literature review findings of Duddell and Jain by a large margin. This is possibly due to the presence of exclusion criteria in this research study, omitting multiple gestation infants, infants with congenital anomalies, ambiguous genitalia, and infants transferred into the study site after delivery. Over half of this sample was omitted due to the application of exclusion criteria. A second possibly explanation is the calculation of gestational age, which may vary from one to two weeks (Campbell et. al, 1985). A comparison of gestational age and gender was also surprisingly insignificant. Male infants that were 35 weeks gestational age were just as likely to fail transition as male infants that were 36 weeks gestational age in this sample.

The significance of the association of lower five minute Apgar scores and transition failure was an expected finding. As previously discussed, Aydin et. al (2007) used Apgar scoring as a method to evaluate newborn wellness related to the effects of maternal anesthesia. In this study, the range of Apgar scores for the case group and control groups were identical, with a minimum score of 6 and maximum score of 10 for both groups. However, the average 5-minute Apgar score for the case group was slightly lower ( $\mathrm{m}=8.46$ case group, $\mathrm{m}=8.82$ case group). The explanation of this finding is explained by the higher frequency of lower Apgar scores $(<7)$ in the case group than in the control group with fewer lower Apgar scores. This finding indicates that lower 5- 
minute Apgar scores represent a negative impact on transition outcome, but are not a consistent finding in transition failure.

As the primary indicator of physiologic illness in newborns (Askin, 2009a), elevated respiratory rate was an expected finding associated with respiratory distress in the case group. Supported by the literature review (Askin, 2009a; Askin 2002; Sinha and Donn, 2006; Dudell and Jain, 2006) a common practice observation is that newborns are considered to escalate in illness as their respiratory rate escalates, indicating further respiratory compromise. The highest respiratory rate for the case group was $71 \mathrm{rpm}$, significantly higher than the control group $(63 \mathrm{rpm})$. Although the most statistically significant independent variable $(p=.000)$ measured in this study, the case group demonstrated an average respiratory rate that was only $12 \%$ higher than the control group during transition (Table 9).

For further analysis, the variable respiratory rate was stratified into normal $(<60$ rpm), slightly abnormal (60-69 rpm), and abnormal (>70 rpm), and the results are more clearly understood (Table 10). The failed transition group had more than twice the number of newborns with abnormally high respirations than the case group. Related to this finding, the number of newborns with normal respiratory rates $(<60 \mathrm{rpm})$ were twice as many in the control group than in the case group. A more unexpected finding is that the case group had fewer infants that had slightly abnormal respiratory rates. A possible explanation is that late preterm infants that fail transition are predominantly more tachypneic than those babies that do not fail transition.

The regression model constructed of the four significant independent variables entered into the model simultaneously correctly classified transition failure $66.7 \%$ of the 
time and transition success $71 \%$ of the time. This is a beneficial clinical finding as an insight to the assessment of transition late preterm infants. The ability to classify late preterm infants during transition effects decision making and resource management surrounding care practice and policy.

\section{Other Findings}

The average maternal age for the case group was nearly identical to the control group $($ case $=29.07$ years, control $=28.55$ years $)$. There were 22 teenage mothers $(<20$ years old) distributed evenly between the two groups. Ethnicities represented in the sample were as expected based on the available maternal demographic data for Florida in 2007 (March of Dimes, 2007) and is a reflection of the reported population ethnicity of Florida.

As expected, mothers of infants failing transition were more likely to have experienced pregnancy complications related to vascular disorders such as pregnancyinduced hypertension and placenta previa. Unexpectedly, of the infants of diabetic mothers in this sample $(47,24 \%)$, less than half of them $(16,34 \%)$ failed transition and most of the babies passed transition $(31,65 \%)$. This finding was unexpected because infants of diabetic mothers are more likely to have respiratory distress and hypoglycemia, compounded with the risk of prematurity.

The most unexpected maternal demographic finding was maternal smoking. Almost the entire sample (97\%) reported they were nonsmokers. Based on the literature review, a reported $20 \%$ of pregnant women in the United States are smokers (Cnattingius, 2004). This disparity may be attributed to the method of reporting (self-reporting) in the 
medical record. Mothers may have interpreted this question to apply to duration and amount of smoking.

Prenatal steroids are not as commonly used in preterm labor after 34 weeks' gestation, supporting the finding that most of the mothers did not receive prenatal steroids prior to delivery. Of the 16 mothers who received prenatal steroids, 11 of the newborns transitioned successfully and 6 did not. The number of doses and timing of doses prior to delivery was not considered in this finding. Although this data reflects a small number of newborns, this finding suggests that 35- and 36-week infants might benefit from the use of prenatal steroids.

The hours of ruptured membranes prior to delivery ranged from zero to 72 hours with a nearly equal length of ruptured membranes between the case group ( 6.23 hours) and the control group ( 7.40 hours). The closely related means translated to a statistically insignificant difference between groups. One possible influencing factor is that the event of ruptured membranes in this sample is commonly classified as premature rupture of membranes and may result in stronger consideration of cesarean delivery because of the possibility of chorioamnionitis (Seo, McGregor, \& French, 1992), resulting in a shorter duration of ruptured membranes overall.

The incidence of cesarean section was $54.2 \%$ for this population and relatively high. As reported in Chapter One, the cesarean section rate in Florida in 2007 was 37.2\%, indicating that late-preterm infants included in this study were more likely to be delivered by cesarean section than to have been delivered vaginally. Without considering the presence or absence of labor, ruptured membranes, or the administration of prenatal steroids, nearly the same number of newborns delivered by cesarean section failed 
transition (49\%) as passed transition (51\%). The findings were nearly the same for the vaginal group $($ case group $=44.8 \%$; control group $=46.9 \%$ ). The equal balance among groups contributed to the lack of significance of this variable.

Consistent with the literature review, an expected finding was that the newborns were primarily delivered by use of epidural anesthesia, followed in lesser frequency by spinal, local, and no anesthesia. Transition success and anesthesia in this sample were not related. This finding is consistent with the literature review citing the inconclusive relationship between maternal anesthesia and birth transition (Mercer et al., 2007).

The variable of temperature was initially anticipated to be a significant one because of the association of hypothermia with illness in newborns. Data were initially viewed as highest and lowest to capture the existence of febrile and hypothermic infants. The average highest temperature during transition for both groups was within normal temperature range. The average lowest temperature for both groups revealed that both groups experienced hypothermia during transition $\left(\mathrm{m}=96.9^{\circ} \mathrm{F}\right)$. Based on the literature review, temperature instability is expected to be found in $10 \%$ of late preterm infants (Wang, et. al., 2004). Laptook and Jackson stated that thermal adaptative processes were inadequate (2006). In this study, the lowest temperature during the first 6 hours of life was below normal for both the case and control groups, lessening the significance of the between-group measurement of temperature. Surprisingly, the difference in temperature between the two groups was not significantly different, indicating that hypothermia is a risk for all late-preterm infants and was not associated with transition in this sample as expected. This is consistent with the findings of Bastek et al. (2008) who did not include 
hypothermia, rather temperature instability, as a composite outcome variable for consideration of late preterm morbidity (Table 2).

A possible explanation for the lack of association of hypothermia and wellness in this population may be the duration of hypothermia. This study determined the lowest and highest transition temperature in the first six hours of life, but did not address duration of hypothermia. Another consideration is the contribution of presence of comordities such as respiratory distress low Apgar scores, or hypoglycemia along with hypothermia, as aggravating variables contributing to the transition failure of some late preterm infants.

Transition heart rate was evaluated in this study as an exploratory variable aimed at describing the expected heart rate range of late preterm infants during transition. Heart rate monitoring in newborns generally yields a beats per minute numerical value and a tracing of heart rate rhythm. The results between the average quantified heart rate of the case group and control group were nearly identical for average heart rate. However, the literature review results considered heart rate as a factor primarily look at the technology of heart rate analysis of beat to beat variability (Verklan, 2002). This technology could be beneficial to add to the utility of heart rate monitoring of late preterm infants during transition but is not commonly found in use with newborns.

\section{Hospital Days}

The hospital length of stay was significantly longer for late-preterm infants who failed transition than for those who did not. This finding is consistent with those of Wang et al. (2004). Their retrospective review determined late-preterm infants had an increased 
risk of more costly hospitalization and varied hospital lengths of stay, regardless of vaginal or cesarean birth.

\section{Study Limitations}

The first limitation of this study is related to study site and sampling. This study represented a purposive sample of 35-and 36-week gestational age late-preterm infants delivering in one study site during a sampling frame fulfilling specified inclusion criteria and with medical record availability.

The first limitation of this study is related to the study site and sampling. This study represented a purposive sample of late preterm infants delivering in one study site during a specified sampling frame, and excluded multiple-gestation newborns. This design limits applicability of the study to a large subset of late-preterm infants. In addition, the use of a single center for data collection subjects the research findings to the policies and practices of a single institution and one geographic population. However, the research site chosen was demonstrated to be a diverse population representative of Florida. A related limitation is the use of purposive sampling and limited generizabilty of the study findings to other populations (Polit \& Beck, 2004)..

As mentioned, a second limitation is related to the variable labor. The length of

labor was not consistently documented, necessitating the dichotomization of this variable. Labor also has multiple levels of intensity, making the capture of this phenomenon difficult when the data collection process is chart review. The length of labor and intensity of labor would be beneficial pieces of information to relate to transition outcome and might best be determined by a qualitative or mixed-method study involving the interview of women in labor. 
A third limitation is the determination of gestational age. Based on the literature review, the 20 -week gestation ultrasound is the gold standard for determining gestational age, but is not an exact measurement (Campbell et. al, 1985; Lynch \& Zhang, 2007). For the purpose of this study, gestational age was defined as the age documented in the medical record at the time of delivery based on the highest level of obstetrical knowledge. Because gestational age is determined prenatally, a variable related to this limitation is the estimation of prenatal care visits. This was the only variable found to have missing data in this study. Although only three case and one control patient were specifically documented in the medical record to have had no prenatal care, approximately $14 \%$ of this data was missing in both groups. Other than the medical records stating "no prenatal care," the remaining records were cross-referenced for further evidence of prenatal care and found to have had prenatal care as evidenced by indications on the delivery room record such as the finding of prenatal ultrasound data as indicated on the delivery room record, but an unknown number of prenatal visits.

\section{Implications}

The implications for the research findings are varied. Primarily, the first implication is that these babies should be identified prenatally and acknowledged by caregivers as preterm regardless of birth weight. It is noted that during the chart review, the control infants were not assigned the diagnosis or classified as preterm, indicating that this group received care identical to term infants. Recognition of these newborns prior to delivery would alert caregivers to observe for characteristics of physiologic immaturity and provide physiologic monitoring during transition for these newborns. The creation of policies specific to this population regarding physiologic monitoring and more frequent 
assessment for late preterm infants admitted to the well nursery following delivery should be implemented. Upon discharge, discharge teaching and follow-up guidelines should be similar to the guidelines established for preterm infants discharged from the neonatal unit with follow-up within 48 hours of discharge.

A second educational and practice implications for this study is directed at the avoidance of preterm delivery without labor. Operationalization and development of a protocol identifying late preterm newborns delivered without the benefit of labor as highrisk provides identification of these newborns prior to delivery. A policy mandating attendance of the delivery by the neonatal resuscitation teams, and a higher level of care following delivery and during transition would minimize the risk of further illness due to transition challenge. Currently, newborns that are 35 weeks gestational age are in some areas admitted to the NICU or observed in areas designed for transitioning infants. Based on the study results and the possibility of error in the calculation of gestational age, infants that are 36 weeks gestational age should also be monitored closely for transition failure. In addition, because transition failure is associated with increased hospital days, transition support may be beneficial to identify potential illness earlier resulting in intervention such as pulse oximetry, assessment of acid-base status, and oxygen or continuous positive airway pressure delivery.

Thirdly, one of the compelling issues driving inquiry into the field of late-preterm infant care is that previous newborn research has either solely addressed term infants or combined late-preterm infant and term infants into one population. Currently, ongoing research is focused on the negative long-term outcomes of late prematurity without specific regard to early hospital course. A future research focus examining the 
relationship between transition success and short- and long-term outcomes would be beneficial to address the impact of transition care practices that are related to improved outcome.

A screening tool for the identification of late-preterm infants that includes the predisposing factors and physiological symptoms of transition failure would be beneficial to rapidly score and identify newborns at risk for transition failure and prolonged hospitalization. This tool could have a positive impact in the anticipatory care of latepreterm infants. Caregiver and parental expectations guided by scoring could help to steer at-risk late-preterm infants to an expected level of care and provide realistic expectations to parents regarding safe discharge. Parents whose expectations are level-set appropriately may be better equipped to navigate the phenomenon of transition failure by their late-preterm newborns.

Regarding temperature, the source of hypothermia for newborns is hugely impacted by environment and technology. A systems assessment of delivery room care of late preterm infants would be beneficial to determine areas in need of policy and practice revision. By targeting delivery room practices of providing warmth (Mance, 2008) and the use of the technology available, prevention of heat loss by education regarding the use of these resources would prevent heat loss and possibly the worsening of associated respiratory distress or hypoglycemia (Sherman,et. al,2006). Implementation of a program of provider and parental education promoting skin-to-skin placement of preterm newborns at delivery would normalize temperature. 


\section{Conclusions}

Further research regarding the aspect of birth transition is needed. Collectively, the variables labor, gender, five minute Apgar score, and respiratory rate are associated with late preterm infant transition outcome but are not single variable predictors of birth transition outcome. Late-preterm infants without the benefit of labor (those delivered by cesarean section), with lower 5-minute Apgar scores and who present with tachypnea in the first 6 hours of life are more likely to fail birth transition and be hospitalized longer than those who do not. The quality and duration of labor is difficult to capture in the medical record and might best be approached prospectively for future study. Lower Apgar scoring is more significant to transition outcome than higher Apgar scores. As previously stated and based on the limitations of this study, these conclusions are not generalizable to the population, and warrant replication in multiple centers to increase the validity of the findings.

Late-preterm infants represent a large and complex population of newborns. The care policies related to the late-preterm infant require change to reflect the nuances of this special population. As a preamble to hospitalization, birth transition is the first opportunity to for caregivers to identify the individual uniqueness of each late-preterm infant. Difficult to categorize, late-preterm infants are less resilient than term infants, and less fragile than earlier preterm infants. Birth transition is the first challenge faced by the late-preterm infant and very telling of the newborn's physiological capacities. 
APPENDIX A: STUDY MAP 


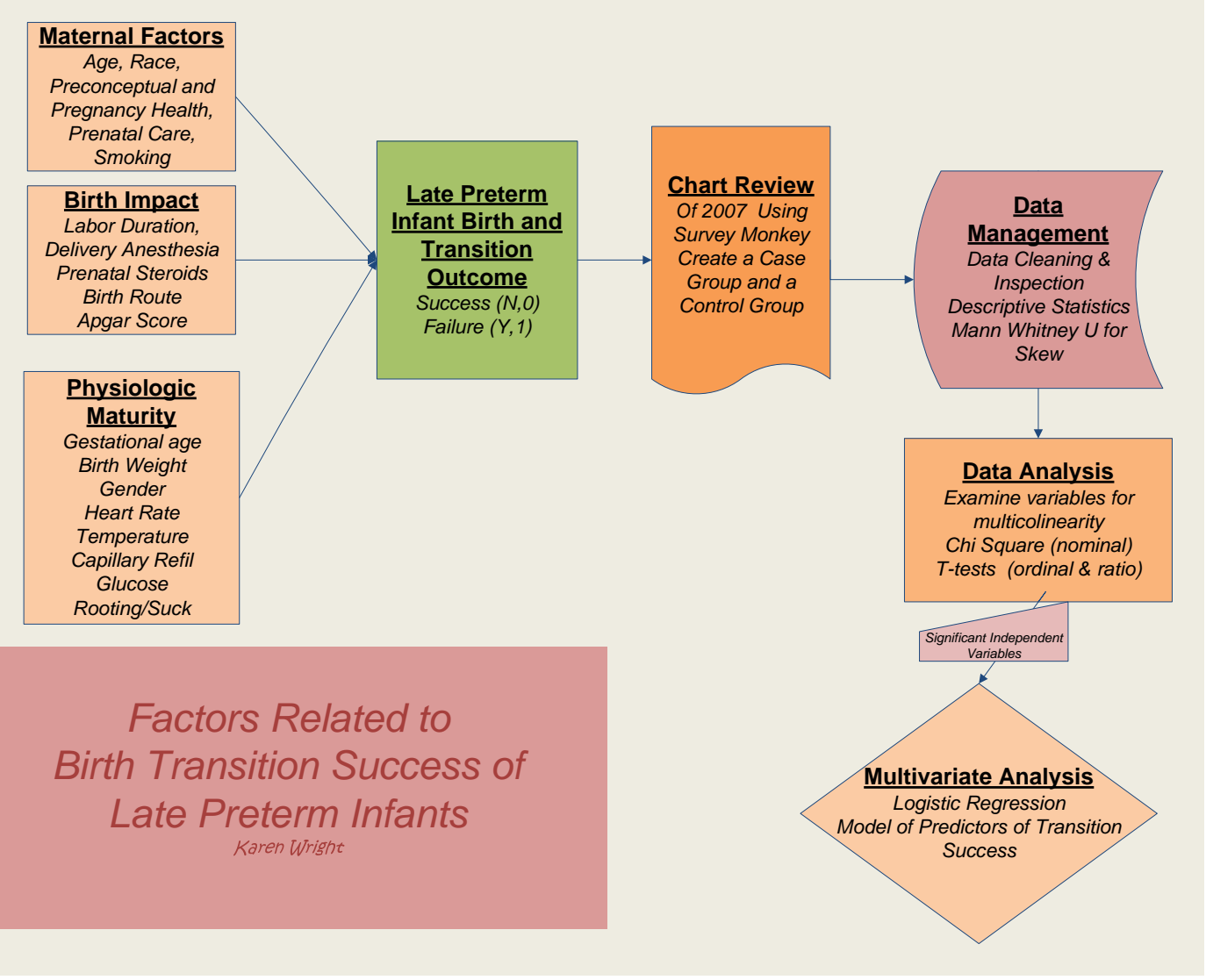


APPENDIX B: DATA COLLECTION SHEET (FROM SURVEYMONKEY) 


\section{Default Section}

1. Random study number

2. Date of Birth

3. Maternal age at time of delivery

\section{Maternal Age}

$\square$ not documented

$\square$ Less than 18

$\square 18 \cdot 34$

35- 39

$\square 40$ and above

\section{Maternal ethnicity}

$\square$ Unknown

$\square$ African American

$\square$ Caucasian

$\square$ Hispanic

$\square$ Other

6. Delivery route

$\square$ Vag

$\square$ cls

7. Delivery Method

$\square$ not documented

$\square$ Vaginal spontaneous

$\square$ Vaginal assisted vacuum

$\square$ Vaginal assisted forcepts

$\square$ Cesarean 
8. Prenatal care

$\square$ Unknown

$\square$ Yes

$\square$ Late - started after 20 weeks

$\square$ No prenatal care

9. Number of prenatal visits

10. Coded maternal pre-existing illness

$\square$ none

$\square$ diabetes

$\square$ hypertension

$\square$ asthma

$\square$ depression

$\square$ other

11. Maternal smoking packs per day?

$\square 0$

$\square 1$

$\square 2$

$\square 3$

$\square 4$ or more

12. Maternal steroid doses?

$\square 0$

$\square 1$

$\square 2$

$\square>2$

13. Prenatally estimated gestational age at time of delivery

$\bigcirc_{35}$

$\bigcirc_{36}$ 
14. Gestational age by Ballard Exam

$\square$ Not documented

\35

36

15. Labor length or no labor

$\square$ Unknown

$\square$ No Labor

$\square$ Labor less than 2 hours

Labor 2 hours or greater

\section{Labor length}

17. Maternal anesthesia

$\square$ Unknown

$\square$ No anesthesia

$\square$ Local anesthesia

$\square$ Epidural anesthesia

$\square$ Spinal anesthesia

General anesthesia

18. Gender

$\square$ Male

$\square$ Female

Uncertain

19. Birth weight in grams

20. 5 minute Apgar score

21. Highest documented temperature taken from birth to six hours of age

22. Lowest temperature documented between birth and 6 hours of age

23. Highest heart rate documented between birth and six hours of age 
24. Lowest heart rate documented between birth and 6 hours of age

25. Highest respiratory rate documented between birth and 6 hours of age

26. Lowest respiratory rate documented between birth and 6 hours of age

27. Highest capillary refil documented between birth and six hours of age

28. Lowest glucose documented between birth and 6 hours of age

29. Documentation of rooting between birth and six hours of life

$\square$ Not documented
$\square$ Yes
$\square$ No
$\square$ Both

30. Transition outcome at 6 hours of age

No - not admitted to the NICU

Yes-admitted to the NICU

31. If failed transition, why?

Unknown

Respiratory

$\square$ Cardiac

Glucose

Neurologic

Circulatory

Thermal

32. Number of hospital days 
APPENDIX C: UNIVERSITY OF CENTRAL FLORIDA IRB APPROVAL 


\section{Approval of Human Research}

\section{From: UCF Institutional Review Board \#1 FWA00000351, IRB00001138}

To:

Karen L. Wright

Date:

August 18, 2010

Dear Researcher:

On 8/18/2010, the IRB approved the following human participant research until 8/17/2011 inclusive:

Type of Review: UCF Initial Review Submission Form

Project Title: Factors related to birth transition success of late preterm infants

Investigator: Karen L Wright

IRB Number: SBE-10-07064

Funding Agency.

Grant Title:

Research ID:

Grant ID: <Delete if none or manually enters

$\mathrm{ND}$ or IDE: <Delete if none or manualy enters

The Continuing Review Application must be submitted 30days prior to the expiration date for studies that were previously expedited, and 60 days prior to the expiration date for research that was previously reviewed at a convened meeting. Do not make changes to the study (i.e., protocol, methodology, consent form, personnel, site, etc.) before obtaining IRB approval. A Modification Form cannot be used to extend the approval period of a study. All forms may be completed and submitted anline at https://iris.research.ucf.edu,

If continuing review approval is not granted before the expiration date of 8/17/2011, approval of this research expires on that date. When von have completed vour research. please submit a Study Closure request in iRIS so that IRB records will be accurate.

In the conduct of this research, you are responsible to follow the requirements of the Inwestigator Manual

On behalf of Joseph Bielitzki, DVM, UCF IRB Chair, this letter is signed by:

Signature applied by Joanne Muratori on 08/18/2010 09:39:43 AM EDT

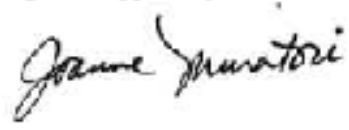

IRB Coordinator 
APPENDIX D: SURVEY SITE IRB APPROVAL 

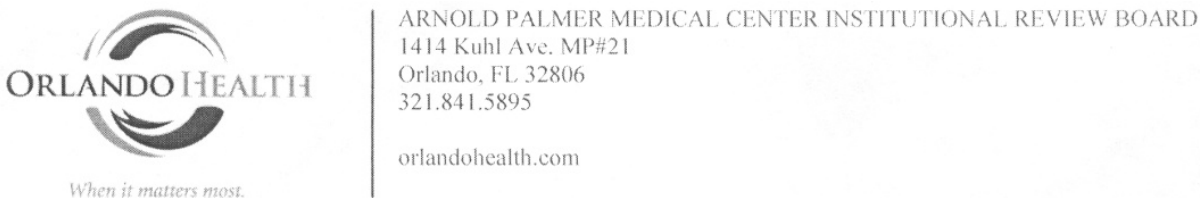

August 24, 2010

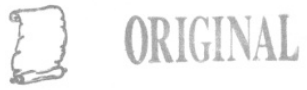

Karen Wright ARNP

199 Highway A1A, B 104

Satellite Beach, FL 32937

Dear Ms. Wright:

Concerning the following Study:

Our Study \# 1009008

Protocol Title: Factors Related to Birth Transition Success of Late Preterm Infants

Under federal guidelines for expedited review, I have reviewed and approved the Expedited Review Request Research Involving Human Subjects application, HIPAA Waiver of Authorization form, and version 1 of the protocol dated 6/28/10 for your project stated above. The study is approved under 21CFR 56.110 (b) (1) for this project since it presents no more than minimal risk. The waiver of informed consent is approved under 45 CFR 46.116 (d) and 45CFR 46.117(C)(2) for this project since it presents no more than minimal risk and protected health information will be de-identified. The Chair has approved this study at all Orlando Health, Inc. facilities and your office. The Arnold Palmer Medical Center (APMC) Institutional Review Board review process is in compliance with GCP's and included review of potential risks to subjects, risk benefit ratio, subject selection criteria and safety, content of the informed consent, confidentiality and appropriate safeguards. The project was reviewed in detail on $8 / 24 / 2010$. It will be sent to the $10 / 21 / 2010$ APMC Institutional Review Board meeting and be reviewed by a majority of membership with quorum present.

Subjects may be enrolled in your project from the date of this letter through $8 / 23 / 2011$. For approval to be extended after that date, a continuing review report must be submitted to the APMC Institutional Review Board meeting prior to the deadline date. If you wish to terminate your project before the expiration date, please notify the APMC IRB office at 321-841-5895.

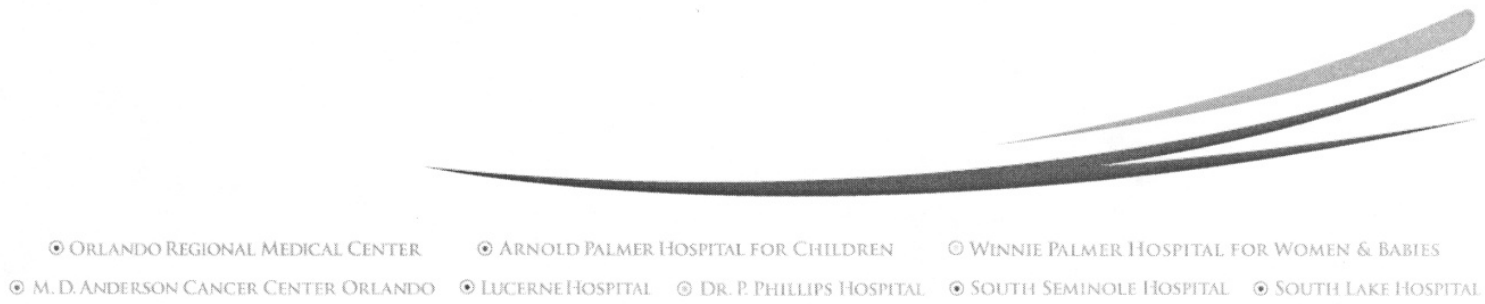




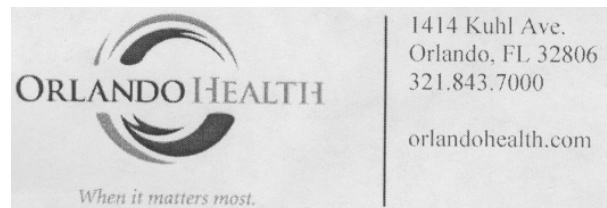

Wright

1009008

\section{Page Two}

Institutional Review Board approval is contingent upon:

1. Per the guidelines for expedited review and approval, you may begin enrollment as of the date of this letter. However, enrollment may not continue after the expiration date. This expedited information will be submitted to the APMC Institutional Review Board for final review.

2. Modifications to protocol must be approved prior to implementation unless they reduce immediate danger to subject.

3. All protocol deviations must be reported to the APMC Institutional Review Board within 5 working days.

4. FDA requires you to notify the IRB of any change of Investigator or site location, amendment or changes in the protocol, significant protocol deviations, or termination of the study. Please note that you must submit all protocol amendments to the Chairman, prior to implementing the amendment.

If you have any questions, please feel free to contact the IRB Office at 321-841-5895.

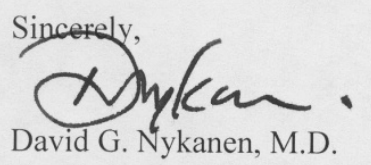

Co-Chairman of APMC Institutional Review Board

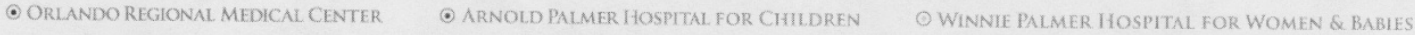

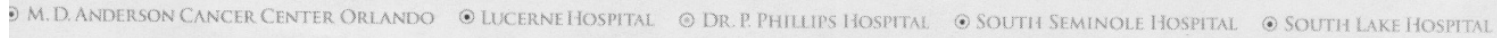




\section{REFERENCES}

American Academy of Pediatrics and the American College of Obstetricians and Gynecologists. (2007). Guidelines of perinatal care (6th ed.). Elk Grove Village, IL: Author.

American Congress of Obstetricians and Gynecologists. (2009, March 3). Resource center: Cesarean section rates in the United States. Retrieved January 5, 2010, from http://www.acog.org/departments/dept_notice.cfm?recno=20\&bulletin=264

Askin, D. F. (2002). Complications in the transition from fetal to neonatal life. Journal of Obstetric, Gynecologic, and Neonatal Nursing, 31(3), 318-327. doi: 10.1111/ j.1552-6909.2002.tb00054.x

Askin, D. F. (2009a). Fetal to neonatal transition. What is normal and what is not? Part 2: Red flags. Neonatal Network, 28(3), p. e39-e40. Retrieved from http://www.neonatalnetwork.com/

Askin, D. F. (2009b). What is normal and what is not? Part 1: The physiology of birth transition. Neonatal Network, 28(3), e33-e36. Retrieved from http://www.neonatalnetwork.com/

Aydin, G. B., Coskun, F., Sahin, A., \& Aypar, U. (2008). Influence of sevoflurane and desflurane on neurological and adaptive capacity scores in newborns. Saudi Medical Journal, 29(6), 841-846. Retrieved from http://www.smj.org.sa/

Aylott, M. (2006a). The neonatal energy triangle. Part 1: Metabolic adaptation. Paediatric Nursing, 18(6), 38-42, 43. Retrieved from http://paediatricnursing.rcnpublishing.co.uk/

Aylott, M. (2006b). The neonatal energy triangle. Part 2: Thermoregulatory and respiratory adaptation. Paediatric Nursing, 18(7), 38-42. Retrieved from http://paediatricnursing.rcnpublishing.co.uk/

Bakewell-Sachs, S. (2007). Near-term/late preterm infants. Newborn and Infant Nursing Reviews, 7(2), 67-71. doi: 10.1053/j.nainr.2007.05.001

Bastek, J. A., Sammel, M. D., Emmanuelle, P., Srinivas, S. K., Posencheg, M. A., \& Elovits, M. A. (2008). Adverse neonatal outcomes: Examining the risks between preterm, late preterm, and term infants. American Journal of Obstetrics and Gynecology, 199(4), 367.e1-367.e8. doi: 10.1016/j.ajog.2008.08.002

Bell, A. F., White-Traut, R., \& Medoff-Cooper, B. (2010). Neonatal neurobehavioral organization after exposure to maternal epidural analgesia in labor. Journal of Obstetrical, Gynecologic, and Neonatal Nursing, 39(2), 178-190. doi: 10.1111/ j.1552-6909.2010.01100.x 
Blackburn, S. T. (2007). Maternal, fetal, \& neonatal physiology: A clinical perspective (3rd ed.). St. Louis, MO: Elsevier.

Bland, R. D. (2001). Loss of liquid from the lung lumen in labor: More than a simple "squeeze." American Journal of Physiology, 280(4), L602-L605. Retrieved from http://ajplung.physiology.org/

Campbell, S., Warsof, S. L., Little, D., \& Cooper, D. J. (1985). Routine ultrasound screening for the prediction of gestational age. Obstetrics and Gynecology, 65(5), 613-620. Retrieved from http://journals.lww.com/greenjournal/

Casey, B. M., McIntire, D. D., \& Leveno, K. J.(2001). The continuing value of the Apgar score for the assessment of newborn infants. The New England Journal of Medicine, 344(7), 467-471. doi: 10.1056/NEJM200102153440701

Chyi, L. J., Lee, H. C., Hintz, S. R., Gould, J. B., \& Sutcliffe, T. L. (2008). School outcomes of late preterm infants: Special needs and challenges for infants born at 32 to 36 weeks gestation. The Journal of Pediatrics, 153(1), 25-31. doi: 10.1016/ j.jpeds. 2008.01 .027

Cnattingius, S. (2004). The epidemiology of smoking during pregnancy: Smoking prevalence, maternal characteristics, and pregnancy outcomes. Nicotine \& Tobacco Research, 6(Suppl. 2), S125-S140. doi:

$10.1080 / 14622200410001669187$

Davidoff, M. J., Dias, T., Damus, K., Russell, R., Bettegowda, V. R., Dolan, S., . . . Petrini, J. (2006). Changes in the gestational age distribution among U.S. singleton births: Impact on rates of late preterm birth, 1992 to 2002. Seminars in Perinatology, 30(1), 8-15. doi: 10.1053/j.semperi.2006.01.009

Dobak, W. J., \& Gardner, M. O. (2006). Late preterm gestation: Physiology of labor and implications for delivery. Clinics in Perinatology, 33(4), 765-776. doi: 10.1016/ j.clp.2006.09.001

Dudell, G. G., \& Jain, L. (2006). Hypoxic respiratory failure in the late preterm infant. Clinics in Perinatology, 33(4), 803-830. doi: 10.1016/j.clp.2006.09.006

Eder, C., Fullerton, J., Benroth, R., \& Lindsay, S. P. (2005). Pragmatic strategies that enhance the reliability of data abstracted from medical records. Applied Nursing Research, 18(1), 50-54. doi: 10.1016/j.apnr.2004.04.005

Engle, W. A. (2006). A recommendation for the definition of "late preterm"(near-term) and the birth weight-gestational age classification system. Seminars in Perinatology, 30(1), 2-7. doi: 10.1053/j.semperi.2006.01.007

Escobar, G. J., Clark, R. H., \& Greene, J. D. (2006). Short-term outcomes of infants born at 35 and 36 weeks gestation: We need to ask more questions. Seminars in Perinatology, 30(1), 28-33. doi: 10.1053/j.semperi.2006.01.005 
Fiscella K. (1996). Race, perinatal outcome, and amniotic infection. Obstetrical \& Gynecological Survey, 51(1), 60-66. doi: 10.1097/00006254-199601000-00022

Fuchs, K., \& Wapner, R. (2006). Elective cesarean section and induction and their impact on late preterm births. Clinics in Perinatology, 33(4), 793-801. doi: 10.1016/j.clp.2006.09.010

Garg, M., \& Devaskar, S. U. (2006). Glucose metabolism in the late preterm infant. Clinics in Perinatology, 33(4), 853-870. doi: 10.1016/j.clp.2006.10.001

Goldenberg, R. L., Culhane, J. F., Iams, J. D., \& Romero, R. (2008). Epidemiology and causes of preterm birth. The Lancet, 371, 75-84. doi: 10.1016/S01406736(08)60074-4

Griffin, M. P., O’Shea, T. M., Bissonette, E. A., Harrell, F. E., Jr., Lake, D. E., \& Moorman, J. R. (2004). Abnormal heart rate characteristics are associated with neonatal mortality. Pediatric Research, 55(5), 782-788. doi: 10.1203/ 01.PDR.0000119366.21770.9E

Hamilton, B. E., Martin, J. A., \& Ventura, S. J. (2009). Births: Preliminary data for 2007. National Vital Statistics Reports, 57(12). Retrieved from http://www.cdc.gov/nchs/data/nvsr/nvsr57/nvsr57_12.pdf

Hawdon, J. M. (2008). Investigation and management of impaired metabolic adaptation presenting as neonatal hypoglycaemia. Paediatrics and Child Health, 18(4), 161165. doi: 10.1016/j.paed.2007.12.012

Hernández-Díaz, S., van Marter, L. J., Werler, M. M., Louik, C., \& Mitchell, A. A. (2007). Risk factors for persistent pulmonary hypertension of the newborn. Pediatrics, 120(2), e272-e282. doi: 10.1542/peds.2006-3037

Hess, D. R. (2004). Retrospective studies and chart reviews. Respiratory Care, 49(10), 1171-1174. Retrieved from http://www.rcjournal.com/

Iams, J. D., Romero, R., Culhane, J. F., \& Goldenberg, R. L. (2008). Primary, secondary, and tertiary interventions to reduce the morbidity and mortality of preterm birth. The Lancet, 371(9607), 164-175. doi: 10.1016/S0140-6736(08)60108-7

Jain, L., \& Dudell, G. G. (2006). Respiratory transition in infants delivered by cesarean section. Seminars in Perinatology, 30(5), 296-304. doi: 10.1053/ j.semperi.2006.07.011

Jain, L., \& Eaton, D. C. (2006). Physiology of fetal lung fluid clearance and the effect of labor. Seminars in Perinatology, 30(1), 34-43. doi: 10.1053/ j.semperi.2006.01.006

Jain, L., \& Raju, T. N. K. (Eds.). (2006). Late preterm pregnancy and the newborn [Special issue]. Clinics in Perinatology, 33(4). 
Jorgensen, A. M. (2008). Late preterm infants: Clinical complications and risk: Part two of a two-part series. Nursing for Women's Health, 12(4), 316-331. doi:

10.1111/j.1751-486X.2008.00353.x

Kattwinkel, J. (2000). Textbook of neonatal resuscitation (4th ed.). Elk Grove Village, IL: American Academy of Pediatrics and the American Heart Association.

Klaus, M. H., \& Fanaroff, A. A. (2001). Care of the high-risk neonate (5th ed.). Philadelphia, PA: Saunders.

Kramer, M. S., Demissie, K., Yang, H., Platt, R. W., Suavé, R., \& Liston, R. (2000). The contribution of mild and moderate preterm birth to infant mortality. Journal of the American Medical Association, 284(7), 843-849. doi: 10.1001/jama.284.7.843

Laptook, A., \& Jackson, G. L. (2006). Cold stress and hypoglycemia in the late preterm ("near-term") infant: Impact on nursery of admission. Seminars in Perinatology, 30(1), 24-27. doi: 10.1053/j.semperi.2006.01.014

Littleford, J. (2004). Effects on the fetus and newborn of maternal analgesia and anesthesia: A review. Canadian Journal of Anesthesia, 51(6), 586-509. doi: 10.1007/BF03018403

Luck, J., Peabody, J. W., Dresselhaus, T. R., Lee, M., \& Glassman, P. (2000). How well does chart abstraction measure quality? A prospective comparison of standardized patients with the medical record. The American Journal of Medicine, 108(8), 642649. doi: 10.1016/S0002-9343(00)00363-6

Lynch, C. D., \& Zhang, J. (2007). The research implications of the selection of a gestational age estimation method. Paediatric and Perinatal Epidemiology, 21(s2), 86-96. doi: 10.1111/j.1365-3016.2007.00865.x

Mance, M. J. (2008). Keeping infants warm: Challenges of hypothermia. Advances in Neonatal Care, 8(1), 6-12. doi: 10.1097/01.ANC.0000311011.33461.a5

March of Dimes. (2007). PeriStats. Retrieved June 5, 2010 from http:/www.marchofdimes.com/peristats/

March of Dimes. (2009a, November 19). U.S. gets a " $D$ " for preterm birth rate [News bulletin]. Retrieved June 13, 2010, from http://www.marchofdimes.com/news/nov17_2009.html

March of Dimes. (2009b). Perinatal data snapshots: Maternal and infant health overview (Florida). Retrieved June 13, 2010, from http://www.marchofdimes.com/ PeriStats/pdflib/999/pds_12_all.pdf 
Martin, J. A., Kirmeyer, S., Osterman, M., \& Shepherd, R. A. (2009). Born a bit too early: Recent trends in late preterm births (NCHS Data Brief No. 24). Atlanta, GA: Centers for Disease Control and Prevention. Retrieved from Centers for Disease Control and Prevention website: http://www.cdc.gov/nchs/data/ databriefs/db24.htm

Mercer, J. S., Erickson-Owens, D. A., Graves, B., \& Haley, M. M. (2007). Evidencebased practices for the fetal to newborn transition. Journal of Midwifery \& Women's Health, 52(3), 262-272. doi: 10.1016/j.jmwh.2007.01.005

Moster, D., Lie, R. T., \& Markestad, T. (2008). Long-term medical and social consequences of preterm birth. New England Journal of Medicine, 359(3), 262273. doi: 10.1056/NEJMoa0706475

Moulsdale, W., \& Hermann, S. (2008). In utero exposure to selective serotonin reuptake inhibitors: Evidence for poor neonatal adaptation. Newborn and Infant Nursing Reviews, 8(3), 123-130. doi: 10.1053/j.nainr.2008.06.006

Pampel, F. C. (2000). Logistic regression: A primer. Thousand Oaks, CA: Sage.

Peng, C.-Y. J., Lee, K. L., \& Ingersoll, G. M. (2002). An introduction to logistic regression analysis and reporting. The Journal of Education and Research, 96(1), 3-14. doi: 10.1080/00220670209598786

Petrini, J. R., Dias, T., McCormick, M. C., Massolo, M. L., Green, N. S., \& Escobar, G. J. (2009). Increased risk of adverse neurological development for late preterm infants. The Journal of Pediatrics, 154(2), 169-176.e3. doi: 10.1016/ j.jpeds.2008.08.020

Pinheiro, J. M. B. (2009). The Apgar cycle: A new view of a familiar scoring system. Archives of Disease in Childhood, Fetal and Neonatal Edition, 94(1), F70-F72. doi: $10.1136 /$ adc.2008.145037

Platt, M. W., \& Deshpande, S. (2005). Metabolic adaptation at birth. Seminars in Fetal and Neonatal Medicine, 10(4), 341-350. doi: 10.1016/j.siny.2005.04.001

Polit, D. F. (2010). Statistics and data analysis for nursing research (2nd ed.). Upper Saddle River, NJ: Pearson.

Polit, D. F., \& Beck, C. T. (2004). Nursing research: Principles and methods (7th ed.). Philadelphia, PA: Lippincott Williams \& Wilkins.

Polit, J. F., \& Beck, C. T. (2008). Nursing research: Generating and assessing evidence for nursing practice (8th ed.). Philadelphia, PA: Lippincott Williams \& Wilkins.

Raju, T. N. K. (2006). Epidemiology of late preterm (near-term) births. Clinics in Perinatology, 33(4), 751-763. doi: 10.1016/j.clp.2006.09.009 
Raju, T. N. K., Higgens, R. D., Stark, A. R., \& Leveno, K. J. (2006). Optimizing care and outcomes for late-preterm (near-term) infants: A summary of the workshop sponsored by the National Institute of Child Health and Human Development. Pediatrics, 118(3), 1207-1214. doi: 10.1542/peds.2006-0018

Ramachandrappa, A., \& Jain, L. (2008). Elective cesarean section: Its impact on neonatal respiratory outcome. Clinics in Perinatology, 3(2), 373-393. doi: 10.1016/ j.clp.2008.03.006

Ronca, A. E., Abel, R. A., Ronan, P. J., Renner, K. J., \& Alberts, J. R. (2006). Effects of labor contractions on catecholamine release and breathing frequency in newborn rats. Behavioral Neuroscience, 120(6), 1308-1314. doi: 10.1037/07357044.120.6.1308

Rosenberg, R. E., Ahmed, A. S., Ahmed, S., Saha, S. K., Chowdhury, M. A., Black, R. E., ... Darmstadt, G. (2009). Determining gestational age in a low-resource setting: Validity of last menstrual period. Journal of Health, Population, and Nutrition, 27(3), 332-338. Retrieved from http://www.icddrb.org/ publication.cfm?classificationID $=30$

Seo, K., McGregor, J. A., \& French, J. I. (1992). Preterm birth is associated with increased risk of maternal and neonatal infection. Obstetrics and Gynecology, 79(1), 75-80. Retrieved from http://journals.lww.com/greenjournal/pages/ default.aspx

Shapiro-Mendoza, C. K., Tomashek, K. M., Kotelchuck, M., Barfield, W., Nannini, A., Weiss, J., \& Declercq, E. (2008). Effect of late-preterm birth and maternal medical conditions on newborn morbidity risk. Pediatrics, 121(2), e223-e232. doi: $10.1542 /$ peds.2006-3629

Sherman, T. I., Greenspan, J. S., St. Clair, N., Touch, S. M., \& Shaffer, T. H. (2006). Optimizing the neonatal thermal environment. Neonatal Network: The Journal of Neonatal Nursing, 25(4), 251-260. Retrieved from http://neonatalnetwork.metapress.com/

Sinha, S. K., \& Donn, S. M. (2006). Fetal-to-neonatal maladaption. Seminars in Fetal and Neonatal Medicine, 11(3), 166-173. doi: 10.1016/j.siny.2006.01.008

SurveyMonkey [Computer software]. (n.d.). Accessed from http://www.surveymonkey.com/

Tabachnick, B. G., \& Fidell, L. S. (1996). Using multivariate statistics (3rd ed.). New York, NY: HarperCollins.

Tomashek, K. M., Shapiro-Mendoza, C. K., Davidoff, M. J., \& Petrini, J. R. (2007). Differences in mortality between late-preterm and term singleton infants in the United States, 1995-2002. The Journal of Pediatrics, 151(5), 450-456.e1. doi: 10.1016/j.jpeds.2007.05.002 
Verklan, M. T. (2002). Physiologic variability during transition to extrauterine life. Critical Care Nursing, 24(4), 41-56. Retrieved from http://www.nursingcenter.com/

Verklan, M. T., \& Padhye, N. S. (2004). Spectral analysis of heart rate variability: An emerging tool for assessing stability during transition to extrauterine life. Journal of Obstetric, Gynecolic, and Neonatal Nursing, 33(2), 256-265. doi: 10.1177/ 0884217504263301

Verklan, M. T., \& Walden, M. (2004). Core curriculum for neonatal intensive care nursing (3rd ed.). St. Louis, MO: Elsevier Saunders.

Volpe, J. (2008). Neurology of the Newborn, (5th ed.). Philadelphia, PA: Elsevier.

Wang, M. L., Dorer, D. J., Fleming, M. P., \& Catlin, E. A. (2004). Clinical outcomes of near-term infants. Pediatrics, 114(2), 372-376. doi: 10.1542/peds.114.2.372

Wu, L., \& Ashton, C. M. (1997). Chart review: A need for reappraisal. Evaluation and the Health Professions, 20(2), 146-163. doi: 10.1177/016327879702000203

Zelenina, M., Zelenin, S., \& Aperia, A. (2005). Water channels (aquaporins) and their role for postnatal adaptation. Pediatric Research, 57(5 Part 2), 47R-52R. doi: 10.1203/01.PDR.0000159572.79074.0B 
